This report has been reproduced directly from the best available copy.

Available to DOE and DOE contractors from the Office of Scientific and Technical Information, P.O. Box 62, Oak Ridge, TN 37831; prices avaiiable from (615) 576-8401, FTS 626-8401.

Available to the public from the National Technical Information Service, U.S. Department of Commerce, 5285 Port Royal Rd., Springfield, VA 22161.

This report was prepared as an account of work sponsored by an agency of the United States Government. Neither the United States Government nor any agency thereof, nor any of their employees, makes any warranty, express or implied, or assumes any legal liability or responsibility for the accuracy, completeness, or usefulness of any information, apparatus, product, or process disclosed, or represents that its use would not infringe privately owned rights. Reference herein to any specific commercial product, process, or service by trade name, trademark, manufacturer, or otherwise, does not necessarily constitute or imply its endorsement, recommendation, or favoring by the United States Government or any agency thereof. The views and opinions of authors expressed herein do not necessarily state or reflect those of the United States Government or any agency thereot. 


\title{
SEISMIC HAZARD EVALUATION FOR THE HIGH-FLUX ISOTOPE REACTOR (HFIR) OAK RIDGE NATIONAL LABORATORY OAK RIDGE, TENNESSEE
}

FINAL REPORT

\author{
Robin K McGuire \\ Gabriel R. Toro
}

Risk Engineering, Inc. Golden, Colorado

Date Published: September 1991

Prepared by PICKARD, LOWE AND GARRICK, INC. 4590 MacArthur Boulevard, Suite 400 Newport Beach, California 92660-2027

Subcontract 96X-SA443V

Funded by

Office of Energy Research ERKCR01

Prepared for

Research Reactors Division

OAK RIDGE NATIONAL LABORATORY

Oak Ridge, Tennessee 37831 managed by

MARTIN MARIETTA ENERGY SYSTEMS, INC. for the U.S. DEPARTMENT OF ENERGY under contract DE-AC05-84OR21400 


\section{CONTENTS}

$\underline{\text { Section }}$

$\underline{\text { Page }}$

1 INTRODUCTION

1.1 REFERENCES

1-1

1-2

2 EPRI/SOG METHODOLOGY AND RESULTS

2-1

2.1 INTRODUCTION 2-1

2.2 EPRI/SOG METHODOLOGY 2-1

2.2.1 Basic Seismic Hazard Model 2-1

2.2.2 Treatment of Uncertainty 2-4

2.2.3 Development of Seismological Interpretations $2-6$

2.2.4 Computer Codes 2-8

2.3 TECTONIC AND SEISMICITY INTERPRETATIONS $2-10$

2.3.1 Seismic Sources 2-11

2.3.2 Maximum Magnitudes and Seismicity Options 2-12

2.3.3 Seismic Sources near the HFIR Site 2-13

2.4 GROUND-MOTION ATTENUATION 2-28

2.5 CALCULATIONS $2-33$

2.5.1 Overview 2-33

2.5.2 Screening of Seismic Sources 2-34

2.5.3 Development of Source Combinations $2-34$

2.5.4 Results 2-43

2.6 REFERENCES $2-47$ 
3 LLNL METHODOLOGY AND RESULTS 3-1

3.1 METHODOLOGY 3-1

3.2 SEISMICITY INTERPRETATIONS 3-1

3.3 GROUND MOTION MODELS 3-2

3.4 COMPUTATIONS $3-3$

3.5 RESULTS $3-3$

3.6 REFERENCES 3-4

4 RESULTS 4-1

4.1 OVERVIEW 4-1

4.2 COMBINATION OF EPRI/SOG AND LLNL RESULTS 4-1

4.3 TREATMENT OF LLNL MEAN HAZARD 4-3

4.4 CAUSES OF DIFFERENCES BETWEEN EPRI/SOG AND LLNL RESULTS $4-4$

4.5 REFERENCES 4-6

5 CONCLUSIONS $5-1$

5.1 REFERENCES $5-2$ 


\section{LIST OF FIGURES}

Figure

$\underline{\text { Page }}$

2-1 Seismic hazard computational model.

2-2 Logic tree representation of uncertain parameters in the EPRI/SOG methodology

2-3 EQHAZARD modules: their functions and data flow.

2-4 Map showing the seismic sources specified by the Bechtel team in the region around Oak Ridge.

2-5 Map showing the seismic sources specified by the Dames and Moore team in the region around the HFIR Site.

2-6 Map showing the seismic sources specified by the Law team in the region around the HFIR Site.

2-7 Map showing the seismic sources specified by the Rondout team in the region around the HFIR Site.

2-8 Map showing the seismic sources specified by the Weston team in the region around the HFIR Site.

2-9 Map showing the seismic sources specified by the Woodward-Clyde team in the region around the HFIR Site.

2-10 Ground motions predicted by the EPRI/SOG attenuation equations for $m_{b} 5$ and 6 .

2-11 Seismic hazard at HFIR computed using the EPRI/SOG methodology. Results shown as 30 equally weighted hazard curves for peak ground acceleration.

2-12 Seismic hazard at HFIR computed using the EPRI/SOG methodology. Results shown as fractile hazard curves and mean hazard curve for peak acceleration.

2-13 Seismic hazard at HFIR computed using the EPRI/SOG methodology. Results shown as uniform hazard spectra.

3-1 Main set of seismic sources provided by LLNL seismicity expert 1. 
3-2 Main set of seismic sources provided by LLNL seismicity expert 2.

3-3 Main set of seismic sources provided by LLNL seismicity expert 3.

3-4 Main set of seismic sources provided by LLNL seismicity expert 4.

3-5 Main set of seismic sources provided by LLNL seismicity expert 5.

3-6 Main set of seismic sources provided by LLNL seismicity expert 6.

3-7 Main set of seismic sources provided by LLNL seismicity expert 7.

3-8 Main set of seismic sources provided by LLNL seismicity expert 10.

3-9 Main set of seismic sources provided by LLNL seismicity expert 11.

3-10 Main set of seismic sources provided by LLNL seismicity expert 12 .

3-11 Main set of seismic sources provided by LLNL seismicity expert 13.

3-12 Seismic hazard at HFIR computed by LLNL using the LLNL methodology (excluding LLNL ground-motion expert 5). Results shown as fractile hazard curves for peak acceleration.

3-13 Seismic hazard at HFIR computed by LLNL using the LLNL methodology (including LLNL ground-motion expert 5). Results shown as fractile hazard curves for peak acceleration.

3-14 Seismic hazard at HFIR computed by LLNL using the LLNL methodology (excluding LLNL ground-motion expert 5). Results shown as uniform hazard spectra.

3-15 Seismic hazard at HFIR computed by LLNL using the LLNL methodology (including LLNL ground-motion expert 5). Results shown as uniform hazard spectra.

4-1 Comparison of EPRI/SOG and LLNL hazard results (excluding LLNL ground-motion expert 5).

4-2 Comparison of EPRI/SOG and LLNL hazard results (including LLNL ground-motion expert 5).

4-3 Hazard curves for input for PRA analyses. Synthesized from EPRI/SOG and LLNL analyses (excluding LLNL ground-motion expert 5.

4-4 Hazard curves for input for PRA analyses. Synthesized from EPRI/SOG and LLNL analyses (including LLNL ground-motion expert 5.

4-5 Uniform-hazard spectra synthesized from EPRI/SOG and LLNL analyses (excluding LLNL ground-motion expert 5 ).; $10^{-3}$ exceedance probability 
4-6 Uniform-hazard spectra synthesized from EPRI/SOG and LLNL analyses (excluding LLivL ground-motion expert 5).; $10^{-4}$ exceedance probability

4-7 Uniform-hazard spectra synthesized from EPRI/SOG and LLNL analyses (excluding LLNL ground-motion expert 5).; $10^{-5}$ exceedance probability

4-8 Uniform-hazard spectra synthesized from EPRI/SOG and LLNL analyses (including LLNL ground-motion expert 5).; $10^{-3}$ exceedance probability

4-9 Uniform-hazard spectra synthesized from EPRI/SOG and LLNL analyses (including LLNL ground-motion expert 5).; $10^{-4}$ exceedance probability

4-10 Uniform-hazard spectra synthesized from EPRI/SOG and LLNL analyses (including LLNL ground-motion expert 5).; $10^{-5}$ exceedance probability

4-11 Comparison of predicted peak acceleration by the EPRI/SOG and LLNL attenuation equations. Predictions are shown for $m_{b} 5$ and 7 .

4-12 Comparison of response spectra predicted by the EPRI/SOG and LLNL attenuation equations. Predictions are shown for an epicentral distance of $25 \mathrm{~km}$ and for $m_{b} 5$ and 7 . 


\section{LIST OF TABLES}

\section{Table}

2-1 Summary of Bechtel Team Sources Near the HFIR Site

2-2 Summary of Dames and Moore Team Sources Near the HFIR Site

2-3 Summary of Law Engineering Team Sources Near the HFIR Site

2-4 Summary of Rondout Associates Team Sources Near the HFIR Site

2-5 Summary of Weston Geophysical Team Sources Near the HFIR Site

2-6 Summary of Woodward-Clyde Consultants Team Sources Near the HFIR Site

2-7 Attenuation Equations Used in EPRI/SOG Calculations 2-29

2-8 Screening of Seismic Sources: Bechtel Team 2-35

2-9 Screening of Seismic Sources: Dames and Moore Team 2-36

2-10 Screening of Seismic Sources: Law Engineering Team 2-37

2-11 Screening of Seismic Sources: Rondout Associates Team 2-38

2-12 Screening of Seismic Sources: Weston Geophysical Team 2-39

2-13 Screening of Seismic Sources: Woodward-Clyde Team 2-40

2-14 Sources used for Seismic Hazard Calculations 2-41

2-15 Source Combinations and Their Probabilities 2-42

2-16 Seismic Hazard at HFIR Computed using the EPRI/SOG Methodology: results in the form of 30 equally weighted hazard curves

3-1 Seismic Hazard at HFIR Computed using the LLNL Methodology (excluding Ground-Motion Expert 5): results in the form of 10 fractile hazard curves

3-2 Seismic Hazard at HFIR Computed using the LLNL Methodology (including Ground-Motion Expert 5): results in the form of 10 fractile hazard curves 
4-1 Hazard Curves for Input to PRA Analyses (synthesized from EPRI/SOG and LLNL analyses; excluding LLNL G-expert 5)

4-2 Hazard Curves for Input to PRA Analyses (synthesized from EPRI/SOG and LLNL analyses; including LLNL G-expert 5)

4-3 Summary of Dominant EPRI/SOG Seismic Sources and their Parameters

4-4 Summary of Dominant LLNL Seismic Sources and their Parameters 


\section{Section 1}

\section{INTRODUCTION}

This study investigates the probabilistic hazard of earthquake-induced ground shaking at the HFIR facility, Oak Ridge, Tennessee. These results will be used to calculate plant response and potential effects in a Probabilistic Risk Assessment (PRA). For this purpose, several guidelines apply to this work. First, both the frequency of exceedance and the uncertainty in frequency of exceedance of various ground motion levels must be represented. These are required by the PRA so that the frequency and uncertainty of various possible plant states can be expressed. Second, there is a deliberate attempt to provide an unbiased distribution of frequencies of exceedance, i.e. to present results that are neither conservative nor unconservative. This is consistent with the goals of a PRA, to provide unbiased estimates of plant effects from which appropriate decisions (for instance about evaluating existing levels of seismic design) can be reached.

Recent intensive studies of seismic hazard in the central and eastern United States (CEUS) have been completed by the Electric Power Research Institute (EPRI), funded by the Seismicity Owners Group (1), and by the Lawrence Livermore National Laboratory (LLNL), funded by the U.S. Nuclear Regulatory Commission (2). These studies represent major efforts to characterize the seismic hazard for nuclear power plants in the CEUS, and use the most recent, up-to-date understandings of seismicity and ground motion relations for the region. With these studies as a resource, the current effort relies exclusively on the seismicity and ground motion assumptions therein to formulate seismic hazard curves for the HFIR facility. The interpretation of these studies to derive seismic hazard curves in a format suitable for input to a PRA is described in this report.

The HFIR facility is located at latitude 35.95 north and longitude 84.33 west. Structures at the site are founded on rock, so there is no amplification of ground motion as a result of surficial soil deposits. Consistent with other recent seismic hazard analyses for PRA, we report the distribution of peak horizontal ground acceleration (PGA), and also show constant percentile hazard curves to demonstrate a typical spectral shape that might apply for the ground motions of interest.

Section 2 of this report summarizes the application of the EPRI methodology for the HFIR site, which was conducted under this study. The LLNL method was applied for the site 
by LLNL, who transmitted results to us for use in this analysis. Their results and our interpretation of them for PRA input are described in Section 3. The synthesis of the results of the two studies is described in Section 4, in the form of multiple hazard curves that represent the distribution of frequency of exceedance of PGA levels. Finally, Section 5 presents conclusions of the study and some important qualifications to these results.

\subsection{REFERENCES}

1. Seismic Hazard Methodology for the Central and Eastern United States. Technical Report NP-4726-A, Electric Power Research Institute, July 1986. Vol. 1, Part 1: Methodology, Vol. 1, Part 2: Theory, Vol. 2: EQHAZARD Programmer's Manual, Vol. 3: EQHAZARD User's Manual, Vol. 4: Applications, Vols. 5 through 10: Tectonic Interpretations, Vol. 11: Nuclear Regulatory Commission Safety Review.

2. D. L. Bernreuter, J. B. Savy, R. W. Mensing, and J. C. Chen. Seismic Hazard Characterization of 69 Plant Sites East of the Rocky Mountains. Technical Report NUREG/CR5250, UCID-21517, U. S. Nuclear Regulatory Commission, 1988. 
Section 2

EPRI/SOG METHODOLOGY AND RESULTS

\subsection{INTRODUCTION}

This Section describes the EPRI/SOG methodology and inputs for seismic-hazard analysis in the central and eastern United States, documents the application of these for the HFIR site, and presents the results obtained from this application.

The EPRI/SOG methodology calculates ground-motion exceedance probabilities using earthscience hypotheses about the causes and characteristics of earthquakes in the central and eastern United States. Scientific uncertainty about the causes of earthquakes and about the physical characteristics of potentially active tectonic features lead to uncertainties in the inputs to the seismic hazard calculations. These uncertainties are quantified by using the tectonic interpretations developed by six Earth Science Teams, who quantified the likelihood associated with alternative tectonic features and the likelihood associated with alternative characteristics of these potential sources.

These and other uncertainties are carried through the entire analysis. The result of the analysis is a suite of hazard curves and their associated weights; they quantify the seismic hazard at the site and its uncertainty.

\subsection{EPRI/SOG METHODOLOGY}

\subsubsection{Basic Seismic Hazard Model}

The methodology to calculate seismic hazard at a site is well established in the literature $(1,2,3,4,5)$. In the SOG methodology, calculation of the hazard contributed by one source . requires specification of three inputs:

1. Source geometry: the geographic description of the seismic source. A seismic source is a portion of the earth's crust, associated with a tectonic feature or with a concentration of historic seismicity, which may be capable of producing earthquakes. Source geometry determines the probability distribution of distance from the earthquake to the site: $f_{R}(r)$. In the SOG methodology, each seismic source is divided into cells of 1 degree latitude by 1 degree longitude and $f_{R(i)}(r)$ is computed for each cell. 
2. Seismicity: the rate of occurrence $\nu_{i}$ and magnitude distribution $f_{M(i)}(m)$ of earthquakes within each cell. Magnitude is characterized by the body-wave magnitude $m_{b}$.

3. Attenuation functions: a relationship that allows the estimation of ground motion at the site as a function of earthquake magnitude and distance.

These inputs are illustrated in figure 2-1, parts a through c. Figure 2-1a shows the geometry of a seismic source and a cell within that source. From the cell's geometry, $f_{R(i)}(r)$, can be derived. The density function on magnitude $f_{M(i)}(m)$ is the doubly truncated exponential distribution as shown in figure 2-1b. Seismicity in a cell is completely specified by a minimum magnitude $m_{0}$, a maximum magnitude $m_{\max }$, and parameters $a$ and $b$. $a$ is a measure of seismic activity per unit area, $b$ is a measure of relative frequency of large versus small events, and $\log \left[\nu_{i} f_{M(i)}(m)\right]$ is proportional to $a+b m$ for $m_{0}<m \leq m_{\max }$. The ground motion is modeled by an attenuation function, as illustrated in figure 2-1c. Attenuation functions are usually of the form $\ln [Y]=f(M, R)+\epsilon$, where $Y$ is ground-motion amplitude, $M$ is magnitude, $R$ is distance, and $\epsilon$ is a random variable that represents scatter. The attenuation function is used to calculate $G_{Y \mid m, r}(y)=P[Y>y \mid m, r]$ : the probability that the ground-motion amplitude be larger thain $y$, for given $M$ and $R$. The seismic hazard contributed by a source is calculated as :

$$
\frac{P[Y>y \text { in time } t]}{t} \simeq \sum_{i} \nu_{i} \iint P[Y>y \mid m, r] f_{M(i)}(m) f_{R(i)}(r) d m d r
$$

in which the summation is performed over all cells that comprise the source.

Equation 2-1 is formulated using the assumption that earthquakes (most particularly, successive earthquakes) are independent in size and location. In all seismic hazard applications, primary interest is focused on computing probabilities for high (rare) ground motions (as a result, the probability of two exceedances in time $t$ is negligible). Thus, the quantity on the right side of Equation 2-1 - which is the rate of earthquakes with $Y>y-$ is a good approximation to the probability of exceeding amplitude $y$ in time $t$. The same argument holds when considering hazard at a site from multiple sources. Terms similar to the right hand side of equation 2-1 are summed to compute, to very good approximation, the total hazard at the site (see Figure 2-1d).

The calculation of hazard from all sources is performed for multiple values of $y$ in order to generate the hazard curve, which gives the annual probability of exceedance as a function of $y$. This calculation is performed for 6 different measures of ground motion: peak ground acceleration and spectral velocities at 5 frequencies $(1,2.5,5,10,25 \mathrm{~Hz} ; 5 \%$ damping). 


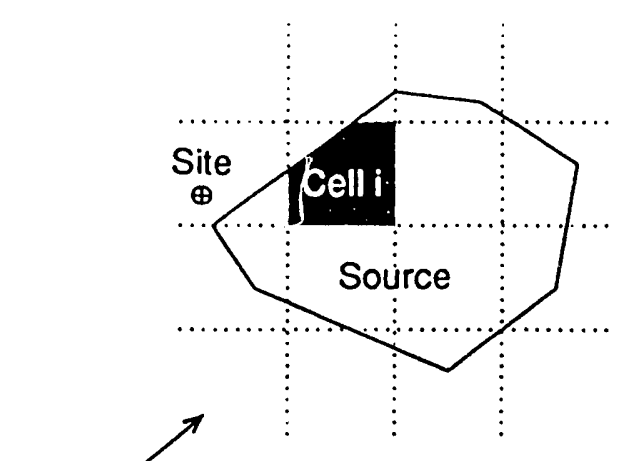

a.

Distribution on distance $f_{R(i)}(r)$ for cell $i$

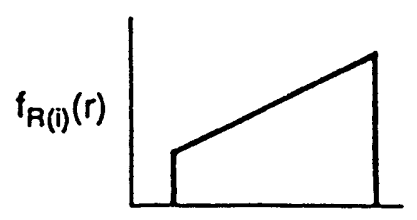

Distance $r$

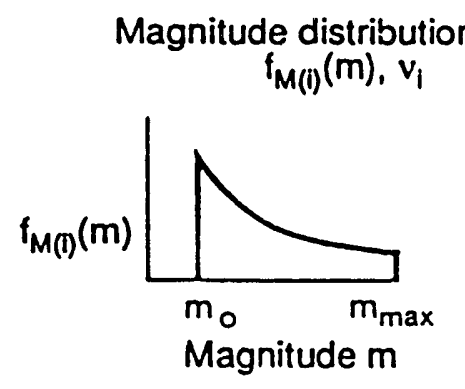

b.
Ground motion attenuation $G_{Y \mid m, r}(Y)$

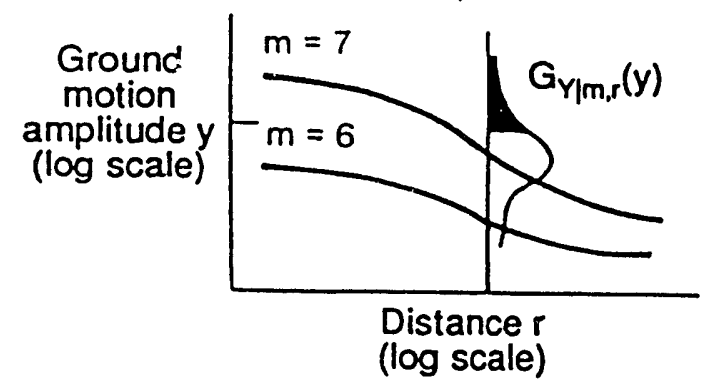

c.

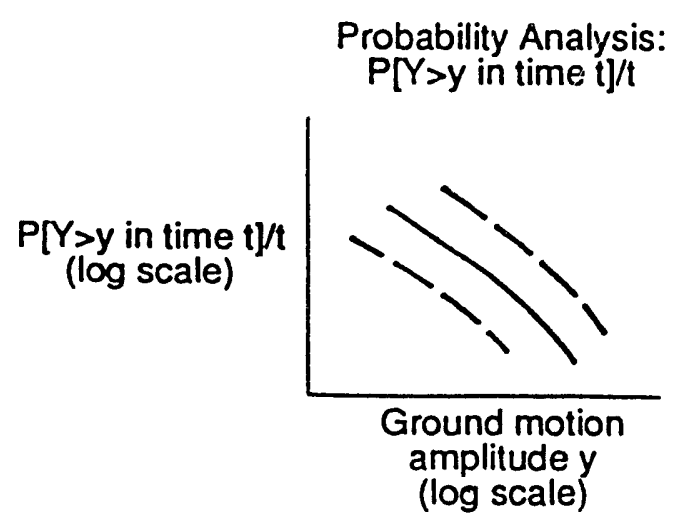

d.

Figure 2-1. Seismic hazard computational model. Source: (ㅁ). 


\subsubsection{Treatment of Uncertainty}

In probabilistic risk analyses (PRAs), it is necessary to distinguish between two types of variability: randomness and uncertainty. Randomness is probabilistic variability that results from natural physical processes. The size, location and time of the next earthquake on a fault and the details of the ground motion are examples of random events. In concept, these elements cannot be predicted even with collection of additional data, so the randomness component of variability is irreducible. The second category of variability is "uncertainty" which is the statistical or modeling variability that result from lack of knowledge about the true state of nature. In principle, this variability can be reduced with the collection of additional data.

These two types of variability are treated differently in seismic hazard analyses for PRAs: integration is carried out over probabilistic variabilities to get a single hazard curve (see equation 2-1), whereas modeling uncertainties are expressed by multiple assumptions, hypotheses, or parameter values. These multiple interpretations result in a suite of hazard curves and their associated weights.

There are uncertainties associated with each of the three inputs to the seismic-hazard evaluation, as follows:

- Uncertainty about seismic sources (i.e., which tectonic features in a region are actually earthquake sources) arises because there are multiple hypotheses about the causes of earthquakes in CEUS and because there is incomplete knowledge about the physical characteristics of tectonic features. Uncertainty may also arise about the geometry of a seismic source.

- Uncertainty in seismicity is generally divided into uncertainty in maximum magnitude and uncertainty in seismicity parameters $a$ and $b$. Uncertainty about, $m_{\max }$, the maximum magnitude that a given source can generate arises for the same reasons described above. Estimates of $m_{\max }$ are obtained from physical characteristics of the source and from historic seismicity. Uncertainty in seismicity parameters $a$ and $b$ arises from statistical uncertainty and from uncertainty about the variability of $a$ and $b$ between cells in a given source.

- Uncertainty in the attenuation functions arises from alternative hypotheses about the dynamic characteristics of earthquakes in CEUS. This uncertainty has been large because there have been few strong-motion recordings from earthquakes of engineering interest in CEUS. 
The EPRI/SOG methodology quantifies seismic hazard and its uncertainty by using as inputs the tectonic interpretations developed by six multidisciplinary Earth-Science Teams. In addition, each team quantified its uncertainty about seismic sources, maximum magnitudes, and seismicity parameters, as follows:

- Uncertainty about seismic sources was characterized by specifying an activity probability $P^{a}$ to each seismic source and specifying activity dependencies among sources in the same region.

- Uncertainty about maximum magnitude is characterized by a discrete distribution of $m_{\max }$ for each source. That is, multiple values of $m_{\max }$ are specified and given weights.

- Uncertainty about seismicity parameters is characterized by considering multiple sets of parameter values of each source, and giving them weights. Each set of parameters is computed, for instance, using different assumptions about spatial continuity of $a$ and $b$, or using different portions of the earthquake catalog.

Ground-motion attenuation in CEUS, and its uncertainty, is quantified by considering three alternative attenuation functions for each ground-motion measure, and giving them weights (see Section 2.4). The development and selection of these attenuation equations is documented in ( $\underline{7})$ and in Appendix $A$ of (ㅁ) .

In order to organize and display the multiple hypotheses, assumptions, parameter values and their possible combinations, a logic tree approach is used. Logic trees are a convenient means to express alternative interpretations and their probabilities.

Each level of the logic tree represents one source of uncertainty. The branches emanating from one node represent possible values of a parameter. The probability assigned to a branch represents the likelihood of the parameter value associated with that branch, given certain values of the preceding parameters.

The logic tree in Figure 2-3 represents the treatment of parameter uncertainty in the SOG methodology, for one team. Associated with each terminal node, there is one hazard curve, which corresponds to certain sources being active, each active source having a certain $m_{\max }$ and certain seismicity parameters, and a certain attenuation function being the true attenuation model. The probability associated with that end branch is the product of the probabilities of all branches traversed to reach that terminal node. 


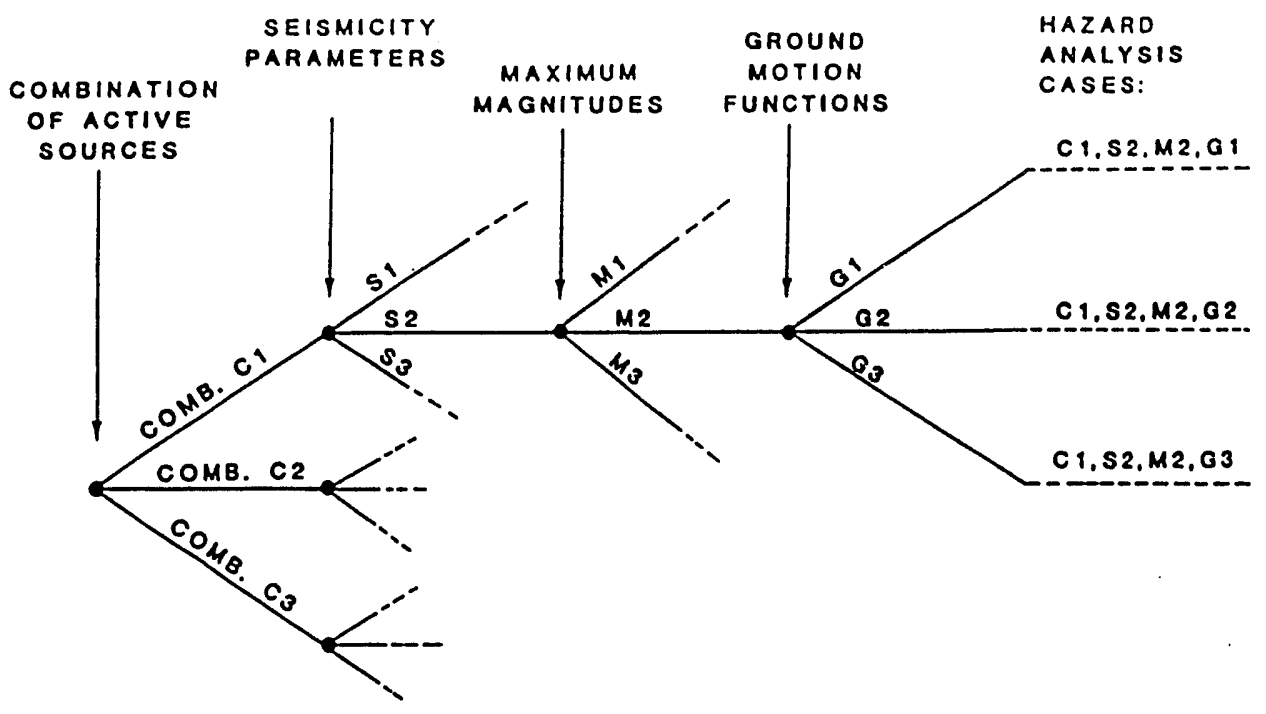

Figure 2-2. Logic tree representation of uncertain parameters in the EPRI/SOG methodology

The hazard curves obtained by the 6 teams are given equal weights and then combined. The resulting family of hazard curves and their associated probabilities, corresponding to all end branches of the six teams' logic trees, contains all the information about seismic hazard at the site, its uncertainty, and the different contributors to that uncertainty.

\subsubsection{Development of Seismological Interpretations}

This section briefly describes the development of the EPRI/SOG seismic sources and the estimation of their their parameters; a complete description is found in Volume 1, Sections 3 and 4 , of ( $(\underline{8})$. Volumes 5 through 10 of (ㅇ) document the seismological interpretations by the six Earth-Science Teams. Section 2.3 describes the seismic sources that contribute to hazard at the HFIR site, and the characteristics of these sources.

Seismic Sources. In the SOG methodology, seismic sources have the following characteristics:

- A seismic source is associated with potentially active tectonic features or with a cluster of seismicity.

- The entire source is either active or inactive.

- Every point within the source has the same maximum magnitude. 
- The seismic source is composed of individual cells (1 degree latitude by 1 degree longitude). Seismicity parameters $a$ and $b$ may be specified separately for each cell within the source.

The EPRI/SOG seismic sources were developed using the tectonic framework: a structured approach to identify tectonic features that may be capable of generating earthquakes, interpret scientific knowledge concerning the causative mechanisms of earthquakes in CEUS, delineate seismic sources, and assess probabilities of activity $\left(P^{a}\right)$ for these sources.

In addition, the teams assessed joint activity probabilities for multiple sources in the same region. In most cases, the Teams specified joint activity probabilities through simple forms of dependence, such as perfect dependence or mutual exclusivity. Activity dependencies have no effect on the mean hazard (because the total hazard is a linear combination of source hazards), but they have an effect on uncertainty. Perfect dependence produces the highest uncertainty, mutual exclusivity produces the lowest uncertainty.

Seismicity Parameters. Seismicity parameters $a$ and $b$ are estimated using the maximum likelihood method. Parameters $a$ and $b$ (especially $a$ ) may be allowed to vary spatially within a seismic source. For computational convenience, they are assumed to be constant within each 1-degree cell within the source. The degree of spatial variability (or smoothing) of $a$ and $b$ between adjacent cells in each source is controlled by the seismicity option. Each team captured uncertainty on the appropriate degree of smoothing for each source (i.e., whether the source has homogeneous seismicity or if the activity rates follow the within-source pattern of historic activity) by specifying alternative seismicity options, with associated probabilities. In addition, the teams could specify a prior distribution (in the Bayesian sense) on $b$, and other parameters of the estimation algorithm, with each seismicity option.

Maximum Magnitudes. To calculate seismic hazard at a site, the largest possible earthquake magnitude that can occur in each seismic source must be estimated. This maximum magnitude $m_{\max }$ is generally uncertain. This uncertainty is represented by a probability distribution on the maximum magnitude that the source can generate.

Each team estimated a probability distribution of $m_{\max }$ for each active source that the team had identified. The following considerations were used to constrain the maximum-magnitude estimates:

- Physical Constraints. These approaches relate $m_{\max }$ to the size of the source or the thickness of the earth's crust. 
- Historic Seismicity. These approaches involve the addition of an increment to the maximum historical magnitude, extrapolation of the magnitude-recurrence relation to some justified frequency of occurrence, and the statistical treatment of the earthquake catalog.

- Analogies With Other Sources or Regions. If one is able to identify a number of analogous sources, so that one can assume that they all have the same value of $m_{\max }$, one can improve the precision of $m_{\max }$ estimates obtained from statistical analyses. The analyses of earthquakes in other intraplate regions of the world is another way to increase sample size. A study of this type was performed by EPRI $(\underline{9,10}) ; m_{\max }$ values were obtained for various types of tectonic features.

The SOG methodology uses discrete distributions to represent uncertainty in $m_{\max }$. When a team specified continuous distributions or discrete distributions with excessive numbers of values, equivalent discrete distributions were developed.

Minimum Magnitude. The minimum magnitude $m_{0}$ introduced in Section 2.2 .1 represents the smallest magnitude of interest in the hazard calculations. It is assumed that earthquakes with magnitudes lower than $m_{0}$ are incapable of causing damage. Therefore, the choice of $m_{0}$ is related to the type of facility being analyzed.

Based on the seismological characteristics of small earthquakes, analysis of structural response, and field studies of structural performance during low-intensity ground motions, it has been concluded that it is appropriate to use moment magnitude 5.0 (which corresponds to $m_{b}$ approximately equal to 5.5 ) as the minimum magnitude for seismic-hazard calculations $(11,12)$. As an added measure of conservatism, the EPRI/SOG methodology uses $m_{b} 5.0$ as the minimum magnitude. This value is considered more than sufficiently conservative to compensate for the small probability that an earthquake with $m_{b}<5.0$ could cause damage to a nuclear power plant.

\subsubsection{Computer Codes}

The computer package EQHAZARD performs seismic-hazard calculations using the EPRI/SOG methodology and seismological interpretations. This section provides a brief description of the various modules in EQHAZARD and their functions (see Figure 2-6). Volumes 2 and 3 of () contain a detailed description of these computer codes.

Modules for the Development of a Homogeneous Earthquake Catalog. The development of a homogeneous earthquake catalog is performed by five modules: CREINP, EQCONVERT, 
Inputs

Master (raw)

catalog

Source geometries, Seismicity

options,

Catalog

incompleteness

Attenuation

functions,

Source Geometries

Seismicity options

Maximum magnitudes

Source combinations

Team weights

Site amplification

factors
Module

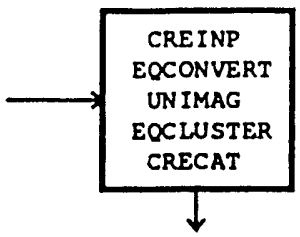

Homogeneous

Catalog

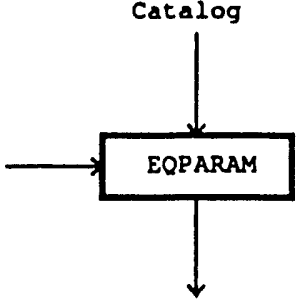

Selsmicity

Parameters

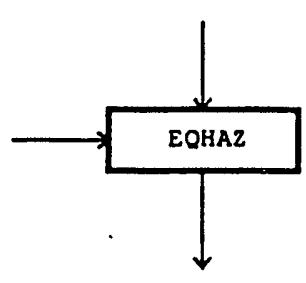

Hazards

from each

source

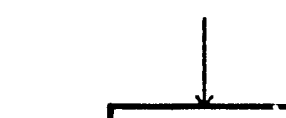

EQPOST

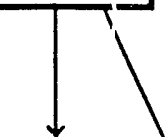

Mean and

standard deviations of log-hazards for each team

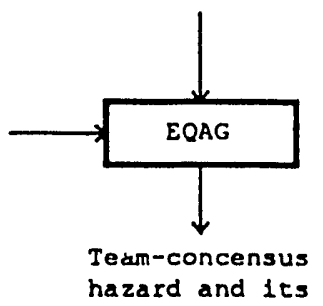

hazard and its
Module Function

Calculate unifom magnitude estimates

for all events,

eliminate secondary events.

Estimate seismicity parameters for all seismic sources. Executed once for each team.

Calculate hazard from each source. Executed once for esch Earth Science team.

Calculate total hazard and its uncertainty. Executed once for each ground-motion measure

Marginal distribution of $\rightarrow$ hazard, sensitivity results.

Calculates a

team-concensus hazard and its uncertainty

Figure 2-3. EQHAZARD modules: their functions and data flow. Source: ()). 
UNIMAG, EQCLUSTER, and CRECAT. These programs perform two main functions: (1) calculate a uniform value of $m_{b}$ for each earthquake, using all size measures available (e.g., $m_{b}, M_{L}$, epicentral intensity, felt area); and (2) identify and eliminate secondary events (e.g., aftershocks). The result is a catalog of main events in which earthquake size is measured by the uniform $m_{b}$.

Module for the estimation of seismicity parameters-EQPARAM. EQPARAM estimates seismicity parameters for area seismic sources, using as basic inputs the earthquake catalog, the source geometries and seismicity parameters specified by one Earth Science team, and catalog incompleteness information.

Modules for the calculation of seismic hazard. EQHAZ calculates the seismic hazard at one site from each source specified by one Earth Science tean. Hazard is simultaneously calculated for several measures of ground motion. EQPOST calculates the total hazard at the site and its uncertainty for one or more Earth Science Teams, and calculates the sensitivity of seismic hazard to attenuation function, maximum magnitudes, seismicity options, and earth-science teams. EQAG calculates the group-consensus mean log hazard as a weighted sum of the teams' results for that site.

\subsection{TECTONIC AND SEISMICITY INTERPRETATIONS}

The specification of potential sources of future earthquakes is the first step in the evaluation of earthquake hazards. Seismic sources indicate where earthquakes inay occur; analysis of historical seismicity within those defined sources indicates the probabilities of occurrence and characteristics of future earthquakes (i.e. we fit a magnitude distribution to historical data within the source, once the source is defined).

In the SOG methodology, a seismic source is defined as a region with a single probability of activity $P^{a}$ and a single maximum magnitude (which may be uncertain). Within a seismic source the seismicity (quantified by parameters $a$ and $b$ ) can vary in space.

In general, the sources derived by the six Teams are based on tectonic features and other evidence (including, in some cases, merely a spatial cluster of historical seismicity). Because of this derivation there is, conceptually, some causal association of earthquakes within a source: they are releasing crustal stresses of the same orientation and amplitude, and/or they are caused by slip on faults with the same general depth, orientation, and sense of slip. Because of these similarities the delineation conforms to the seismic source definition with regard to maximum magnitude and probability of activity. 
This section reviews the characteristics of seismic sources in the SOG methodology and briefly summarizes the interpretations by the 6 Teams. Volumes 5 through 10 of (ㅇ) describe and document these interpretations.

\subsubsection{Seismic Sources}

Sets of seismic sources were derived for the central and eastern US by the six Earth Science Teams, using the project data bases of geologic, geophysical, and seismological evidence (including historical seismicity). The bases for these derivations are given in detail in Volumes 5 through 10 of (ㅇ) . During the project, multiple interpretations were encouraged, to express uncertainty on the causes of earthquakes and their physical expression in the form of seismic sources. In other words, if there were multiple theories on the physical causes of earthquakes, and these theories had different implications in terms of the regions within which future earthquakes were thought possible, the Teams were encouraged to express these uncertainties with multiple tectonic features and seismic sources. Each Team's uncertainty was quantified through its assessments of $P^{a}$ for each source and a specification of the interdependency of activity (whether the state of activity of one source affects the activity of another). Five of the six Teams specified interdependencies among sources.

Joint activity probabilities were often specified through the following simple forms of dependence:

- Perfect Dependence (PD). Two sources $A$ and $B$ are perfectly dependent if the probability that $A$ is active, given that $B$ is active, is unity. This form of dependency arises between tectonic features with the same physical characteristics (e.g., multiple faults with identical orientations).

- Independence. Two sources $a$ and $b$ are independent if the state of activity of source $A$ does not affect the state of activity of source $B$. Mathematically, $P^{a}[A$ and $B]=$ $P^{a}[A] P^{a}[B]$.

- Mutual Exclusivity (ME). Two sources $A$ and $B$ are mutually exclusive if the probability of $A$ being active, given that $B$ is active, is zero. Mutually exclusive sources are used to represent alternative hypotheses for the causes of seismicity in a region or uncertainty on the geographic extent of a seismic source.

- Default Sources. This is a special form of mutual exclusivity. It arises when an earthquake is known to have occurred in a region by the candidate tectonic features (say, 
the features represented by sources $A, B$, and $C$ ) do not make a collectively exhaustive set (i.e., $P^{a}[A$ or $B$ or $\left.C]<1\right)$. A default source $D$, with $P^{a}[D]=1-P^{a}[A$ or $B$ or $C]$ and $P[D \mid(A$ or $B$ or $C)]=0$, must be added in order to have a model of seismicity that is consistent with historica! seismicity.

The Weston and Woodward-Clyde teams characterized the probability of activity using $P^{*}$ : the probability that the source is capable of generating earthquakes with magnitudes larger than 5. $P^{*}$ and $P^{a}$ are related through the distribution of maximum magnitude.

Background sources and their probabilities of activity $P_{B G}^{a}$ require special description, as the interpretation is slightly different from that for primary sources. A background source represents a region where specific causes of earthquakes cannot be identified, but where a Team feels that earthquakes will occur. The regions of background sources are defined so that there is one maximum-magnitude $\left(m_{\max }\right)$ distribution for the entire source, but the interpretation of $P_{B G}^{a}$ is not that the background is active with probability $P_{B G}^{a}$ and inactive with probability $1-P_{B G}^{a}$. Rather, $P_{B G}^{a}$ represents the fraction of area of the background that is active. In the hazard calculations if the background contributes significantly the background hazard is weighted by $P_{B G}^{a}$ to calculate the correct average contribution of hazard from the background.

All Teams except Dames and Moore and Rondout used background sources to some extent. $P_{B G}^{a}$ was set to unity by all teams except Law Engineering. The Woodward-Clyde Consultants Team used local background sources centered at each EPRI-SOG site. For the HFIR site, we used the Watts Bar background. (This is accurate because the two sites are close relative to the size of the background.)

\subsubsection{Maximum Magnitudes and Seismicity Options}

Each team specified maximum magnitudes and seismicity options for each source it had i,entified.

Most teams specified maximum magnitudes in the form of discrete distributions with 2 to 4 values (i.e., they specified multiple alternative values of $m_{\max }$ with associated weights). The Law Engineering Team specified only one value of maximum magnitude for some sources. The Woodward-Clyde Team specified a larger number of values for all sources; these values were transformed into an equivalent discrete distribution with three values.

Each seismicity option specifies the assumptions used in the estimation of seismicity parameters $a$ and $b$ for that source. Each option specifies the cell-to-cell variability of $a$ and $b$, the 
prior distribution of $b$, and the weight (or importance) given to small-magnitude earthquakes in the estimation process. Alternatively, a seismicity option may directly specify the values of $a$ and $b$. All teams except Law and Rondout specified 2 to 4 alternative seismicity options (with associated weights) for most sources.

\subsubsection{Seismic Sources near the HFIR Site}

Figures 2-3 through 2-8 show the seismic sources near the HFIR site, as identified by the six Earth-Science Teams. Tables 2-1 through 2-6 list those seismic sources near HFIR that contribute to seismic hazard at the site. These tables also include the sources' maximum magnitudes, seismicity options, and activity probabilities. 
Table 2-1

Summary of Bechtel Team Sources Near the HFIR Site

\begin{tabular}{|c|c|c|c|c|c|}
\hline Source & Description & $\begin{array}{l}\text { Seis. Opts. } \\
\text { and Probs. }\end{array}$ & $\begin{array}{c}\text { Max. Mags. } \\
\text { and Probs. }\end{array}$ & $P^{a}$ & $\begin{array}{c}\text { Inter- } \\
\text { dependencies }\end{array}$ \\
\hline 24 & Bristol Trends & $\begin{array}{l}1[0.33] \\
2[0.34] \\
4[0.33]\end{array}$ & $\begin{array}{l}5.7[0.10] \\
6.0[0.40] \\
6.3[0.40] \\
6.6[0.10]\end{array}$ & 0.25 & $\begin{array}{l}\text { ME with } 24 \\
\text { and } 25 \mathrm{~A}\end{array}$ \\
\hline 25 & $\begin{array}{l}\text { NY-Alabama } \\
\text { lineament } \\
\text { (short) }\end{array}$ & $\begin{array}{l}1[0.33] \\
2[0.34] \\
4[0.33]\end{array}$ & $\begin{array}{l}5.4[0.10] \\
5.7[0.40] \\
6.0[0.40] \\
6.6[0.10]\end{array}$ & 0.30 & $\begin{array}{l}\text { ME with } 24 \\
\text { and } 25 \mathrm{~A}\end{array}$ \\
\hline $25 \mathrm{~A}$ & $\begin{array}{l}\text { NY-Alabama } \\
\text { lineament } \\
\text { (long) }\end{array}$ & $\begin{array}{l}1[0.33] \\
2[0.34] \\
4[0.33]\end{array}$ & $\begin{array}{l}5.4[0.10] \\
5.7[0.40] \\
6.0[0.40] \\
6.6[0.10]\end{array}$ & 0.45 & $\begin{array}{l}\text { ME with } 24 \\
\text { and } 25\end{array}$ \\
\hline 30 & New Madrid & $\begin{array}{l}1[0.33] \\
2[0.34] \\
4[0.33]\end{array}$ & $\begin{array}{l}7.4[0.10] \\
7.5[0.90]\end{array}$ & 1.00 & $\begin{array}{l}\text { Not contained } \\
\text { in } \mathrm{BZO}\end{array}$ \\
\hline $\mathrm{F}$ & S.E. Appalachians & $\begin{array}{l}1[0.33] \\
2[0.34] \\
4[0.33]\end{array}$ & $\begin{array}{l}5.4[0.10] \\
5.7[0.40] \\
6.0[0.40] \\
6.6[0.10]\end{array}$ & 0.35 & none \\
\hline $\mathrm{H}$ & Charleston & $\begin{array}{l}1[0.33] \\
2[0.34] \\
4[0.33]\end{array}$ & $\begin{array}{l}6.8[0.20] \\
7.1[0.40] \\
7.4[0.40]\end{array}$ & 0.50 & none \\
\hline $\mathrm{BZO}$ & $\begin{array}{l}\text { New Madrid } \\
\text { Region }\end{array}$ & $\begin{array}{l}1[0.33] \\
2[0.34] \\
3[0.33]\end{array}$ & $\begin{array}{l}5.7[0.10] \\
6.0[0.40] \\
6.3[0.40] \\
6.6[0.10]\end{array}$ & 1.00 & $\begin{array}{l}\text { Background } \\
P_{B G}^{a}=1.00\end{array}$ \\
\hline BZ5 & S. Appalachians & $\begin{array}{l}1[0.33] \\
2[0.34] \\
3[0.33]\end{array}$ & $\begin{array}{l}5.7[0.10] \\
6.0[0.40] \\
6.3[0.40] \\
6.6[0.10]\end{array}$ & 1.00 & $\begin{array}{l}\text { Background } \\
P_{B G}^{a}=1.00\end{array}$ \\
\hline
\end{tabular}


Table 2-1 (continued)

Summary of Bechtel Team Sources 'Tear the HFIR Site

\begin{tabular}{|c|c|c|c|c|c|}
\hline Source & Description & $\begin{array}{l}\text { Seis. Opts. } \\
\text { and Probs. }\end{array}$ & $\begin{array}{l}\text { Max. Mags. } \\
\text { and Probs. }\end{array}$ & $P^{a}$ & $\begin{array}{c}\text { Inter- } \\
\text { dependencies }\end{array}$ \\
\hline BZ6 & $\begin{array}{l}\text { S.E. Craton } \\
\text { Region }\end{array}$ & $\begin{array}{l}1[0.33] \\
2[0.34] \\
3[0.33]\end{array}$ & $\begin{array}{l}5.7[0.10] \\
6.0[0.40] \\
6.3[0.40] \\
6.6[0.10]\end{array}$ & 1.00 & $\begin{array}{l}\text { Background } \\
P_{B G}^{a}=1.00\end{array}$ \\
\hline
\end{tabular}

1 Seismicity options are defined as follows:

$1=$ constant $a$, constant $b$ (no prior $b$ );

$2=$ low smoothing on $a$, high smoothing on $b$ (no prior $b$ );

3 = low smoothing on $a$, low smoothing on $b$ (no prior $b$ );

$4=$ low smoothing on $a$, low smoothing on $b$ (weak prior of 1.05).

Weights on magnitude intervals are $[1.0,1.0,1.0,1.0,1.0,1.0,1.0]$ 
Table 2-2

Summary of Dames and Moore Team Sources Near the HFIR Site

\begin{tabular}{|c|c|c|c|c|c|}
\hline Source & Description & $\begin{array}{l}\text { Seis. Opts. } \\
\text { and Probs. }\end{array}$ & $\begin{array}{l}\text { Max. Mags. } \\
\text { and Prots. }\end{array}$ & $P^{a}$ & $\begin{array}{c}\text { Inter- } \\
\text { dependencies }\end{array}$ \\
\hline \multirow[t]{2}{*}{04} & Appalachian & $1[0.75]$ & $6.0[0.80]$ & \multirow[t]{2}{*}{0.35} & \multirow[t]{2}{*}{$\mathrm{ME}$ with $4 \mathrm{~A}$} \\
\hline & Fold Belt & $2[0.25]$ & $7.2[0.20]$ & & \\
\hline \multirow[t]{2}{*}{$4 \mathrm{~A}$} & Kink in & $3[0.75]$ & $6.8[0.75]$ & \multirow[t]{2}{*}{0.65} & \multirow[t]{2}{*}{ ME with 04} \\
\hline & Fold Belts & $4[0.75]$ & $7.2[0.25]$ & & \\
\hline \multirow[t]{2}{*}{05} & E. Continent & $3[0.75]$ & $5.7[0.75]$ & \multirow[t]{2}{*}{0.30} & \multirow[t]{2}{*}{ none } \\
\hline & Gravity High & $4[0.75]$ & $7.2[0.25]$ & & \\
\hline \multirow[t]{4}{*}{21} & \multirow[t]{4}{*}{ New Madrid } & (Use params. & $7.2[0.25]$ & \multirow[t]{4}{*}{1.0} & \multirow[t]{4}{*}{ none } \\
\hline & & from $21 \mathrm{~B}^{\ddagger}$ ) & $7.5[0.75]$ & & \\
\hline & & $3[0.75]$ & & & \\
\hline & & $4[0.25]$ & & & \\
\hline \multirow[t]{2}{*}{41} & Default & $1[0.75]$ & $6.1[0.80]$ & \multirow[t]{2}{*}{0.12} & \multirow{2}{*}{$\begin{array}{l}\text { Default for } \\
42,43 \text {, and } 46\end{array}$} \\
\hline & & $2[0.75]$ & $7.2[0.20]$ & & \\
\hline
\end{tabular}

1 Seismicity options are defined as follows:

$1=$ no smoothing on $a$, no smoothing on $b$ (strong prior of 1.04);

$2=$ no smoothing on $a$, no smoothing on $b$ (weak prior of 1.04);

$3=$ constant $a$, constant $b$ (strong prior of 1.04 );

$4=$ constant $a$, constant $b$ (weak prior of 1.04 );

Weights on magnitude intervals are $[0.1,0.2,0.4,1.0,1.0,1.0,1.0]$

$\ddagger$ To account for differences in areas, the value of $a$ in source 21 is equal to the value of $a$ in source $21 \mathrm{~B}$ plus the quantity $\log _{10}\left(\right.$ Area $_{21 B} /$ Area $\left._{21}\right)$. 
Table 2-3

Summary of Law Engineering Team Sources Near the HFIR Site

\begin{tabular}{|c|c|c|c|c|c|}
\hline Source & Description & $\begin{array}{l}\text { Seis. Opts. } \\
\text { and Probs. }\end{array}$ & $\begin{array}{l}\text { Max. Mags. } \\
\text { and Probs. }\end{array}$ & $P^{a}$ & $\begin{array}{c}\text { Inter- } \\
\text { dependencies }\end{array}$ \\
\hline 01 & $\begin{array}{l}\text { E. Continent } \\
\text { Gravity High }\end{array}$ & $1 \mathrm{a}[1.00]$ & $5.4[1.00]$ & 0.32 & none \\
\hline 17 & $\begin{array}{l}\text { Eastern } \\
\text { Basement }\end{array}$ & $1 \mathrm{~b}[1.00]$ & $\begin{array}{l}5.7[0.20] \\
6.8[0.80]\end{array}$ & 0.62 & none \\
\hline 18 & $\begin{array}{l}\text { Postulated } \\
\text { Faults in } \\
\text { Reelfoot Rift }\end{array}$ & $2 \mathrm{~d}[1.00]$ & $7.4[1.00]$ & 1.00 & none \\
\hline 115 & Indiana Block & $1 \mathrm{a}[1.00]$ & $\begin{array}{l}5.2[0.50] \\
5.5[0.50]\end{array}$ & 1.00 & $\begin{array}{l}\text { Background } \\
P_{B G}^{a}=1.00\end{array}$ \\
\hline 217 & $\begin{array}{l}\text { Eastern Basement } \\
\text { Background }\end{array}$ & $1 \mathrm{~b}[1.00]$ & $\begin{array}{l}4.9[0.50] \\
5.7[0.50]\end{array}$ & 1.00 & $\begin{array}{l}\text { Background } \\
P_{B G}^{a}=0.29 ; \\
\text { same geometry } \\
\text { as } 17\end{array}$ \\
\hline
\end{tabular}

1 Seismicity options are defined as follows:

$1 \mathrm{a}=$ high smoothing on $a$, constant $b$ (strong prior of 1.05 );

$1 \mathrm{~b}=$ high smoothing on $a$, constant $b$ (strong prior of 1.00 );

$1 \mathrm{c}=$ high smoothing on $a$, constant $b$ (strong prior of 0.95 );

$1 \mathrm{~d}=$ high smoothing on $a$, constant $b$ (strong prior of 0.90 );

$2 \mathrm{a}=$ constant $a$, constant $b$ (strong prior of 1.05);

$2 \mathrm{c}=$ constant $a$, constant $b$ (strong prior of 0.35 );

$2 \mathrm{~d}=$ constant $a$, constant $b$ (strong prior of 0.90 );

Weights on magnitude intervals are all 1.0 for the above options

$3 \mathrm{a}=$ high smoothing on $a$, constant $b$ (strong prior of 1.05)

Weights on magnitude intervals are $[0.0,1.0,1.0,1.0,1.0,1.0,1.0]$ for option $3 \mathrm{a}$. 
Table $2-4$

Summary of Rondout Associates Team Sources Near the HFIR Site

\begin{tabular}{|c|c|c|c|c|c|}
\hline Source & Description & $\begin{array}{l}\text { Seis. Opts. } \\
\text { and Probs. }\end{array}$ & $\begin{array}{l}\text { Max. Mags. } \\
\text { and Probs. }\end{array}$ & $P^{a}$ & $\begin{array}{c}\text { Inter- } \\
\text { dependencies }\end{array}$ \\
\hline 1 & New Madrid & $\begin{array}{c}5[1.00] \\
(A=3.85 \\
b=1.00)\end{array}$ & $\begin{array}{l}7.1[0.10] \\
7.3[0.80] \\
7.4[0.10]\end{array}$ & 1.00 & none \\
\hline 5 & $\begin{array}{l}\text { East Continent } \\
\text { Geoph. Anomaly }\end{array}$ & $\begin{array}{c}1[1.00] \\
(a=-1.66 \\
b=0.96)\end{array}$ & $\begin{array}{l}5.2[0.30] \\
6.3[0.55] \\
6.5[0.15]\end{array}$ & 1.00 & none \\
\hline 9 & Eastern Tennessee & $\begin{array}{c}1[0.70] \\
(a=-1.38 \\
b=0.89) \\
6[0.30] \\
(a=-1.08 \\
b=0.81)\end{array}$ & $\begin{array}{l}5.8[0.15] \\
6.5[0.60] \\
6.8[0.25]\end{array}$ & 0.99 & none \\
\hline 25 & S. Appalachians & $\begin{array}{c}1[1.00] \\
(a=-0.63 \\
b=1.15)\end{array}$ & $\begin{array}{l}6.6[0.30] \\
6.8[0.60] \\
7.0[0.10]\end{array}$ & 0.99 & none \\
\hline 26 & $\begin{array}{l}\text { S. Carolina } \\
\text { Zone }\end{array}$ & $\begin{array}{c}1[1.00] \\
(a=-1.39 \\
b=0.97)\end{array}$ & $\begin{array}{l}5.8[0.15] \\
6.5[0.60] \\
6.8[0.25]\end{array}$ & 1.00 & none \\
\hline 27 & $\begin{array}{l}\text { Tennessee-Va. } \\
\text { Border Zone }\end{array}$ & $\begin{array}{c}1[1.00] \\
(a=-1.12 \\
b=0.93)\end{array}$ & $\begin{array}{l}5.2[0.30] \\
6.3[0.55] \\
6.5[0.15]\end{array}$ & 0.99 & none \\
\hline $\begin{array}{c}1 \text { SeisI } \\
1 \\
3 \\
5\end{array}$ & $\begin{array}{l}\text { icity options are defin } \\
=a \text { and } b \text { as listed al } \\
=\text { low smoothing on } \\
=A \text { and } b \text { as listed }\end{array}$ & $\begin{array}{l}\text { as follows: } \\
\text { e; } \\
\text { constant } b \text { (st } \\
\text { ve; }\end{array}$ & $\mathrm{g}$ prior of 1.0 & & \\
\hline
\end{tabular}


Table 2-5

Summary of Weston Geophysical Team Sources Near the HFIR Site

\begin{tabular}{|c|c|c|c|c|c|}
\hline Source & Description & $\begin{array}{l}\text { Seis. Opts. } \\
\text { and Probs. }\end{array}$ & $\begin{array}{c}\text { Max. Mags. } \\
\text { and Probs. }\end{array}$ & $P^{*}$ & $\begin{array}{c}\text { Inter- } \\
\text { dependencies } \\
\end{array}$ \\
\hline 24 & $\begin{array}{l}\text { New York-Alabama } \\
\text { Clingman }\end{array}$ & $1 \mathrm{~b}[1.00]$ & $\begin{array}{l}5.4[0.26] \\
6.0[0.58] \\
6.6[0.16]\end{array}$ & 0.90 & $\begin{array}{l}\text { Contained in } \\
103\end{array}$ \\
\hline 31 & New Madrid & $1 \mathrm{~b}[1.00]$ & $7.2[1.00]$ & 0.95 & none \\
\hline 32 & $\begin{array}{l}\text { Reelfoot } \\
\text { Rift }\end{array}$ & $\begin{array}{l}1 b[0.80] \\
2 b[0.30]\end{array}$ & $7.2[1.00]$ & 1.00 & \\
\hline C11 & $32-31$ & $1 \mathrm{~b}[1.00]$ & $\begin{array}{l}6.0[0.13] \\
6.6[0.77] \\
7.2[0.10]\end{array}$ & NA & Donut source \\
\hline $\mathrm{C} 17$ & $103-23$ & $\begin{array}{l}1 \mathrm{a}[0.70] \\
2 \mathrm{a}[0.30]\end{array}$ & $\begin{array}{l}5.4[0.26] \\
6.0[0.58] \\
6.6[0.16]\end{array}$ & NA & Donut source \\
\hline $\mathrm{C} 19$ & $103-23-24$ & $1 \mathrm{a}[1.00]$ & $\begin{array}{l}5.4[0.26] \\
6.0[0.58] \\
6.6[0.16]\end{array}$ & NA & Donut source \\
\hline
\end{tabular}

$1 \quad$ Seismicity options are defined as follows:

$1 a=$ constant $a$, constant $b$ (medium prior of 1.00 );

$\mathrm{Ib}=$ constant $a$, constant $b$ (medium prior of 0.90 );

$1 c=$ constant $a$, constant $b$ (medium prior of 0.70 );

$2 \mathrm{a}=$ medium smoothing on $a$, medium smoothing on $b$ (medium prior of 1.00 );

$2 \mathrm{~b}=$ medium smoothing on $a$, medium smoothing on $b$ (medium prior of 0.90 );

$2 \mathrm{c}=$ medium smoothing on $a$, medium smoothing on $b$ (medium prior of 0.70 );

Weigits on magnitude intervals are all 1.0 for the above options 
Table 2-6

Summary of Woodward-Clyde Consultants Team Sources Near the HFIR Site

\begin{tabular}{|c|c|c|c|c|c|}
\hline Source & Description & $\begin{array}{l}\text { Seis. Opts. } \\
\text { and Probs. }\end{array}$ & $\begin{array}{l}\text { Max. Mags. } \\
\text { and Probs. }\end{array}$ & $P^{*}$ & $\begin{array}{c}\text { Inter- } \\
\text { dependencies } \\
\end{array}$ \\
\hline 29 & $\begin{array}{l}\text { So. Carolina } \\
\text { Gravity Saddle } \\
\text { (extended) }\end{array}$ & $\begin{array}{l}2[0.25] \\
3[0.25] \\
4[0.25] \\
5[0.25]\end{array}$ & $\begin{array}{l}6.7[0.33] \\
7.0[0.34] \\
7.4[0.33]\end{array}$ & 0.122 & $\begin{array}{l}\text { ME with } 29 A \\
30\end{array}$ \\
\hline $29 \mathrm{~A}$ & $\begin{array}{l}\text { So. Carolina } \\
\text { Gravity Saddle } \\
\# 2\end{array}$ & $\begin{array}{l}2[0.25] \\
3[0.25] \\
4[0.25] \\
5[0.25]\end{array}$ & $\begin{array}{l}6.7[0.33] \\
7.0[0.34] \\
7.4[0.33]\end{array}$ & 0.305 & $\begin{array}{l}\text { ME with } 29 \\
30\end{array}$ \\
\hline $29 B$ & $\begin{array}{l}\text { So. Carolina } \\
\text { Gravity Saddle } \\
\# 3\end{array}$ & $\begin{array}{l}2[0.25] \\
3[0.25] \\
4[0.25] \\
5[0.25]\end{array}$ & $\begin{array}{l}5.4[0.33] \\
6.0[0.34] \\
7.0[0.33]\end{array}$ & 0.183 & $\begin{array}{l}\text { ME with } 29 \\
29 \mathrm{~A}\end{array}$ \\
\hline 31 & $\begin{array}{l}\text { Blue Ridge } \\
\text { Combo }\end{array}$ & $\begin{array}{l}2[0.25] \\
3[0.25] \\
4[0.25] \\
5[0.25]\end{array}$ & $\begin{array}{l}5.9[0.33] \\
6.3[0.34] \\
7.0[0.33]\end{array}$ & 0.024 & ME with $31 \mathrm{~A}$ \\
\hline $31 \mathrm{~A}$ & $\begin{array}{l}\text { Blue Ridge } \\
\text { Combo } \\
\text { (alternate } \\
\text { configuration) }\end{array}$ & $\begin{array}{l}2[0.25] \\
3[0.25] \\
4[0.25] \\
5[0.25]\end{array}$ & $\begin{array}{l}5.9[0.33] \\
6.3[0.34] \\
7.0[0.33]\end{array}$ & 0.211 & ME with 31 \\
\hline 40 & $\begin{array}{l}\text { Disturbed Zone } \\
\text { of Reelfoot } \\
\text { Rift }\end{array}$ & $\begin{array}{l}2[0.33] \\
3[0.34] \\
4[0.33]\end{array}$ & $\begin{array}{l}7.2[0.33] \\
7.5[0.34] \\
7.9[0.33]\end{array}$ & 1.000 & none \\
\hline
\end{tabular}


Table 2-6 (continued)

Summary of Woodward-Clyde Team Sources Near the HFIR Site

\begin{tabular}{|c|c|c|c|c|c|}
\hline Source & Description & $\begin{array}{l}\text { Seis. Opts. } \\
\text { and Probs. }\end{array}$ & $\begin{array}{l}\text { Max. Mags. } \\
\text { and Probs. }\end{array}$ & $P^{*}$ & $\begin{array}{c}\text { Inter- } \\
\text { dependencies }\end{array}$ \\
\hline B29 & $\begin{array}{l}\text { Watts Bar } \\
\text { Background }\end{array}$ & $\begin{array}{l}1[0.25] \\
6[0.25] \\
7[0.25] \\
8[0.25]\end{array}$ & $\begin{array}{l}4.9[0.17] \\
5.4[0.28] \\
5.8[0.27] \\
6.5[0.28]\end{array}$ & 1.000 & $\begin{array}{l}\text { Background } \\
P_{B G}^{a}=1.00\end{array}$ \\
\hline
\end{tabular}

1 Seismicity options are defined as follows:

$1=$ low smoothing on $a$, high smoothing on $b$ (no prior);

$2=$ high smoothing on $a$, high smoothing on $b$ (no prior);

$3=$ high smoothing on $a$, high smoothing on $b$ (medium prior of 1.00 );

4 = high smoothing on $a$, high smoothing on $b$ (medium prior of 0.90 );

$5=$ high smoothing on $a$, high smoothing on $b$ (medium prior of 0.80 );

$6=$ low smoothing on $a$, high smoothing on $b$ (medium prior of 1.00 );

$7=$ low smoothing on $a$, high smoothing on $b$ (medium prior of 0.90 );

$8=$ low smoothing on $a$, high smoothing on $b$ (medium prior of 0.80 );

Weights on magnitude intervals are all 1.0. 


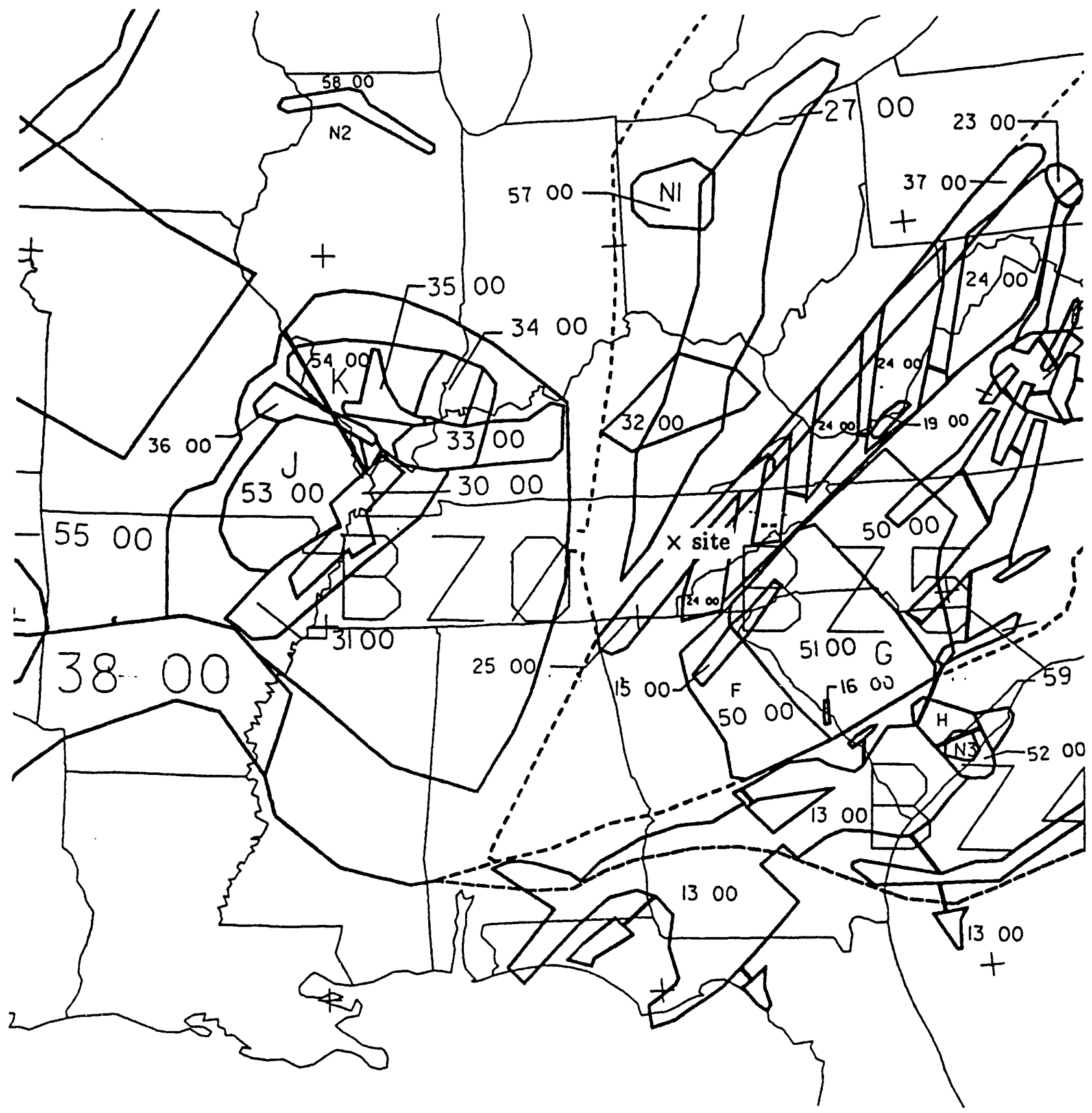

Figure 2-4. Map showing the seismic sources specified by the Bechtel team in the region around Oak Ridge. 


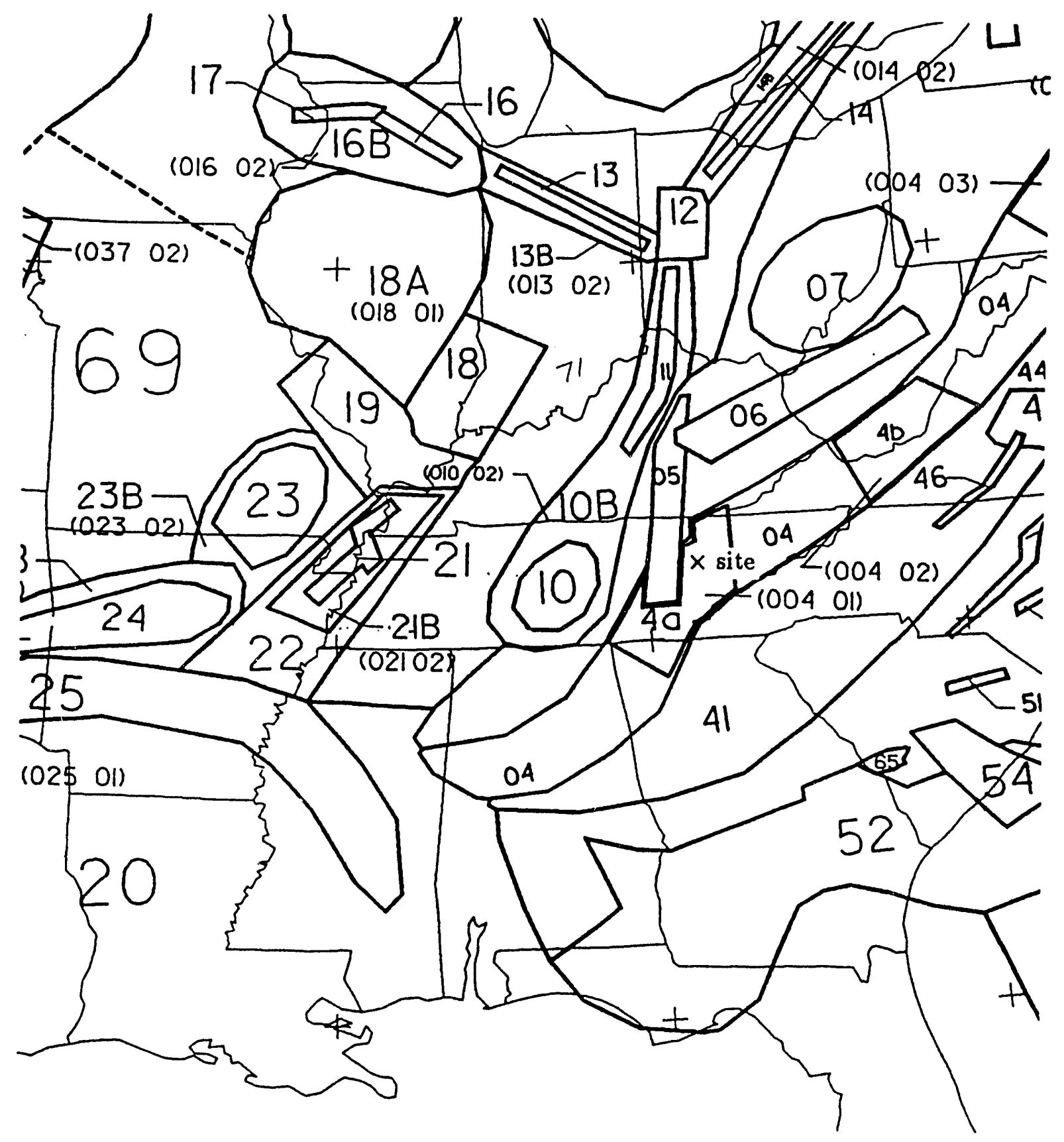

Figure 2-5. Map showing the seismic sources specified by the Dames and Moore team in the region around the HFIR Site. 


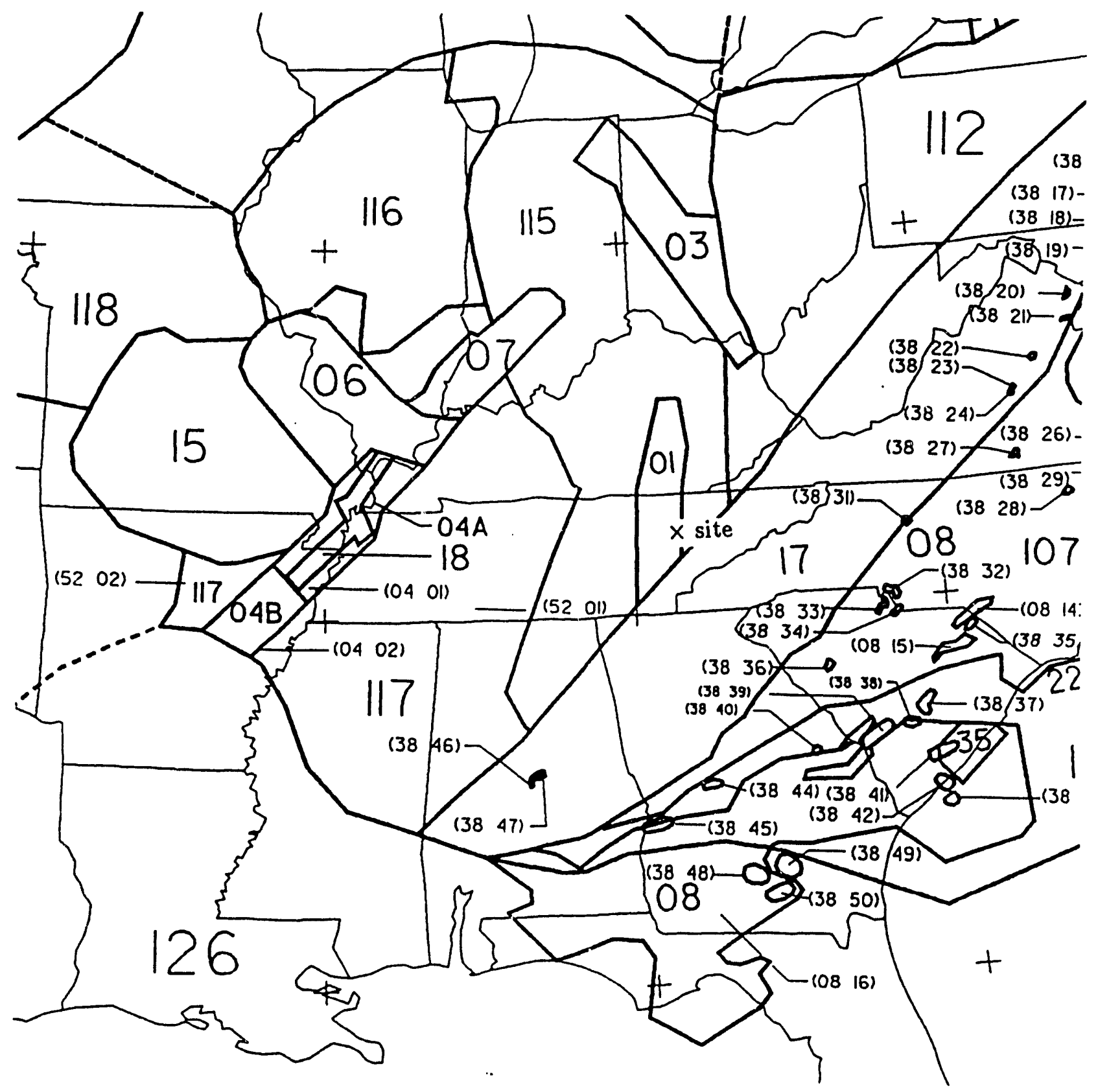

Figure 2-6. Map showing the seismic sources specified by the Law team in the region around the HFIR Site. 


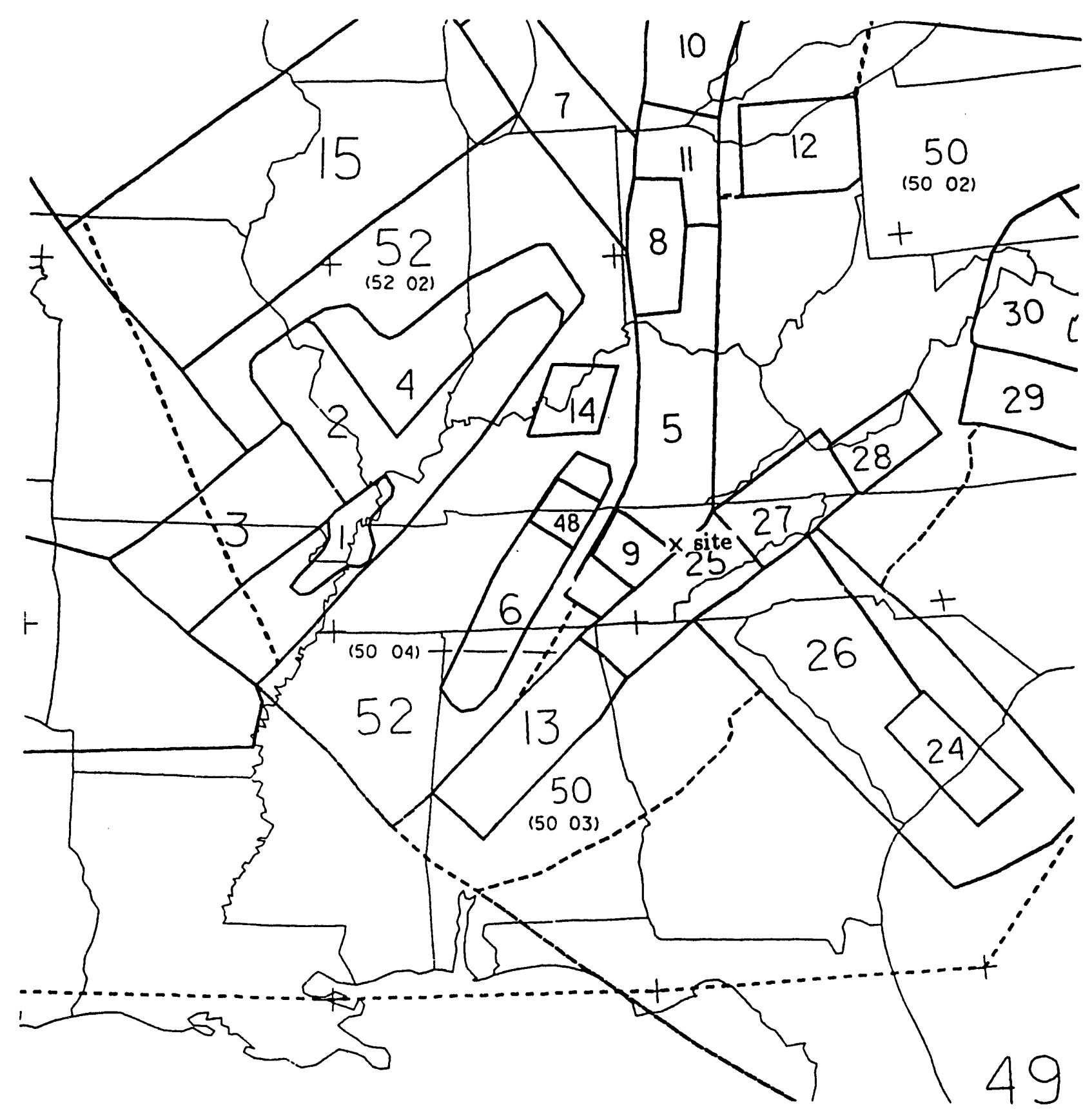

Figure 2-7. Map showing the seismic sources specified by the Rondout team in the region around the HFIR Site. 


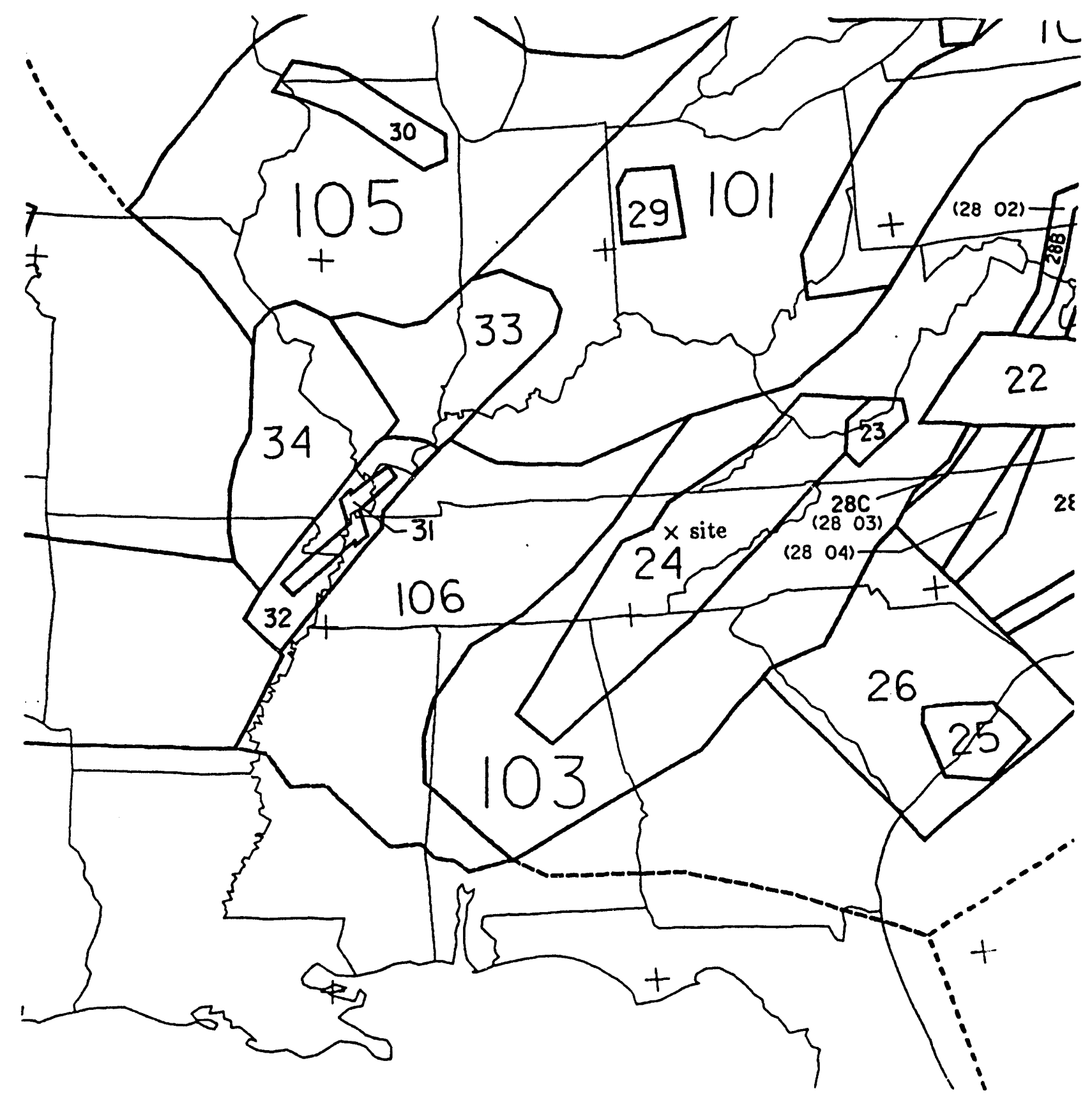

Figure 2-8. Map showing the seismic sources specified by the Weston team in the region around the HFIR Site. 


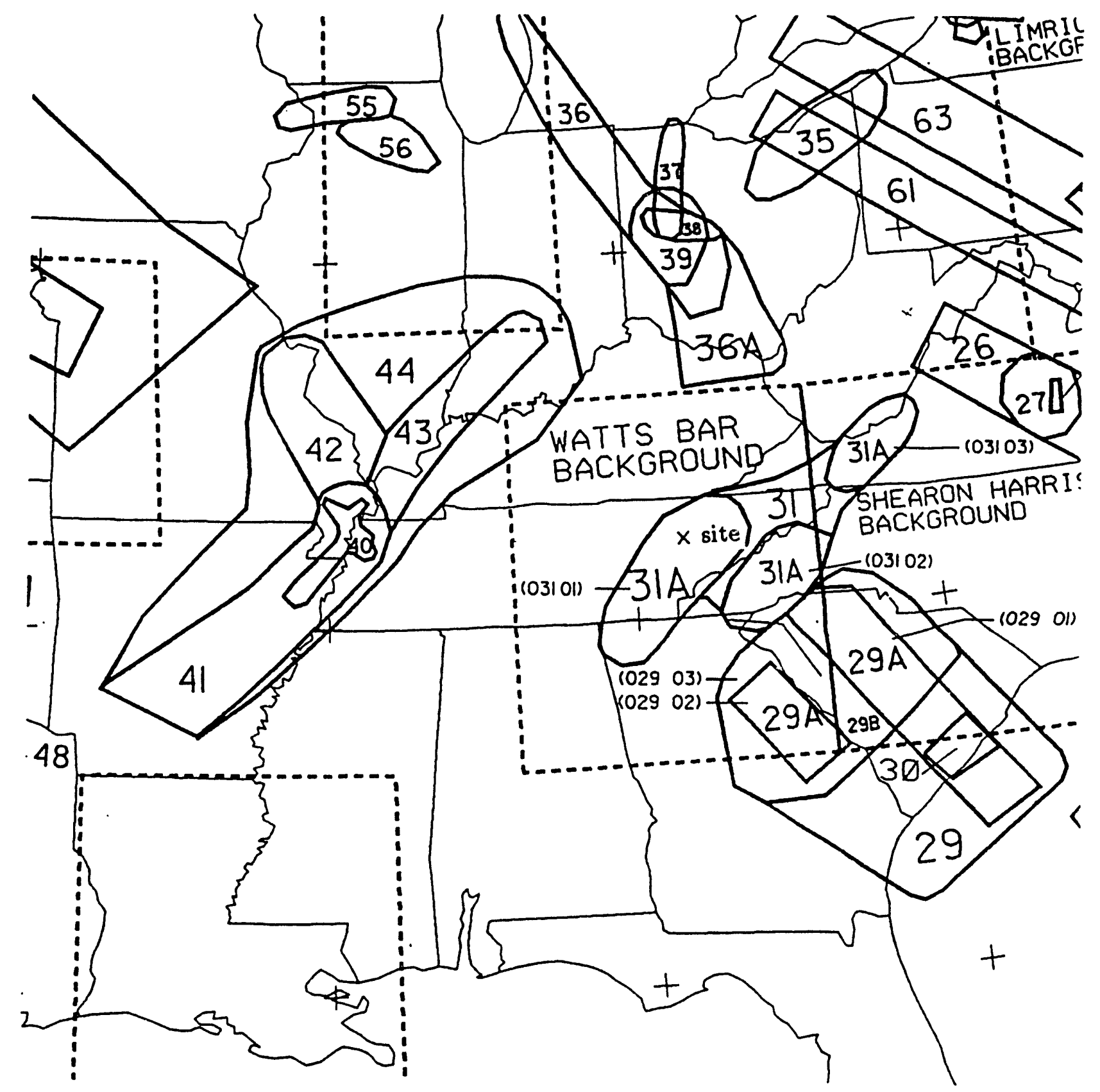

Figure 2-9. Map showing the seismic sources specified by the Woodward-Clyde team in the region around the HFIR Site. 


\subsection{GROUND-MOTION ATTENUATION}

This section presents the ground-motion attenuation functions useci in the EPRI/SOG calculations. The attenuation functions predict six measures of rock-site ground motions: peak acceleration and spectral velocities at five frequencies. Three sets of attenuation functions, with associated weights, characterize uncertainty in ground-motion predictions. The NRC has stated that these attenuation functions are acceptable for computations of seismic hazard $(\underline{13})$.

The attenuation functions used in the EPRI/SOG seismic-hazard calculations are based on simplified physical models of energy release at the seismic source and of wave propagation. The model of energy release describes the Fourier spectrum and duration of shaking at a hypothetical site close to the earthquake, and how these vary with seismic moment (seismic moment is a measure of earthquake size). The model of wave propagation describes how the spectrum and duration of shaking vary as the waves travel through the crust. This model contains the effects of geometric spreading (including $L g$ waves at longer distances), anelastic attenuation, and dispersion. The combined predictions of these models are consistent with seismograph and accelerograph data from the region.

Uncertainty on attenuation functions arises from uncertainty on the parameters of these models and on the derivation of peak time-domain amplitudes from Fourier spectra. The most important of these are uncertainty on source scaling, on the magnitude-moment relation, and on the spectra to time-domain derivation. These uncertainties are captured by considering three alternative formulations of these models, as follows:

1. The attenuation functions obtained by McGuire et al. ( $(7)$ using an $\boldsymbol{\omega}$-square model with stress drop of 100 bars. This set of attenuation functions is assigned a weight of 0.5 .

2. The attenuation functions obtained by Boore and Atkinson (14) using an w-square model. This set of attenuation functions is assigned a weight of 0.25 .

3. The attenuation function obtained from the velocity and acceleration attenuation equations obtained by Nuttli (토) using the "increasing stress-drop" assumption coupled with the dynamic amplification factors by Newmark and Hall (16). The attenuation functions in (15) were derived using a procedure analogous to that of Herrmann and Nuttli (17). This set of attenuation functions is given a weight of 0.25 .

Table 2-7 contains the coefficients of these models. Figure 2-10 shows their predictions for magnitudes 5 and 6 . 
Table 2-7

ATTENUATION EQUATIONS USED IN SOG CALCULATIONS

$$
\left(\ln [Y]=a+b m_{b}+c \ln [R]+d R\right)
$$

\begin{tabular}{|c|c|c|c|c|c|c|}
\hline MODEL & WEIGHT & $Y \dagger$ & $a$ & $b$ & $c$ & $d$ \\
\hline \multirow{6}{*}{$\begin{array}{l}\text { McGuire } \\
\text { et al. ( }(7)\end{array}$} & 0.5 & $\operatorname{PSV}(1 \mathrm{~Hz})$ & -7.95 & 2.14 & -1.00 & -0.0018 \\
\hline & & $\operatorname{PSV}(2.5 \mathrm{~Hz})$ & -3.82 & 1.49 & -1.00 & -0.0024 \\
\hline & & $\operatorname{PSV}(5 \mathrm{~Hz})$ & -2.11 & 1.20 & -1.00 & -0.0031 \\
\hline & & $\operatorname{PSV}(10 \mathrm{~Hz})$ & -1.55 & 1.05 & -1.00 & -0.0039 \\
\hline & & $\operatorname{PSV}(25 \mathrm{~Hz})$ & -1.63 & 0.98 & -1.00 & -0.0053 \\
\hline & & Accel. & 2.55 & 1.00 & -1.00 & -0.0046 \\
\hline
\end{tabular}

Boore and

Atkinson (14)

Nuttli $(\underline{15})$,

Newmark-Hall

Amplification

Factors
0.25 All Frequencies More complicated functional and Acceleration form; see Equations 12 and 13 and Table 3 of (14).

0.25

$$
\begin{array}{rcccc}
\operatorname{PSV}(1 \mathrm{~Hz}) \ddagger & 0.29 & 1.15 & -0.83 & -0.0028 \\
\operatorname{PSV}(2.5 \mathrm{~Hz}) \ddagger & -0.62 & 1.15 & -0.83 & -0.0028 \\
\operatorname{PSV}(5 \mathrm{~Hz}) \ddagger & -1.32 & 1.15 & -0.83 & -0.0028 \\
\operatorname{PSV}(10 \mathrm{~Hz}) \ddagger & -2.13 & 1.15 & -0.83 & -0.0028 \\
\operatorname{PSV}(25 \mathrm{~Hz}) \ddagger & -3.53 & 1.15 & -0.83 & -0.0028 \\
\text { Accel. } & 1.38 & 1.15 & -0.83 & -0.0028
\end{array}
$$

$\dagger \quad$ Spectral velocities have units of $\mathrm{cm} / \mathrm{sec}$; acceleration has units of $\mathrm{cm} / \mathrm{sec}^{2} ; R$ has units of $\mathrm{km}$. Variability of $\ln [Y]$ around the predicted value is characterized by a normal distribution with $\sigma=0.5$.

$\ddagger \quad$ For given $m_{b}$ and $R, \ln [Y]$ is the smaller of $a+b m_{b}+c \ln [R]+d R$ and $-8.3+2.3 m_{b}-0.83 \ln [R]-0.0012 R$. 
$1 \mathrm{~Hz} \quad \mathrm{~m}_{\mathrm{b}} 5$
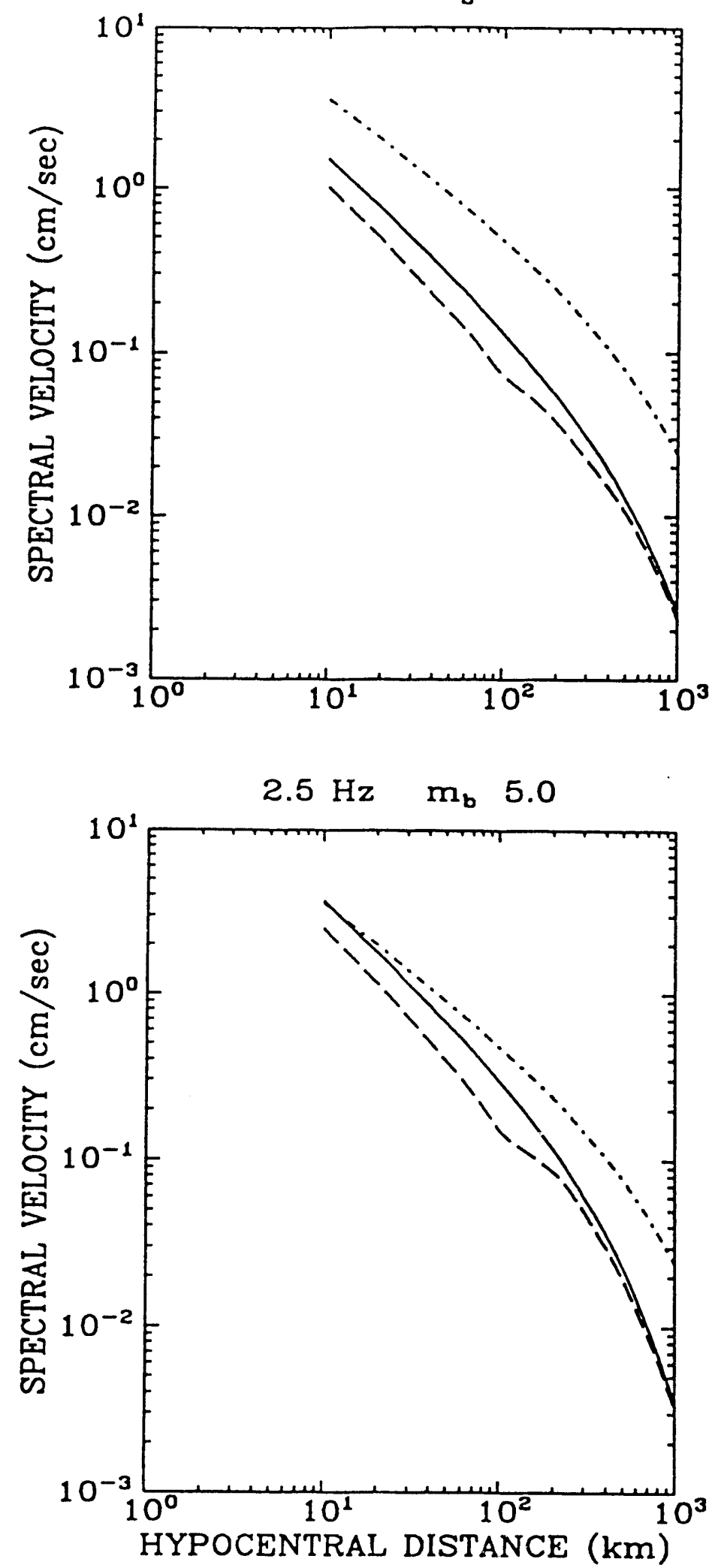
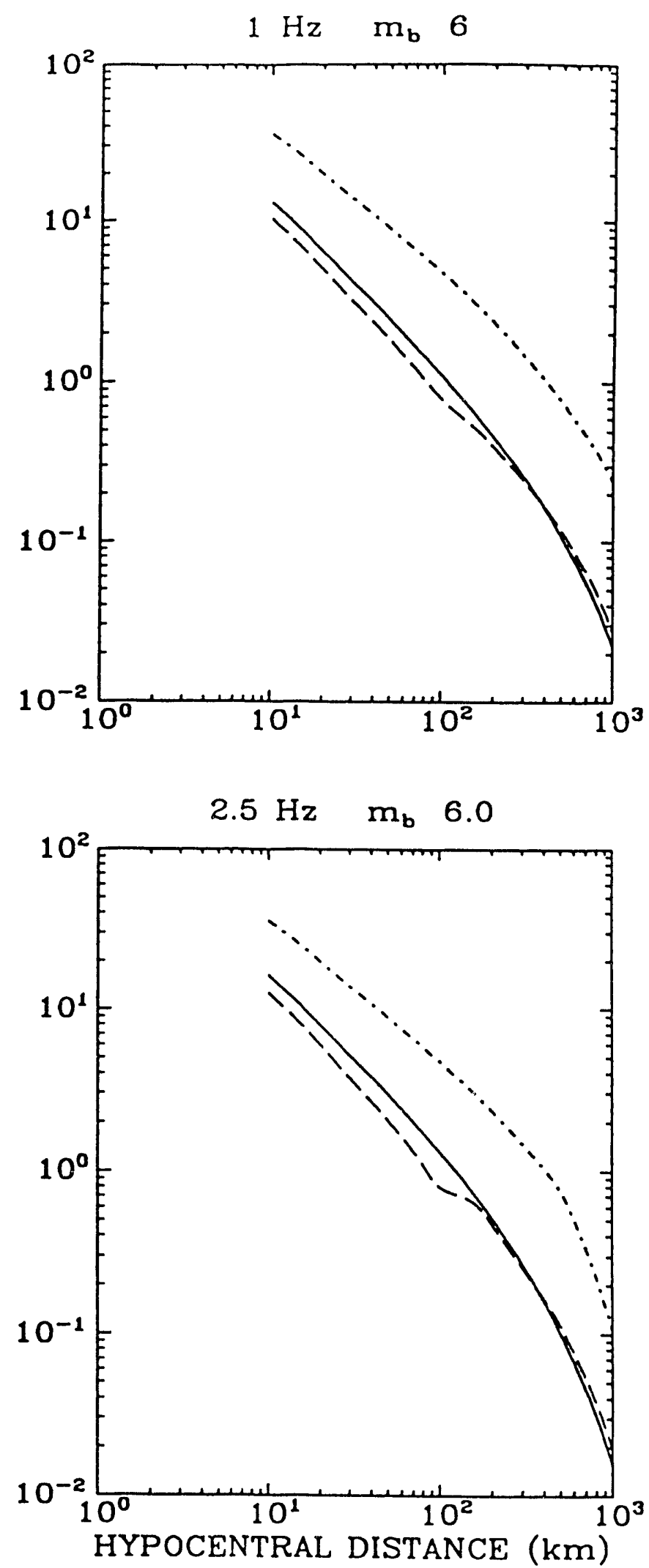

Figure 2-10. Ground motions predicted by the SOG attenuation equations for $m_{b} 5$ and 6 . Key:

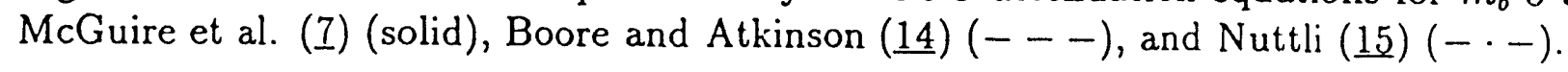


$5 \mathrm{~Hz} \quad \mathrm{~m}_{\mathrm{b}} 5$
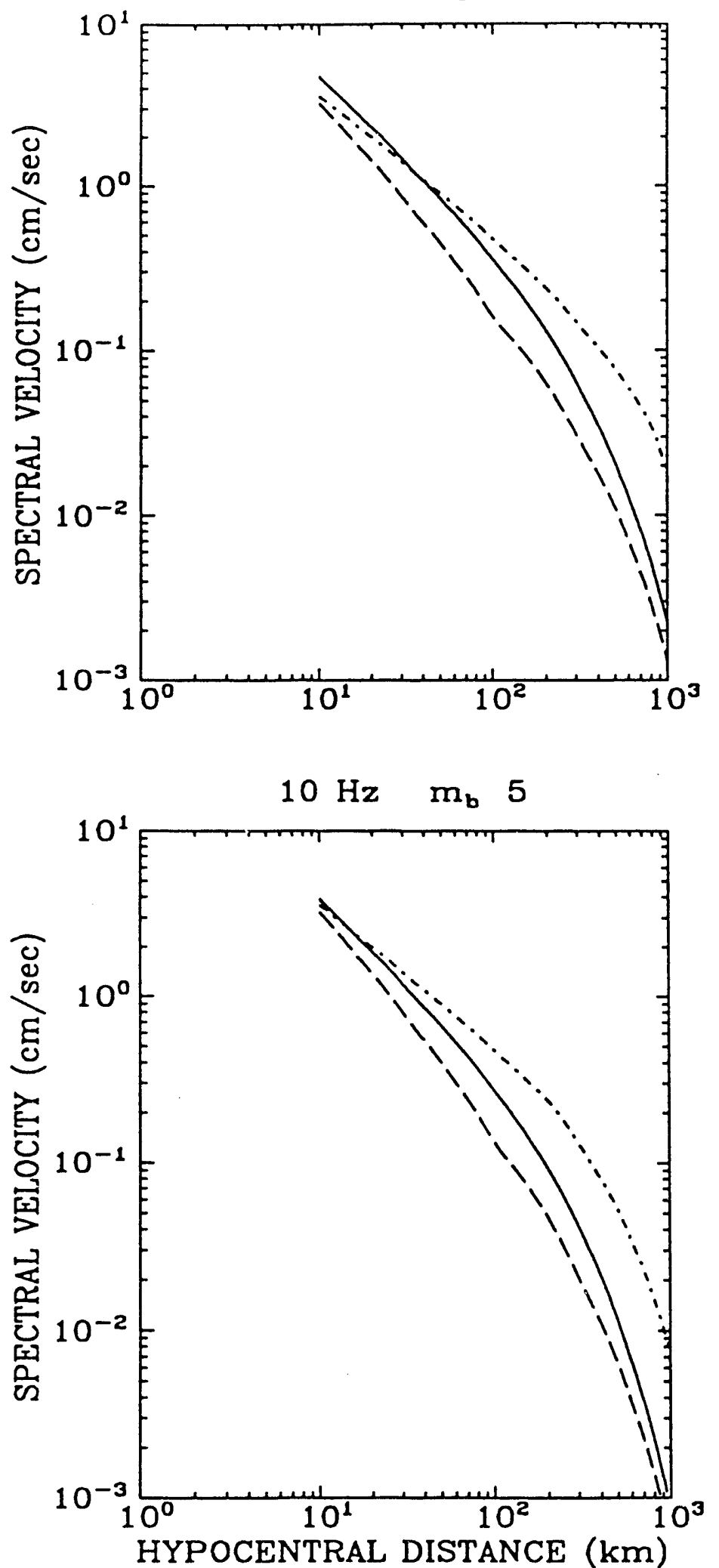

$5 \mathrm{~Hz} \quad \mathrm{~m}_{\mathrm{b}} 6$
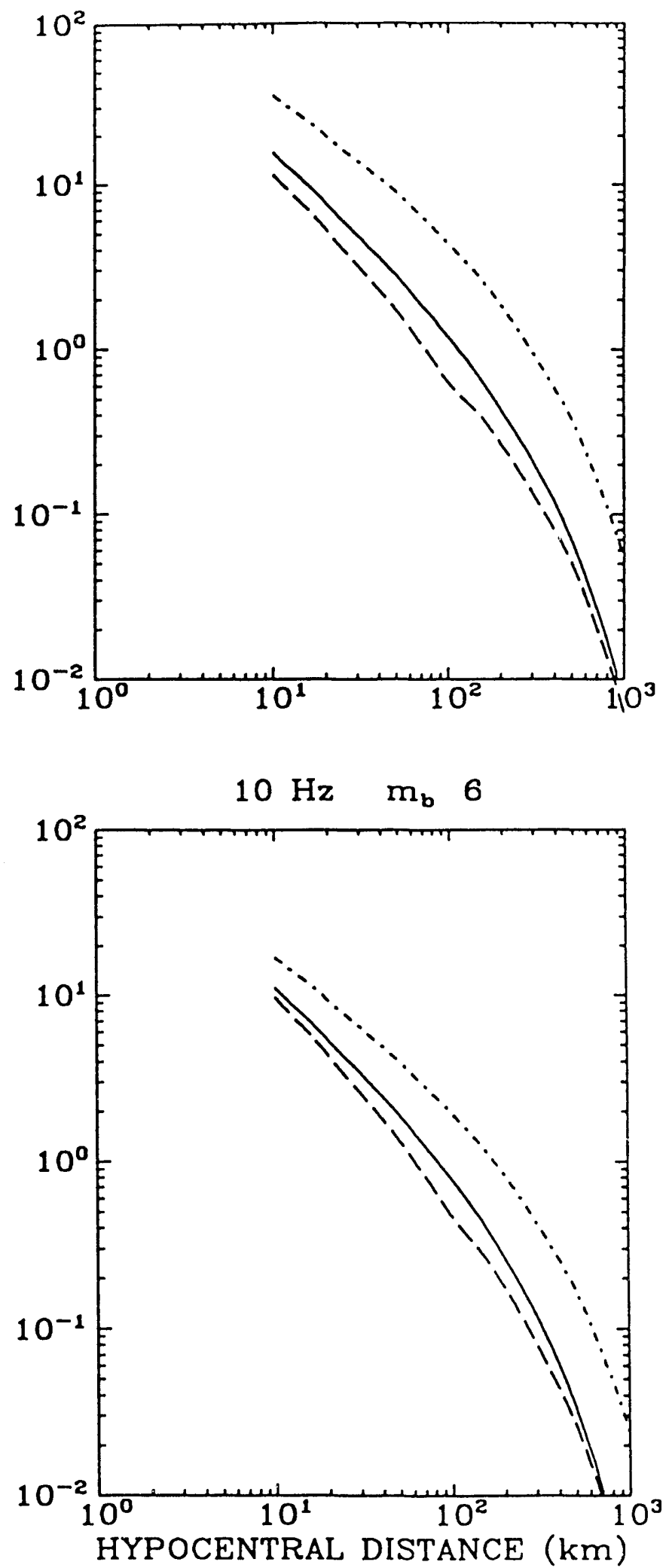

Figure 2-10 (continued). Ground motions predicted by the SOG attenuation equations for $m_{b} 5$

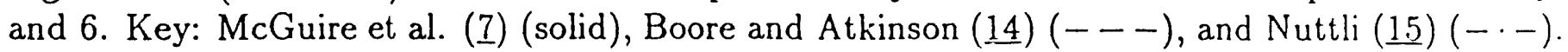



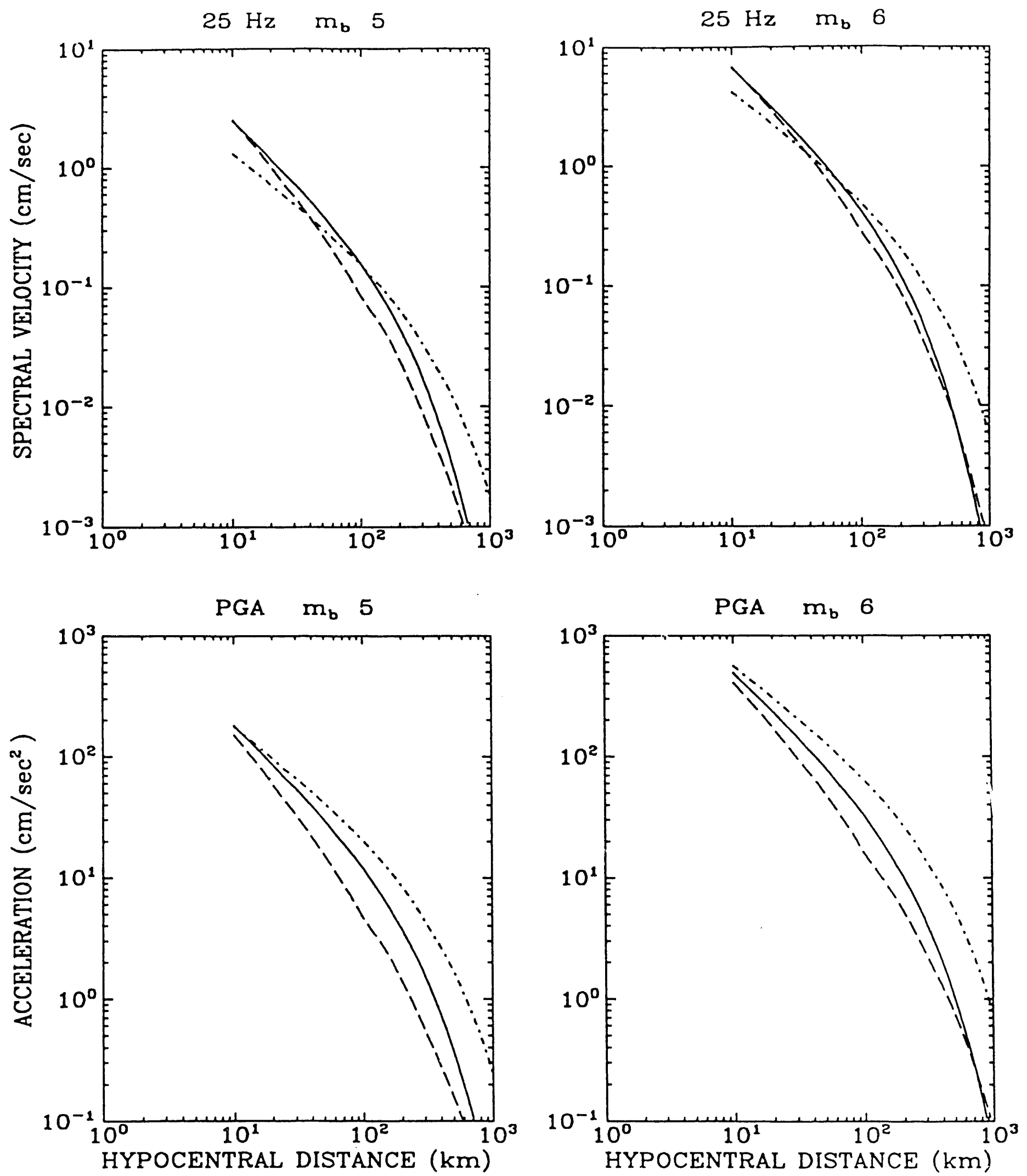

Figure 2-10 (continued). Ground motions predicted by the SOG attenuation equations for $m_{b} 5$

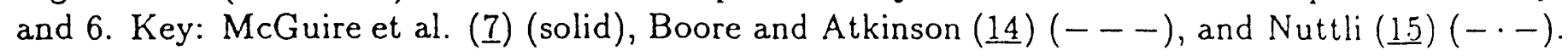




\subsection{CALCULATIONS}

\subsubsection{Overview}

The seismic-hazard calculations for the HFIR site used the EPRI/SOG methodology and inputs, and followed the same steps as the SOG calculations documented in $(\underline{6})$. These steps are as follows:

1. Identify all sources within $200 \mathrm{~km}$ of the site and include them in the screening calculations (step 2). Include also the New Madrid and Charleston sources if they are within $500 \mathrm{~km}$ of the site.

2. Use EQHAZ to perform screening calculations for each team considering one PGA amplitude $(0.25 \mathrm{~g})$ and one $1-\mathrm{Hz}$ amplitude $(10 \mathrm{~cm} / \mathrm{sec})$ and using the Nuttli attenuation functions (see Section 4.2). Evaluate the mean hazard from each source, and its percent contribution to the total hazard considering the source's $P^{a}$. Eliminate those sources that make negligible contributions to the hazard for both ground-motion measures, so that the combined hazards from all excluded sources is less than $1 \%$ of the total hazard.

3. Perform EQHAZ calculations for all amplitudes and 6 measures of ground motion (i.e., peak acceleration and $5 \%$ damped spectral velocity at $1,2.5,5,10$, and $25 \mathrm{~Hz}$ ) using all attenuation functions. These calculations are performed separately for each team.

4. Develop source combinations for each team, considering all sources included in step 2 , their activity probabilities and dependencies. These source combinations are sometimes simplified as described in Volume 3 of (ㅁ), while maintaining the conservative criteria of step 2.

5. Simplify the logic trees for some sites and teams, by considering only 1 seismicity option for each source. (The hazard associated with that one seismicity option is the weighted average of hazards from the original seismicity options.) This simplification was performed for the Bechtel team only, because the number of sources selected in step 2 was too large and EQPOST runs with the full logic trees would require excessive computer time. Test runs indicate that the effect of this simplification is insignificant.

6. Perform EQPOST calculations using the source-hazard results from step 3 and the source combinations from step 4 . These calculations are performed separately for each ground-motion measure. For soil sites, introduce site-amplification factors and their uncertainty. 
This study used the source geometries and seismicity parameters that were generated during the EPRI/SOG project. These data were used to develop the geometry and seismicity input files for the EQHAZ calculations in steps 2 and 3.

\subsubsection{Screening of Seismic Sources}

The screening of seismic sources is performed in order to reduce the number of sources considered in the analysis, thereby simplifying the development of source combinations and reducing the computer time required for the final calculations. The screening is performed using the Nuttli attenuation functions - which have the strongest magnitude dependence and the slowest decay with distance - thus avoiding the possibility of erroneously excluding a distant source that makes a significant contribution to seismic hazard at the site.

The screening is based on the contribution of each source to the mean value of total hazard. Tables 2-8 through 2-13 show the results of the screening calculations. Results for each team contain one table for peak ground acceleration and one table for $1-\mathrm{Hz}$ spectral velocity. Each table shows the contribution to the total hazard from each source within $200 \mathrm{~km}$ of the site. A source's contribution to the total hazard depends on the mean hazard when the source is active (column 2 ) and on the activity probability $P^{a}$ or $P^{*}$ of the source (column 3 ). Donut sources do not have activity probabilities and cannot be included in the computation of total hazard. The decision to include or exclude these sources must be made by considering which sources form the donut and considering the hazard in column 2. Table 2-14 lists the sources selected for final calculations.

\subsubsection{Development of Source Combinations}

The source combinations represent all possible states of activity of the seismic sources that contribute to hazard at the site (i.e., all the sources selected in the screening process above). The source combinations are developed considering the following three types of information: (1) the activity probabilities $P^{a}$ or $P^{*}$ of the vario's sources, (2) the interdependencies of source activities, and (3) the geographic relationships among sources.

The most common geographic relationship occurs with background sources. If the site is within a background source and within a standard source, the background is included only in source combinations where the standard source is not active. In some instances, "donut" sources of the type BACKGROUND - STANDARD SOURCE have also been digitized and analyzed. In those instances, the appropriate donut should be included in each source combination, depending on which standard sources are active.

Table 2-15 shows the source combinations and their probabilities, for the six Earth Science Teams. 
Table 2-8

Screening of Seismic Sources: Bechtel Team

SCREENING OF SEISMIC SOURCES

site: HFIR team: BEC peak accel.

\begin{tabular}{|c|c|c|c|c|c|c|}
\hline Source & Hazard & $\mathrm{P} \star$ & $\operatorname{Haz} . \mathrm{P}^{\star}$ & 1 & Acum. \& & Include \\
\hline B25 & $7.53 \mathrm{E}-05$ & 1.000 & $7.53 E-05$ & 50.7 & 50.7 & $Y$ \\
\hline BZ 6 & $2.70 \mathrm{E}-05$ & 1.000 & $2.70 \mathrm{E}-05$ & 18.2 & 69.0 & $Y$ \\
\hline $25 \mathrm{~A}$ & $5.17 E-05$ & 0.450 & $2.33 E-05$ & 15.7 & 84.6 & $\mathbf{Y}$ \\
\hline 25 & $6.50 E-05$ & 0.300 & $1.95 E-05$ & 13.1 & 97.8 & $Y$ \\
\hline 24 & $1.28 E-05$ & 0.250 & $3.20 \mathrm{E}-06$ & 2.2 & 99.9 & $Y$ \\
\hline 27 & $2.64 \mathrm{E}-07$ & 0.200 & $5.28 E-08$ & 0.0 & 100.0 & $\mathrm{~N}$ \\
\hline $\mathbf{F}$ & $7.32 E-08$ & 0.350 & $2.56 E-08$ & 0.0 & 100.0 & $\mathrm{~N}$ \\
\hline G & $5.77 E-08$ & 0.350 & $2.02 E-08$ & 0.0 & 100.0 & $\mathbf{N}$ \\
\hline B2O & $1.23 E-08$ & 1.000 & $1.23 \mathrm{E}-08$ & 0.0 & 100.0 & $\mathrm{~N}$ \\
\hline 32 & $2.19 E-08$ & 0.350 & $7.67 E-09$ & 0.0 & 100.0 & $\mathrm{~N}$ \\
\hline B23 & $4.75 E-09$ & 1.000 & $4.75 E-09$ & 0.0 & 100.0 & $\mathrm{~N}$ \\
\hline 30 & $2.40 \mathrm{E}-09$ & 2.000 & $2.40 E-09$ & 0.0 & 100.0 & $\mathrm{~N}$ \\
\hline N3 & $1.00 \mathrm{E}-10$ & 0.530 & $5.31 E-11$ & 0.0 & 100.0 & N \\
\hline H & $1.00 \mathrm{E}-10$ & 0.500 & $5.01 E-11$ & 0.0 & 100.0 & $\mathrm{~N}$ \\
\hline 15 & $1.00 E-10$ & 0.050 & $5.01 E-12$ & 0.0 & 100.0 & $\mathbf{N}$ \\
\hline donut & \multicolumn{6}{|c|}{ sources, etc. } \\
\hline $\operatorname{cog}$ & \multicolumn{6}{|c|}{$2.86 E-07$} \\
\hline $\mathrm{cos}$ & \multicolumn{6}{|l|}{$1.21 E-06$} \\
\hline C1O & \multicolumn{6}{|l|}{$1.27 \mathrm{E}-06$} \\
\hline
\end{tabular}

SCREENING OF SEISMIC SOURCES site: HFIR team: BEC 1-Hz psv

\begin{tabular}{|c|c|c|c|c|c|c|}
\hline Source & Hazard & $\mathrm{P} \star$ & $\operatorname{Haz} \cdot \mathrm{P}^{\star}$ & + & Acum. & Include \\
\hline B25 & $1.91 E-04$ & 1.000 & $1.91 E-04$ & 42.8 & 42.8 & $Y$ \\
\hline 30 & $1.31 E-04$ & 1.000 & $1.31 E-04$ & 29.2 & 72.0 & $\mathbf{Y}$ \\
\hline B26 6 & $3.32 E-05$ & 1.000 & $3.32 E-05$ & 7.4 & 79.4 & $Y$ \\
\hline $25 A$ & $6.14 E-05$ & 0.450 & $2.76 E-05$ & 6.2 & 85.6 & $Y$ \\
\hline 25 & $7.71 E-05$ & 0.300 & $2.31 E-05$ & 5.2 & 90.8 & $Y$ \\
\hline 24 & $6.33 E-05$ & 0.250 & $1.58 \mathrm{E}-05$ & 3.5 & 94.3 & $\mathbf{Y}$ \\
\hline $\mathrm{BZO}$ & $8.99 E-06$ & 1.000 & $8.99 E-06$ & 2.0 & 96.3 & $\mathbf{Y}$ \\
\hline $\mathbf{F}$ & $1.25 E-05$ & 0.350 & $4.37 E-06$ & 1.0 & 97.3 & $\mathbf{Y}$ \\
\hline G & $8.34 E-06$ & 0.350 & $2.92 E-06$ & 0.7 & 98.0 & $\mathbf{Y}$ \\
\hline $\mathrm{H}$ & $5.55 E-06$ & 0.500 & $2.78 E-06$ & 0.6 & 98.6 & $\mathbf{Y}$ \\
\hline N3 & $4.91 E-06$ & 0.530 & $2.60 E-06$ & 0.6 & 99.2 & $Y$ \\
\hline 32 & $7.43 E-06$ & 0.350 & $2.60 E-06$ & 0.6 & 99.8 & $\mathrm{~N}$ \\
\hline BZ3 & $9.29 E-07$ & 1.000 & $9.29 \mathrm{E}-07$ & 0.2 & 100.0 & $\mathrm{~N}$ \\
\hline 27 & $8.02 E-07$ & 0.200 & $1.60 \mathrm{E}-07$ & 0.0 & 100.0 & $\mathrm{~N}$ \\
\hline 15 & $1.00 \mathrm{E}-10$ & 0.050 & $5.01 \mathrm{E}-12$ & 0.0 & 100.0 & N \\
\hline donut & \multicolumn{6}{|c|}{ sources, etc. } \\
\hline $\cos$ & \multicolumn{6}{|c|}{$8.99 E-07$} \\
\hline Co6 & \multicolumn{6}{|l|}{$4.07 E-06$} \\
\hline C10 & \multicolumn{6}{|l|}{$4.49 E-06$} \\
\hline
\end{tabular}


Table 2-9

Screening of Seismic Sources: Dames and Moore Team

SCREENING OF SEISMIC SOURCES

site: HFIR team: DAM peak accel.

$\begin{array}{lcccccc}\text { Source } & \text { Hazard } & \text { P* } & \text { Haz.P* } & \text { Acum. } & \text { Include } \\ 4 \mathrm{~A} & 3.31 \mathrm{E}-04 & 0.650 & 2.15 \mathrm{E}-04 & 80.6 & 80.6 & \mathrm{Y} \\ 04 & 1.44 \mathrm{E}-04 & 0.350 & 5.02 \mathrm{E}-05 & 18.8 & 99.4 & \mathrm{Y} \\ 05 & 4.07 \mathrm{E}-06 & 0.300 & 1.22 \mathrm{E}-06 & 0.5 & 99.8 & \mathrm{~N} \\ 08 & 3.01 \mathrm{E}-06 & 0.080 & 2.40 \mathrm{E}-07 & 0.1 & 99.9 & \mathrm{~N} \\ 41 & 1.83 \mathrm{E}-06 & 0.120 & 2.20 \mathrm{E}-07 & 0.1 & 100.0 & \mathrm{~N} \\ 10 \mathrm{~B} & 4.72 \mathrm{E}-08 & 0.390 & 1.84 \mathrm{E}-08 & 0.0 & 100.0 & \mathrm{~N} \\ 10 & 1.99 \mathrm{E}-08 & 0.300 & 5.96 \mathrm{E}-09 & 0.0 & 100.0 & \mathrm{~N} \\ 21 & 1.10 \mathrm{E}-09 & 1.000 & 1.10 \mathrm{E}-09 & 0.0 & 100.0 & \mathrm{~N} \\ 06 & 3.19 \mathrm{E}-09 & 0.240 & 7.67 \mathrm{E}-10 & 0.0 & 100.0 & \mathrm{~N} \\ 11 & 1.74 \mathrm{E}-09 & 0.310 & 5.40 \mathrm{E}-10 & 0.0 & 100.0 & \mathrm{~N} \\ 54 & 1.00 \mathrm{E}-10 & 1.000 & 1.00 \mathrm{E}-10 & 0.0 & 100.0 & \mathrm{~N} \\ \text { donut sources, etc. } & & & & & \\ \text { C15 } & 1.36 \mathrm{E}-10 & & & & & \\ \text { C03 } & 2.03 \mathrm{E}-08 & & & & & \\ \text { C02 } & 3.00 \mathrm{E}-06 & & & & & \\ \text { C01 } & 3.67 E-06 & & & & & \end{array}$

SCREENING OF SEISMIC SOURCES

site: HFIR team: DAM 1-Hz psv

$\begin{array}{lcccrcc}\text { Source } & \text { Hazard } & \mathrm{P}^{*} & \text { Haz.P* } & \text { Acum. } & \text { Include } \\ 4 \mathrm{~A} & 5.77 \mathrm{E}-04 & 0.650 & 3.75 \mathrm{E}-04 & 67.4 & 67.4 & \mathrm{Y} \\ 04 & 2.38 \mathrm{E}-04 & 0.350 & 8.34 \mathrm{E}-05 & 15.0 & 82.4 & \mathrm{Y} \\ 21 & 8.24 \mathrm{E}-05 & 1.000 & 8.24 \mathrm{E}-05 & 14.8 & 97.3 & \mathrm{Y} \\ 41 & 6.40 \mathrm{E}-05 & 0.120 & 7.68 \mathrm{E}-06 & 1.4 & 98.6 & \mathrm{Y} \\ 05 & 8.56 \mathrm{E}-06 & 0.300 & 2.57 \mathrm{E}-06 & 0.5 & 99.1 & \mathrm{Y} \\ 54 & 2.50 \mathrm{E}-06 & 1.000 & 2.50 \mathrm{E}-06 & 0.4 & 99.6 & \mathrm{~N} \\ 08 & 1.28 \mathrm{E}-05 & 0.080 & 1.02 \mathrm{E}-06 & 0.2 & 99.7 & \mathrm{~N} \\ 10 \mathrm{~B} & 2.20 \mathrm{E}-06 & 0.390 & 8.57 \mathrm{E}-07 & 0.2 & 99.9 & \mathrm{~N} \\ 10 & 1.11 \mathrm{E}-06 & 0.300 & 3.32 \mathrm{E}-07 & 0.1 & 99.9 & \mathrm{~N} \\ 11 & 5.39 \mathrm{E}-07 & 0.310 & 1.67 \mathrm{E}-07 & 0.0 & 100.0 & \mathrm{~N} \\ 06 & 5.04 \mathrm{E}-07 & 0.240 & 1.21 \mathrm{E}-07 & 0.0 & 100.0 & \mathrm{~N} \\ \text { donut sources, etc. } & & & & & \\ \text { C03 } & 7.86 \mathrm{E}-07 & & & & & \\ \text { C15 } & 1.08 \mathrm{E}-05 & & & & & \\ \text { C02 } & 1.27 \mathrm{E}-05 & & & & & \\ \text { C01 } & 2.77 \mathrm{E}-05 & & & & & \end{array}$


Table 2-10

Screening of Seismic Sources: Law Engineering Team

SCREENING OF SEISMIC SOURCES

site: HFIR team: LAW peak accel.

\begin{tabular}{|c|c|c|c|c|c|c|}
\hline Source & Hazard & $P *$ & $\operatorname{Haz} . P \star$ & t & Acum. & Include \\
\hline 17 & 3. $92 E-05$ & 0.620 & $2.43 E-05$ & 59.1 & 59.1 & $\mathbf{Y}$ \\
\hline 115 & $1.37 \mathrm{E}-05$ & 1.000 & $1.37 E-05$ & 33.2 & 92.4 & $Y$ \\
\hline 01 & $7.89 E-06$ & 0.320 & $2.52 E-06$ & 6.1 & 98.5 & $Y$ \\
\hline 217 & $2.14 E-06$ & 0.290 & $6.22 E-07$ & 1.5 & 100.0 & $Y$ \\
\hline 18 & $1.22 E-09$ & 1.000 & $1.22 \mathrm{E}-09$ & 0.0 & 100.0 & $\mathbf{N}$ \\
\hline 117 & $1.00 E-10$ & 1.000 & $1.00 E-10$ & 0.0 & 100.0 & $\mathbf{N}$ \\
\hline $\mathrm{CO}$ & $1.00 \mathrm{E}-10$ & 1.000 & $1.00 \mathrm{E}-10$ & 0.0 & 100.0 & $\mathrm{~N}$ \\
\hline 112 & $1.00 \mathrm{E}-10$ & 0.850 & $8.52 E-11$ & 0.0 & 100.0 & N \\
\hline 35 & $1.00 \mathrm{E}-10$ & 0.450 & $4.51 E-11$ & 0.0 & 100.0 & $\mathbf{N}$ \\
\hline
\end{tabular}

SCREENING OF SEISMIC SOURCES

site: HFIR team: LAW 1-Hz psv

\begin{tabular}{|c|c|c|c|c|c|c|}
\hline Source & Hazard & $P^{\star}$ * & $\operatorname{Haz} \cdot \mathrm{P}^{\star}$ & 8 & Acum. 8 & Include \\
\hline 17 & $3.19 \mathrm{E}-04$ & 0.620 & $1.98 E-04$ & 58.4 & 58.4 & $Y$ \\
\hline 18 & $1.36 \mathrm{E}-04$ & 1.000 & $1.36 \mathrm{E}-04$ & 40.0 & 98.4 & $\mathbf{Y}$ \\
\hline 115 & $3.74 \mathrm{E}-06$ & 1.000 & $3.74 \mathrm{E}-06$ & 1.1 & 99.5 & $Y$ \\
\hline 01 & $1.87 E-06$ & 0.320 & $5.99 E-07$ & 0.2 & 99.7 & $N$ \\
\hline 217 & $1.87 E-06$ & 0.290 & $5.44 E-07$ & 0.2 & 99.9 & $\mathbf{N}$ \\
\hline 35 & $9.12 E-07$ & 0.450 & $4.10 E-07$ & 0.1 & 100.0 & $\mathrm{~N}$ \\
\hline 117 & 2. $40 E-10$ & 1.000 & $2.40 E-10$ & 0.0 & 100.0 & $\mathrm{~N}$ \\
\hline $\mathrm{CO} 7$ & $2.38 E-10$ & 1.000 & $2.38 \mathrm{E}-10$ & 0.0 & 100.0 & $\mathbf{N}$ \\
\hline 112 & $1.00 E-10$ & 0.850 & $8.52 E-11$ & 0.0 & 100.0 & $\mathbf{N}$ \\
\hline
\end{tabular}


Table 2-11

Screening of Seismic Sources: Rondout Associates Team

SCREENING OF SEISMIC SOURCES

site: HFIR team: RND peak accel.

$\begin{array}{lcccccc}\text { Source } & \text { Hazard } & \text { P* } & \text { Haz.P* } & \text { Acum. } & \text { Include } \\ 25 & 1.12 E-04 & 0.990 & 1.10 E-04 & 58.6 & 58.6 & \text { Y } \\ 9 & 7.05 E-05 & 0.990 & 6.98 E-05 & 37.0 & 95.6 & \text { Y } \\ 5 & 7.80 E-06 & 1.000 & 7.80 E-06 & 4.1 & 99.7 & \text { Y } \\ 26 & 2.97 E-07 & 1.000 & 2.97 E-07 & 0.2 & 99.9 & \mathrm{~N} \\ 27 & 2.73 E-07 & 0.990 & 2.71 E-07 & 0.1 & 100.0 & \mathrm{~N} \\ 48 & 7.12 E-09 & 0.870 & 6.19 E-09 & 0.0 & 100.0 & \mathrm{~N} \\ 6 & 1.03 E-09 & 0.830 & 8.57 E-10 & 0.0 & 100.0 & \mathrm{~N} \\ 1 & 6.82 E-10 & 1.000 & 6.82 E-10 & 0.0 & 100.0 & \mathrm{~N} \\ 13 & 5.98 E-10 & 1.000 & 5.98 E-10 & 0.0 & 100.0 & \mathrm{~N} \\ \text { C02 } & 2.25 E-10 & 1.000 & 2.25 E-10 & 0.0 & 100.0 & \mathrm{~N} \\ 52 & 2.19 E-10 & 1.000 & 2.19 E-10 & 0.0 & 100.0 & \mathrm{~N} \\ 24 & 1.00 E-10 & 1.000 & 1.00 E-10 & 0.0 & 100.0 & \mathrm{~N} \\ \text { donut SOUICes, etc. } & & & & & \\ \text { C07 } & 2.02 E-10 & & & & & \end{array}$

SCREENING OF SEISMIC SOURCES site: HEIR team: RND 1-Hz psv

\begin{tabular}{|c|c|c|c|c|c|c|}
\hline Source & Hazard & $P \star$ & $\operatorname{Haz} . P^{\star}$ & $t$ & Acum. & Include \\
\hline 25 & $2.74 E-04$ & 0.990 & $2.71 E-04$ & 43.5 & 43.5 & $Y$ \\
\hline 1 & $1.54 E-04$ & 1.000 & $1.54 E-04$ & 24.7 & 68.2 & $Y$ \\
\hline 9 & $1.37 E-04$ & 0.990 & 1. $35 E-04$ & 21.7 & 89.8 & $Y$ \\
\hline 26 & $2.60 E-05$ & 1.000 & $2.60 E-05$ & 4.2 & 94.0 & $Y$ \\
\hline 5 & $2.12 \mathrm{E}-05$ & 1.000 & $2.12 E-05$ & 3.4 & 97.4 & $\mathbf{Y}$ \\
\hline 27 & $1.23 E-05$ & 0.990 & $1.22 E-05$ & 2.0 & 99.4 & $\mathbf{Y}$ \\
\hline 24 & $2.23 E-06$ & 1.000 & $2.23 E-06$ & 0.4 & 99.7 & $\mathbf{N}$ \\
\hline 48 & $8.50 E-07$ & 0.870 & $7.39 E-07$ & 0.1 & 99.9 & $\mathbf{N}$ \\
\hline 13 & $7.21 E-07$ & 1.000 & $7.21 E-07$ & 0.1 & 100.0 & $\mathrm{~N}$ \\
\hline 6 & $2.28 E-07$ & 0.830 & $1.89 E-07$ & 0.0 & 100.0 & $\mathrm{~N}$ \\
\hline 52 & $1.60 E-09$ & 1.000 & $1.60 E-09$ & 0.0 & 100.0 & $\mathrm{~N}$ \\
\hline $\mathrm{CO} 2$ & $1.34 E-09$ & 1.000 & $1.34 E-09$ & 0.0 & 100.0 & $\mathrm{~N}$ \\
\hline $\begin{array}{l}\text { donut } \\
\mathrm{CO} 7\end{array}$ & $\begin{array}{l}\text { ources, et } \\
1.08 \mathrm{E}-09\end{array}$ & & & & & \\
\hline
\end{tabular}


Table 2-12

Screening of Seismic Sources: Weston Geophysical Team

SCREENING OF SEISMIC SOURCES

site: HFIR team: WGC peak accel.

$\begin{array}{lcccccc}\text { Source } & \text { Hazard } & \text { P* } & \text { Haz.P* } & \text { Acum. } & \text { Include } \\ 24 & 1.54 E-04 & 0.900 & 1.38 E-04 & 59.0 & 59.0 & \text { Y } \\ 103 & 9.63 E-05 & 1.000 & 9.63 E-05 & 41.0 & 100.0 & \text { Y } \\ 106 & 2.44 E-08 & 1.000 & 2.44 E-08 & 0.0 & 100.0 & \text { N } \\ 101 & 1.42 E-09 & 1.000 & 1.42 E-09 & 0.0 & 100.0 & \text { N } \\ 31 & 2.09 E-10 & 0.950 & 1.98 E-10 & 0.0 & 100.0 & \text { N } \\ \text { C11 } & 1.67 E-10 & 0.950 & 1.59 E-10 & 0.0 & 100.0 & \mathrm{~N} \\ 25 & 1.00 E-10 & 0.990 & 9.92 E-11 & 0.0 & 100.0 & \text { N } \\ 32 & 1.25 E-09 & 0.050 & 6.23 E-11 & 0.0 & 100.0 & \text { N } \\ \text { donut } & \text { sources, etc. } & & & & \\ \text { C16 } & 1.40 E-09 & & & & & \\ \text { C12 } & 1.52 E-09 & & & & & \\ \text { C15 } & 1.52 E-09 & & & & & \\ \text { C14 } & 1.72 E-09 & & & & & \\ \text { C13 } & 1.80 E-09 & & & & & \\ \text { C19 } & 1.53 E-06 & & & & & \\ \text { C18 } & 1.63 E-06 & & & & & \\ \text { C17 } & 6.44 E-05 & & & & & \end{array}$

SCREENING OF SEISMIC SOURCES

site: HFIR team: WGC $1-H z$ psv

\begin{tabular}{|c|c|c|c|c|c|c|}
\hline $\begin{array}{l}\text { Source } \\
24\end{array}$ & $\begin{array}{c}\text { Hazard } \\
2.41 E-04\end{array}$ & $\begin{array}{c}\mathrm{p} \star \\
0.900\end{array}$ & $\begin{array}{c}\text { Haz.P* } \\
2.17 E-04\end{array}$ & 44.9 & $\begin{array}{c}\text { Acum. } \\
44.9\end{array}$ & $\begin{array}{c}\text { Include } \\
Y\end{array}$ \\
\hline 103 & $1.69 \mathrm{E}-04$ & 1.000 & $1.69 \mathrm{E}-04$ & 34.9 & 79.9 & $Y$ \\
\hline 31 & $7.93 E-05$ & 0.950 & $7.53 E-05$ & 15.6 & 95.5 & $\mathbf{Y}$ \\
\hline 32 & $1.86 E-04$ & 0.050 & $9.31 \mathrm{E}-06$ & 1.9 & 97.4 & $Y$ \\
\hline C11 & $9.69 E-06$ & 0.950 & $9.21 E-06$ & 1.9 & 99.3 & $Y$ \\
\hline 25 & $1.17 E-06$ & 0.990 & $1.15 E-06$ & 0.2 & 99.5 & $\mathrm{~N}$ \\
\hline 106 & $1.15 E-06$ & 1.000 & $1.15 E-06$ & 0.2 & 99.8 & $\mathrm{~N}$ \\
\hline 101 & $1.11 E-06$ & 1.000 & $1.11 E-06$ & 0.2 & 100.0 & $\mathrm{~N}$ \\
\hline donut & sources, etc & & & & & \\
\hline C16 & $9.48 E-07$ & & & & & \\
\hline C12 & $1.08 E-06$ & & & & & \\
\hline C15 & $1.08 E-06$ & & & & & \\
\hline C14 & $1.20 \mathrm{E}-06$ & & & & & \\
\hline C13 & $1.28 E-06$ & & & & & \\
\hline C19 & $1.12 E-05$ & & & & & \\
\hline $\mathrm{Cl} 8$ & $1.46 E-05$ & & & & & \\
\hline C17 & $1.13 E-04$ & & & & & \\
\hline
\end{tabular}


Table 2-13

Screening of Seismic Sources: Woodward-Clyde Team

SCREENING OF SEISMIC SOURCES

site: HFIR team: WCC peak accel.

$\begin{array}{lcccrcc}\text { Source } & \text { Hazard } & \text { P* } & \text { Haz.P* } & \text { Acum. } & \text { Include } \\ \text { B29 } & 1.27 E-04 & 1.000 & 1.27 E-04 & 58.8 & 58.8 & Y \\ 31 A & 3.80 E-04 & 0.211 & 8.01 E-05 & 37.2 & 96.0 & Y \\ 31 & 3.56 E-04 & 0.024 & 8.53 E-06 & 4.0 & 100.0 & Y \\ 29 & 2.98 E-07 & 0.122 & 3.63 E-08 & 0.0 & 100.0 & \text { N } \\ 29 A & 7.60 E-08 & 0.305 & 2.32 E-08 & 0.0 & 100.0 & N \\ 29 B & 5.25 E-08 & 0.183 & 9.60 E-09 & 0.0 & 100.0 & N \\ 40 & 6.31 E-09 & 1.000 & 6.31 E-09 & 0.0 & 100.0 & N \\ 30 & 1.00 E-10 & 0.573 & 5.74 E-11 & 0.0 & 100.0 & \text { N }\end{array}$

SCREENING OF SEISMIC SOURCES

site: HFIR team: WCC $1-\mathrm{Hz}$ psv

$\begin{array}{lcccccc}\text { Source } & \text { Hazard } & \text { P } & \text { Haz.P } & \text { Acum. } & \text { Include } \\ \text { B29 } & 2.76 \mathrm{E}-04 & 1.000 & 2.76 \mathrm{~F}-04 & 45.3 & 45.3 & \mathrm{Y} \\ 31 \mathrm{~A} & 8.44 \mathrm{E}-04 & 0.211 & 1.78 \mathrm{E}-04 & 29.1 & 74.4 & \mathrm{Y} \\ 40 & 9.78 \mathrm{E}-05 & 1.000 & 9.78 \mathrm{E}-05 & 16.0 & 90.4 & \mathrm{Y} \\ 31 & 8.48 \mathrm{E}-04 & 0.024 & 2.04 \mathrm{E}-05 & 3.3 & 93.7 & \mathrm{Y} \\ 29 \mathrm{~A} & 4.90 \mathrm{E}-05 & 0.305 & 1.49 \mathrm{E}-05 & 2.4 & 96.2 & \mathrm{Y} \\ 29 & 1.09 \mathrm{E}-04 & 0.122 & 1.33 \mathrm{E}-05 & 2.2 & 98.4 & \mathrm{Y} \\ 29 \mathrm{~B} & 3.71 \mathrm{E}-05 & 0.183 & 6.79 \mathrm{E}-06 & 1.1 & 99.5 & \mathrm{Y} \\ 30 & 5.72 \mathrm{E}-06 & 0.573 & 3.27 \mathrm{E}-06 & 0.5 & 100.0 & \mathrm{~N}\end{array}$


Table 2-14

Sources used for Seismic Hazard Calculations

\begin{tabular}{ll} 
Team & \multicolumn{1}{l}{ Sources } \\
Bechtel & $24,25,25 \mathrm{~A}, 30, \mathrm{~F}, \mathrm{H}, \mathrm{BZ0}, \mathrm{BZ5}, \mathrm{BZ6}$ \\
Dames and Moore & $04,4 \mathrm{~A}, 05,21,41$ \\
Law Engineering & $01,17,18,115,217$ \\
Rondout & $1,5,9,25,26,27$ \\
Weston Geophysical & $24,31,32, \mathrm{C} 11, \mathrm{C} 17, \mathrm{C} 19$ \\
Woodward-Clyde & $29,29 \mathrm{~A}, 29 \mathrm{~B}, 31,31 \mathrm{~A}, 40, \mathrm{~B} 29$
\end{tabular}


Table 2-15

Source Combinations and Their Probabilities

\begin{tabular}{|c|c|c|c|c|c|c|c|c|}
\hline \multirow{2}{*}{$\begin{array}{l}\text { Team } \\
\text { Bechtel }\end{array}$} & \multirow{2}{*}{$\frac{\text { Prob. }}{0.09970}$} & \multicolumn{7}{|c|}{ Act Ive Sources } \\
\hline & & 30 & $\mathrm{BZO}$ & BZ5 & B26 & 25 & $\mathrm{H}$ & $\mathbf{F}$ \\
\hline & 0.18530 & 30 & BZO & BZ5 & B26 & 25 & $\mathrm{H}$ & \\
\hline & 0.00530 & 30 & B2O & BZ 5 & B26 & 25 & $\mathbf{E}$ & \\
\hline & 0.00980 & 30 & $\mathrm{BZO}$ & BZ5 & B26 & 25 & & \\
\hline & 0.14960 & 30 & $\mathrm{BZO}$ & B25 & B26 & $25 A$ & $H$ & $\mathbf{F}$ \\
\hline & 0.27790 & 30 & BZO & B25 & B26 & $25 A$ & $H$ & \\
\hline & 0.00790 & 30 & B2O & BZ5 & B26 & $25 A$ & $\mathbf{F}$ & \\
\hline & 0.01460 & 30 & $\mathrm{BZO}$ & B25 & B26 & $25 A$ & & \\
\hline & 0.08310 & 30 & $\mathrm{BZO}$ & BZ5 & B26 & 24 & $\mathrm{H}$ & $\mathbf{F}$ \\
\hline & 0.15440 & 30 & BZO & B25 & B26 & 24 & $H$ & \\
\hline & 0.00440 & 30 & BZO & B2 5 & B26 & 24 & F & \\
\hline & 0.00810 & 30 & BzO & BZ5 & B26 & 24 & & \\
\hline Dames & 0.01260 & 21 & 04 & 05 & 41 & & & \\
\hline \multirow[t]{7}{*}{ Moore } & 0.09240 & 21 & 04 & 05 & & & & \\
\hline & 0.02940 & 21 & 04 & 41 & & & & \\
\hline & 0.21560 & 21 & 04 & & & & & \\
\hline & 0.02340 & 21 & $4 A$ & 05 & 41 & & & \\
\hline & 0.17160 & 21 & $4 A$ & 05 & & & & \\
\hline & 0.05460 & 21 & $4 A$ & 41 & & & & \\
\hline & 0.40040 & 21 & $4 A$ & & & & & \\
\hline Law & 0.19840 & 18 & 115 & 01 & 17 & & & \\
\hline \multirow[t]{3}{*}{ Engineering } & 0.12160 & 18 & 115 & 01 & 217 & & & \\
\hline & 0.42160 & 18 & 115 & 17 & & & & \\
\hline & 0.25840 & 18 & 115 & 217 & & & & \\
\hline Rondout & 0.98010 & 1 & 5 & 26 & 27 & 9 & 25 & \\
\hline \multirow[t]{3}{*}{ Associates } & 0.00990 & 1 & 5 & 26 & 27 & 9 & & \\
\hline & 0.00990 & 1 & 5 & 26 & 27 & 25 & & \\
\hline & 0.00010 & 1 & 5 & 26 & 27 & & & \\
\hline Weston & 0.85500 & 24 & C19 & 31 & C11 & & & \\
\hline \multirow[t]{3}{*}{ Geophysical } & 0.04500 & 24 & C19 & 32 & & & & \\
\hline & 0.09500 & $\mathrm{Cl7}$ & 31 & C11 & & & & \\
\hline & 0.00500 & C17 & 32 & & & & & \\
\hline Woodward- & 0.00290 & 40 & 31 & 29 & & & & \\
\hline \multirow[t]{11}{*}{ Clyde } & 0.00730 & 40 & 31 & $29 A$ & & & & \\
\hline & 0.00440 & 40 & 31 & $29 B$ & & & & \\
\hline & 0.00940 & 40 & 31 & & & & & \\
\hline & 0.02570 & 40 & $31 \mathrm{~A}$ & 29 & & & & \\
\hline & 0.06440 & 40 & $31 \mathrm{~A}$ & $29 A$ & & & & \\
\hline & 0.03860 & 40 & $31 \mathrm{~A}$ & $29 B$ & & & & \\
\hline & 0.08230 & 40 & $31 A$ & & & & & \\
\hline & 0.09330 & 40 & B29 & 29 & & & & \\
\hline & 0.23330 & 40 & B29 & $29 A$ & & & & \\
\hline & 0.14000 & 40 & B29 & $29 B$ & & & & \\
\hline & 0.29830 & 40 & B29 & & & & & \\
\hline
\end{tabular}




\subsubsection{Results}

Seismic hazard calculations were performed for peak acceleration and 5 spectral velocities, using the EPRI/SOG software modules EQHAZ and EQPOST, and considering the seismic sources and source combinations in Tables 2-14 and 2-15. Results for peak ground acceleration are presented in Figures 2-11 and 2-12, and in Table 2-16, in the form of hazard curves. Results for spectral velocities are presented in Figure 2-13, in the form of a uniform-hazard spectrum. 


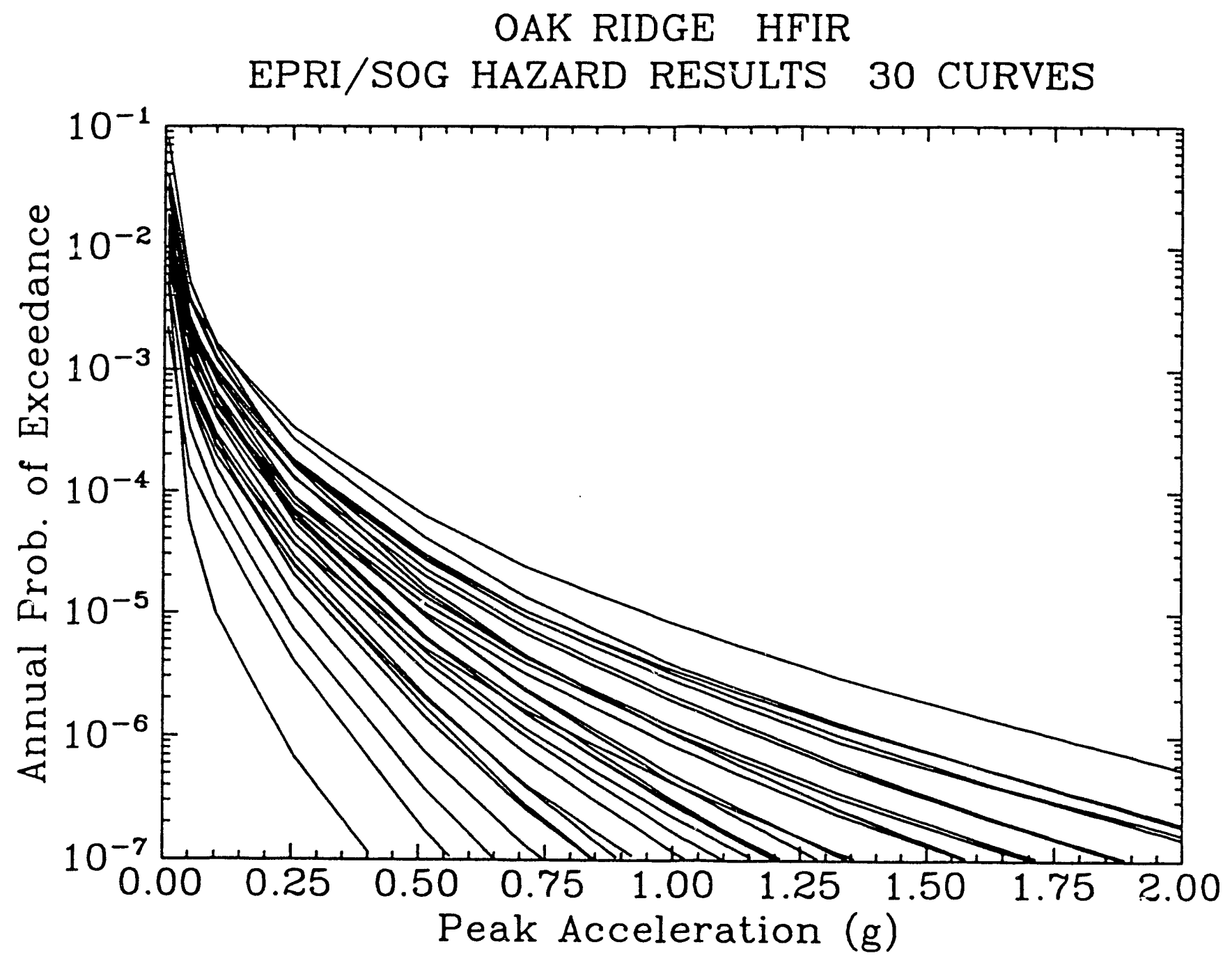

Figure 2-11. Seismic hazard at HFIR computed using the EPRI/SOG methodology. Results shown as 30 equally weighted hazard curves for peak ground acceleration. 


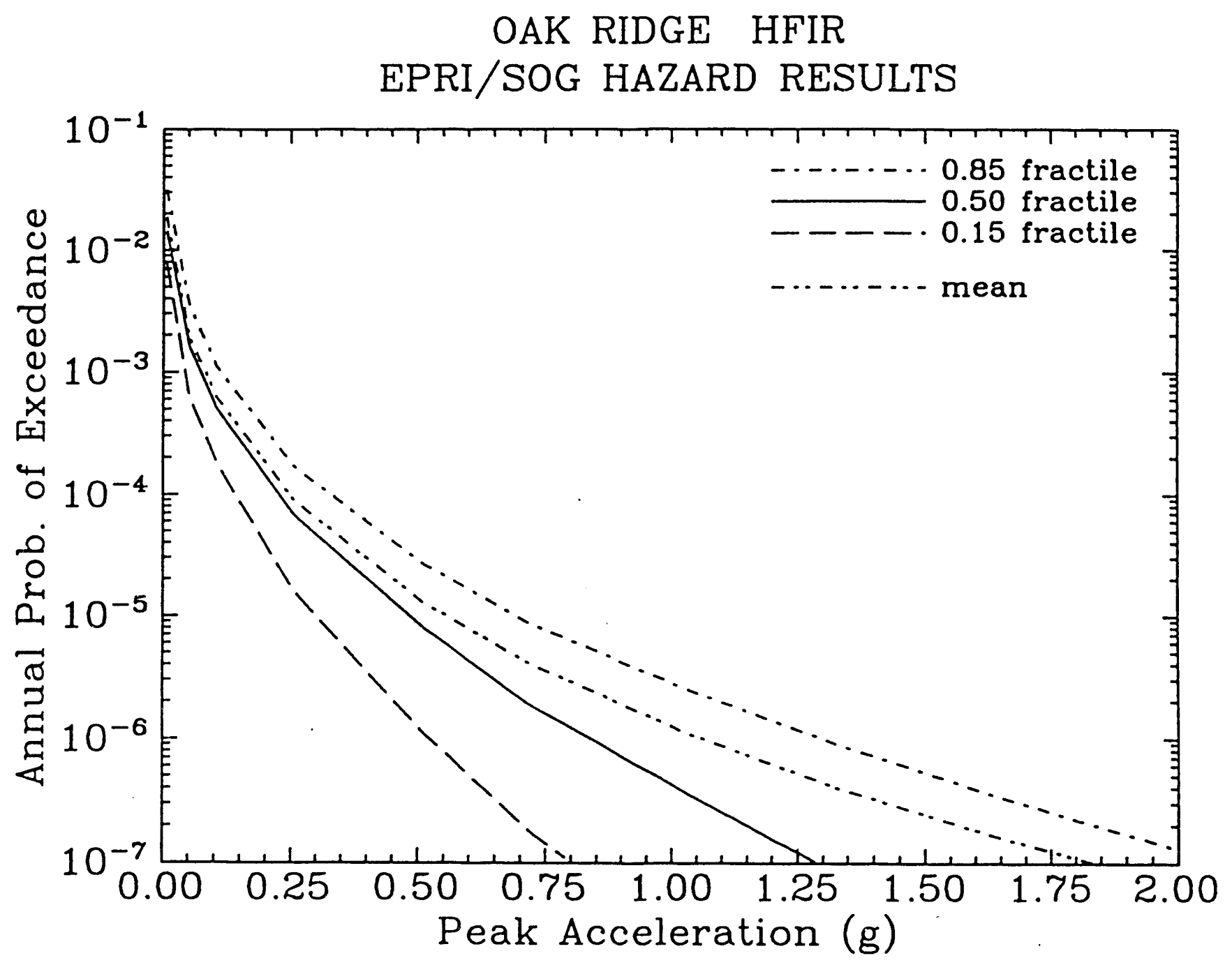

Figure 2-12. Seismic hazard at HFIR computed using the EPRI/SOG methodology. Results shown as fractile hazard curves and mean hazard curve for peak acceleration. 


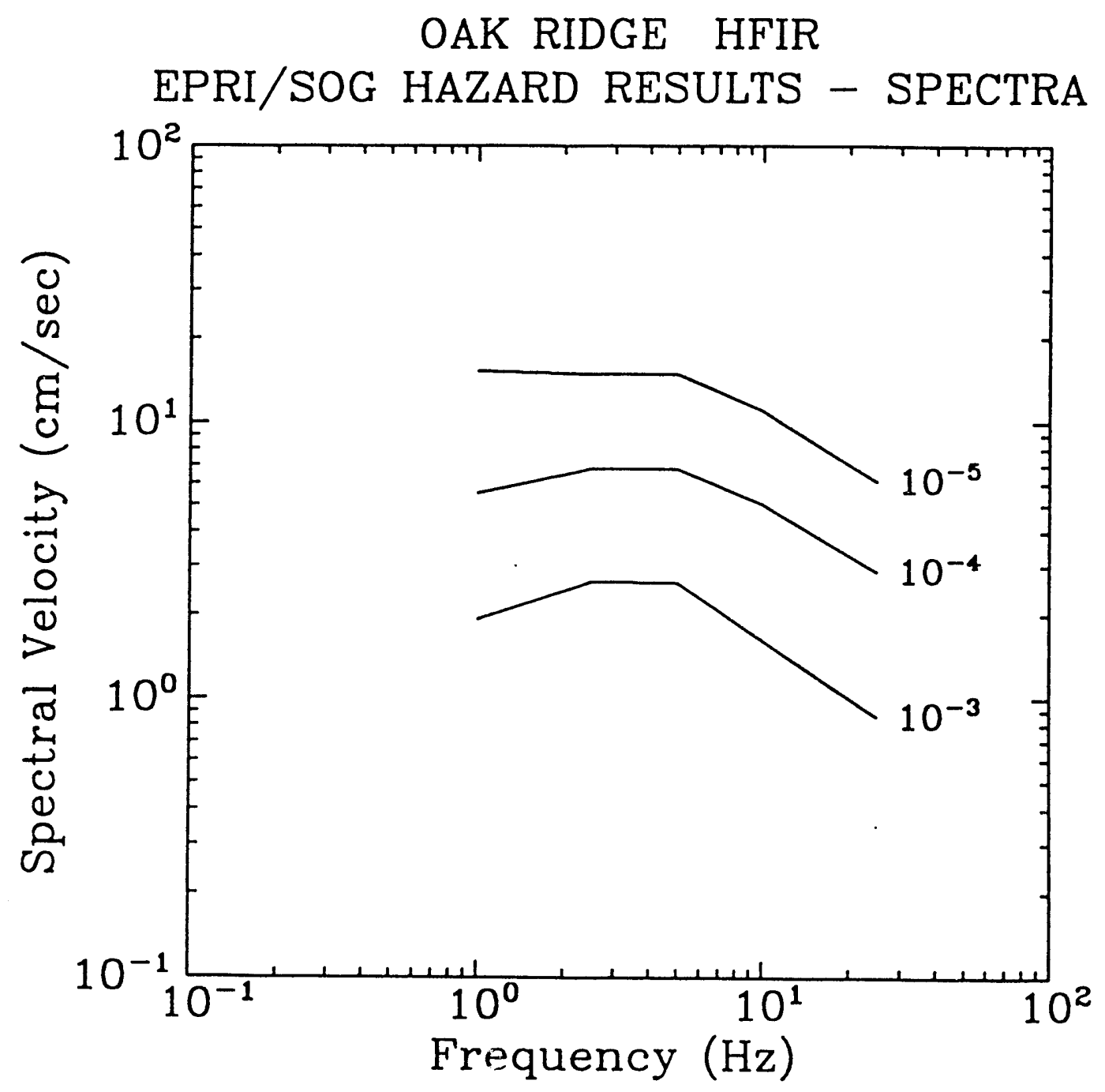

Figure 2-13. Seismic hazard at HFIR computed using the EPRI/SOG methodology. Results shown as uniform hazard spectra for three values of the annual probability of exceedance. 


\subsection{REFERENCES}

1. C. A. Cornell. "Engineering Seismic Risk Analysis". Bulletin of the Seismological Society of America, 58(5):1583-1606, October 1968.

2. C. A. Cornell. Dynamic Waves in Civil Engineering, chapter 27: "Probabilistic Analysis of Damage to Structures under Seismic Loads". Wiley Interscience, 1971.

3. A. Der Kiureghian and A. H. S. Ang. A Line Source Model for Seismic Risk Analysis. Technical Report UILU-ENG-75-2023, Univ. of Illinois, October 1975. pp. 134.

4. R. K. McGuire. FORTRAN Computer Program for Seismic Risk Analysis. Open File Report 76-67, U. S. Geological Survey, 1976. pp. 1-90.

5. D. L. Bernreuter, J. B. Savy, R. W. Mensing, J. C. Chen, and B. C. Davis. Seismic Hazard Characterization of the Eastern United States. Technical Report LLNL UCID-20421, Volumes 1 and 2, Lawrence Livermore National Laboratory, Livermore, Ca., 1985.

6. R. K. McGuire, G. R. Toro, J. P. Jacobson, T. F. O'Hara, and W. J. Silva. Probabilistic Seismic Hazard Evaluations in the Central and Eastern United States: Resolution of the Charleston Earthquake Issue. Final Proyect Report, Electric Power Research Institute, April 1989.

7. R. K. McGuire, G. R. Toro, and W. J. Silva. Engineering Model of Earthquake Ground Motion for Eastern North America. Technical Report NP-6074, Electric Power Research Institute, 1988.

8. Seismic Hazard Methodology for the Central and Eastern United States. Technical Report NP-4726-A, Electric Power Research Institute, July 1986. Vol. 1, Part 1: Methodology, Vol. 1, Part 2: Theory, Vol. 2: EQHAZARD Programmer's Manual, Vol. 3: EQHAZARD User's Manual, Vol. 4: Applications, Vols. 5 through 10: Tectonic Interpretations, Vol. 11: Nuclear Regulatory Commission Safety Review.

9. K. J. Coppersmith, A. C. Johnston, and W. J. Arabasz. "Assessment of Maximum Earthquake Magnitudes in the Eastern United States". Earthquake Notes, 57-1:12, 1986.

10. A. C. Johnston, A. G. Metzger, K. J. Coppersmith, and W. J. Arabasz. "A Systematic Global Overview of Large Intraplate Earthquakes". Earthquake Notes, 57-1:12, 1986.

11. M. W. McCann and J. W. Reed. Selection of a Lower Bound Magnitude for Seismic Hazard Assessment. Technical Report, Electric Power Research Institute, Palo Alto, California, 1988.

12. M. W. McCann and J. W. Reed, editors. Engineering Characterization of SmallMagnitude Earthquakes, Electric Power Research Institute, Palo Alto, California, 1988.

13. L. Reiter. EPRI Ground Motion Models for Eastern North America. NRC Letter to R.A. Thomas, August 3, 1988.

14. D. M. Boore and G. M. Atkinson. "Stochastic Prediction of Ground Motion and Spectral Response Parameters at Hard-Rock Sites in Eastern North America". Bulletin of the Seismological Society of America, 77(2):440-467, 1987. 
15. O. W. Nuttli. Letter dated September 19, 1986 to J. B. Savy. Reproduced in: D. Bernreuter, J. Savy, R. Mensing, J. Chen, and B. Davis. Seismic Hazard Characterization of 69 Nuclear Plant Sites East of the Rocky Muntains: Questionnaires. U. S. Nuclear Regulatory Commission, Technical Report NUREG/CR-5250, UCID-21517, Volume 7, 1989. Prepared by the Lawrence Livermore National Laboratory.

16. N. M. Newmark and W. J. Hall. Earthquake Spectra and Design. Earthquake Engineering Research Institute, Berkeley, CA, 1982.

17. R. B. Herrmann and O. W. Nuttli. "Strong Motion Investigations in the Central United States". In Proceedings: 7th World Conference on Earthquake Engineering, Istanbul, pp. 533-536, 1980. 


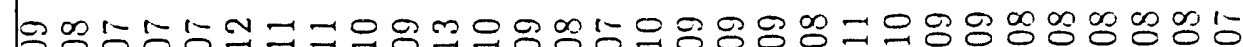

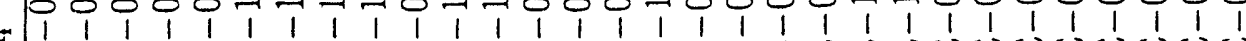

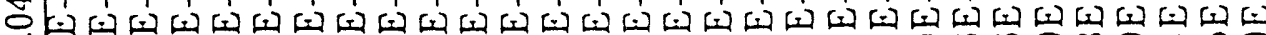

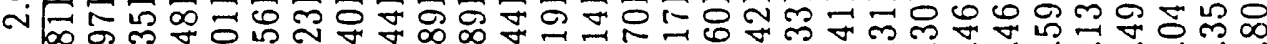
ஸ்

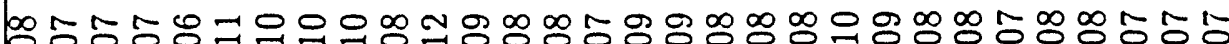

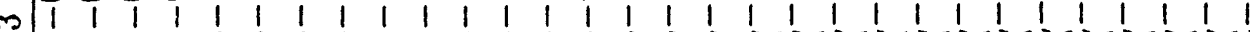

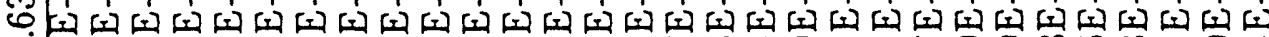
鸟 ம்

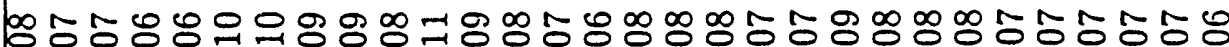
20

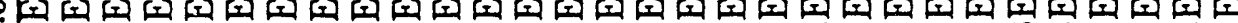

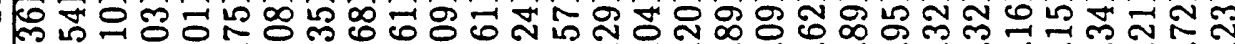
م

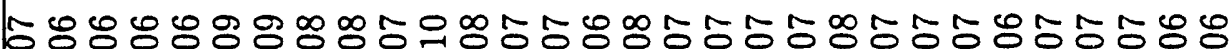

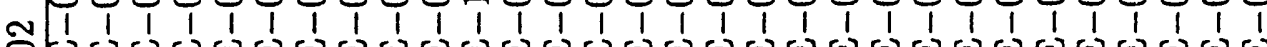

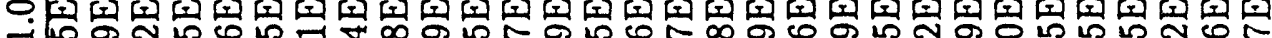
-

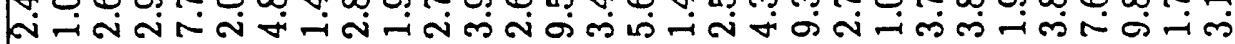

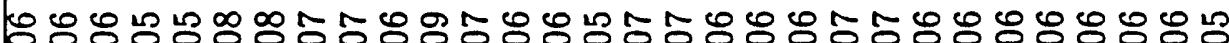

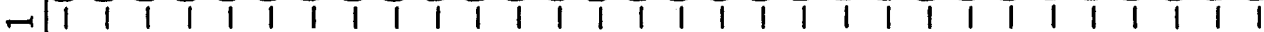

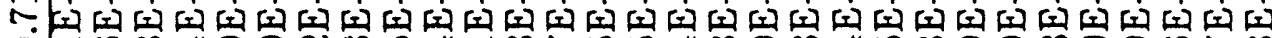

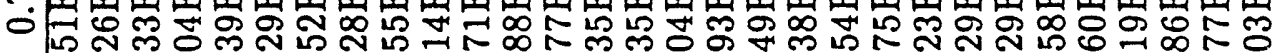
-

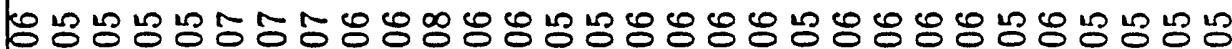

-1

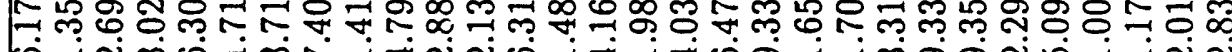
П

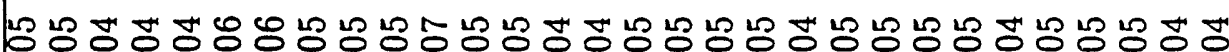
م

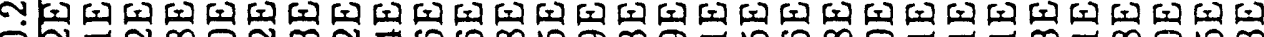
○|స్రై ڤ

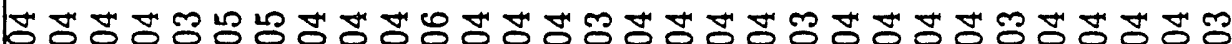

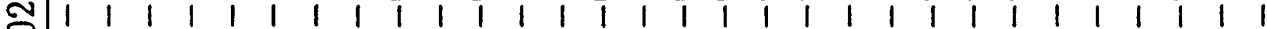

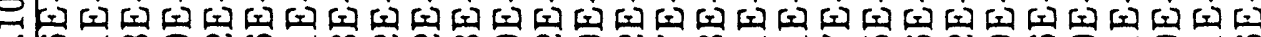

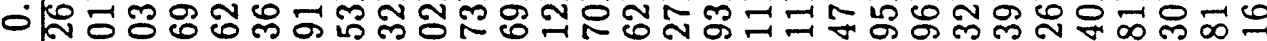

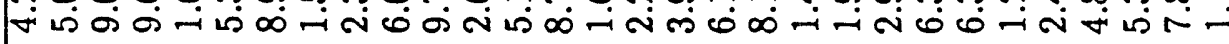

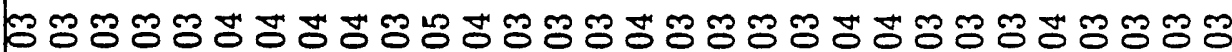
30 감

-

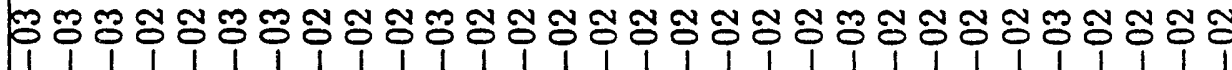

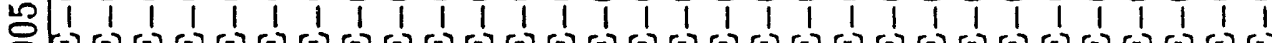

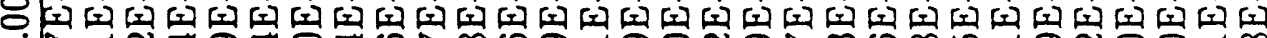

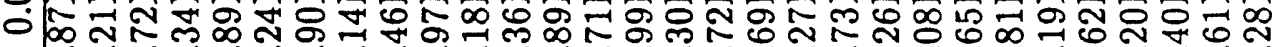

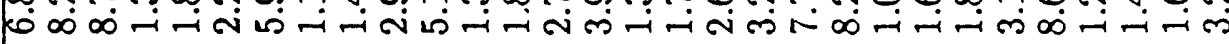

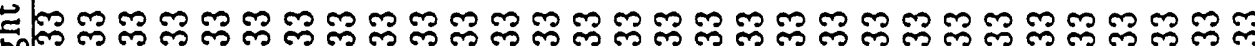

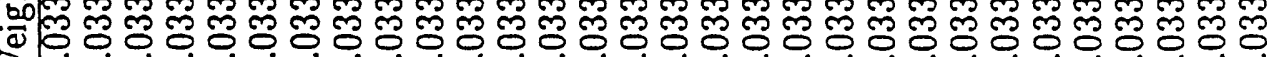

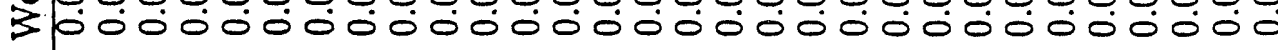
$\stackrel{0}{3} \dot{0}$ 


\section{Section 3}

\section{LLNL METHODOLOGY AND RESULTS}

\subsection{METHODOLOGY}

The second source of interpretations for this study consists of the study of seismic hazard in the CEUS conducted by LLNL (1). This study culminates a decade of effort funded by the U.S. Nuclear Regulatory Commission to characterize earthquake sources, seismicity parameters, and ground motion estimates for the region, for the purpose of evaluating seismic hazard at nuclear plant sites. Two panels of experts were formed. Eleven seismicity experts familiar with the region were polled for interpretations of seismic sources and ground motion parameter values, and five ground motion experts were polled for opinions on appropriate attenuation equations to estimate PGA and response spectrum amplitudes. Uncertainties in the interpretations were represented by discrete and continuous distributions, and uncertainty in the seismic hazard was derived by Monte Carlo sampling of the input distributions, producing a seismic hazard curve for each set of simulated variables and thus representing the uncertainty in the seismic hazard as a function of uncertainty in expert interpretation.

LLNL performed its methodology for the HFIR site under a separate agreement, and provided results for use in this study. We summarize herein some of the important inputs to the LLNL analysis and our interpretations of them for this study.

\subsection{SEISMICITY INTERPRETATIONS}

The eleven seismicity experts provided sets of seismic sources for the CEUS; the basic set of sources for the region are reproduced in Figures 3-1 through 3-11, for comparison to the EPRI sources. Some LLNL experts also specified alternative geometries of sources; these are not reproduced here but are available in the LLNL documentation (1). By contrast to the EPRI study, which specified uncertainty on the seismic activity of each source separately, the LLNL experts specified global alternatives for sets of sources that might be active simultaneously.

Seismicity parameters (rates of activity and Richter $b$-values) for the sources were provided by the seismicity experts, although the LLNL team made available the results of calculations of these parameters using a standard method and an earthquake catalog specified by the 
expert. Distributions and correlations were also specified to represent the uncertainty of these parameters. In addition, the distribution of maximum possible earthquake size was specified for each source by each expert. (Most of them used magnitude to characterize earthquake size; one used MM intensity, and a second used a combination of the two.)

\subsection{GROUND MOTION MODELS}

Five earth scientists and engineers were asked to derive ground motion estimation equations for the CEUS for the LLNL study. These equations were to estimate PGA and response spectrum amplitude as a function of earthquake magnitude and distance. Estimating such equations for the CEUS is problematic because of the lack of recorded strong earthquake motions in the area with which to calibrate empirical techniques or validate theoretical models. Any method thought to be adequate by the five experts was acceptable. The five participants were asked to specify uncertainty in their choice of ground motion equations by designating multiple models with subjective weights.

One of the models selected gives substantially higher ground motion estimates than the others for PGA and response spectrum amplitudes. For PGA this model is designated "G16-A3" in the LLNL report (1); it is a combination of two equations, a correlation between PGA and $M M$ intensity published by Trifunac from California data ( 2 ), and an $M M$ intensity attenuation equation published by Gupta and Nuttli ( $\underline{3})$. A similar procedure was followed for spectral velocities; the resulting model is designated "TL". This selection received $100 \%$ weight from Expert 5, and zero weight from the other panelists. Comparing the predictions from this equation to data available from CEUS seismographs and accelerographs indicates that equation G16-A3 severely over-estimates ground motions in the CEUS, particularly at distances greater than $20 \mathrm{~km}$ from the earthquake source. (See Figures 5-123 through 5-125 of (ㄴ) and for these comparisons and Figures 3-2 through 3-13 of (ㅁ) for comparisons with data from the Saguenay earthquake.]

There are good reasons why equations G16-A3 and TL might lead to poor estimates of ground motion in the CEUS. This function was obtained by substitution of a stochastic relationship between instrumental ground-motion and intensity into a stochastic intensityattenuation relation. This uype of substitution of one regression into another is mathematically incorrect and has been demonstrated to produce significant biases when applied to intensity-attenuation data (6). In particular, after such a substitution the dependent variable does not appear to be as strongly correlated to the independent variable as it should be, which is the behavior evident in comparisons of data with estimates from G16-A3. For example, the data in Figures 5-123 through 5-125 of (4) show a much stronger dependence 
on distance than do the estimates. Further, this model was given zero weight by four of the LLNL panelists (and 100\% weight by the fifth), an indication that the model has a small following in the scientific community [see Tables 3.5 and 3.6 in Volume 1 of (1)]. Because of the theoretical problems in the derivation of equation G16-A3 and its lack of agreement with available data from the CEUS, it appears that this equation lacks credibility and should not be included in results used from the LLNL study.

An important set of earthquake ground motion data became available on November 25, 1988 when the Saguenay earthquake (magnitude $m_{b L g}$ 6.5) occurred in Quebec. This earthquake generated more accelerograph records than any previous earthquake in eastern North America. We have performed a detailed comparison of Saguenay ground motions to predictions by the LLNL and EPRI attenuation functions, a review of seismological studies on the Saguenay earthquake, and an examination of the assumptions and substitution methods employed by LLNL ground-motion expert 5 (5). We conclude from the above study that the attenuation functions proposed by LLNL ground-motion expert 5 should not be used for seismic hazard calculations in eastern North America, because these attenuation functions are inconsistent with all instrumental ground motion data from eastern North America, they are based on assumptions about intensity that are incorrect, and they were obtained using a substitution procedure that is invalid.

\subsection{COMPUTATIONS}

The Monte Carlo simulation procedure used by LLNL to express uncertainty in seismic hazard as a function of uncertain input was conducted as follows. There were 55 possible combinations of the eleven seismicity experts and the five ground motion experts, and each combination was considered separately. For each, 50 simulations of uncertain parameters were made, drawing from the distributions on seismicity parameters, ground motion equations, and attenuation randomness terms specified by each expert. This resulted in 2750 combinations of parameters from which a family of 2750 seismic hazard curves could be calculated. Each of these seismic hazard curves was then assigned a weight based on a selfweighting provided by the experts. This led to an uncertainty distribution on the frequency of exceedance for any PGA level, from which fractiles of seismic hazard can be computed and plotted as fractile seismic hazard curves.

\subsection{RESULTS}

The LLNL results that we present here were obtained by LLNL and transmitted to Risk Engineering, Inc. $(7,8,9)$. At the request of our client, we include results obtained with and 
without the attenuation functions by LLNL ground-motion expert 5. In our opinion, only the results without expert 5 should be used.

Figures 3-1 and 3-2, and Tables 3-1 and 3-2, show fractile hazard curves, without and with LLNL ground-motion expert 5. Figures 3-3 and 3-4 show the corresponding uniform-hazard spectra. Comparison of Figures 3-1 and 3-2 indicates that including expert 5 has a modest effect on the median hazard, but has a large effect on the high fractiles. Comparison of the median spectra in Figures 3-3 and 3-4 indicates that including expert 5 has an effect that is uniform across frequencies; the effect on the 85-percentile spectra is somewhat higher at low frequencies.

\subsection{REFERENCES}

1. D. L. Bernreuter, J. B. Savy, R. W. Mensing, and J. C. Chen. Seismic Hazard Characterization of 69 Plant Sites East of the Rocky Mountains. Technical Report NUREG/CR5250, UCID-21517, U. S. Nuclear Regulatory Commission, 1988.

2. M. D. Trifunac. "A Note on the Range of Peak Amplitudes of Recorded Accelerations, Velocities, and Displacements With Respect to the Modified Mercalli Intensity Scale". Earthquake Notes, 47:9-24, 1976.

3. I. N. Gupta anci O. W. Nuttli. "Spatial Attenuation of Intensities for Central.U.S. Earthquakes". Bulletin of the Seismological Society of America, 743-751, June 1976. Number 66-3.

4. R. K. McGuire, G. R. Toro, and W. J. Silva. Probabilistic Seismic Hazard Evaluations in the Central and Eastern United States - Appendix A: Model of Earthquake Ground Motion for the Central and Eastern United States. Technical Report, Electric Power Research Institute, 1989. EPRI Project RP101-53, prepared by Risk Engineering, Inc.

5. Risk Engineering, Inc. Assessment of the 1988 Saguenay Earthquake - Implications on Attenuation Functions for Seismic Hazard Analysis. Report to Pickard, Lowe and Garrick, Inc, February 1991.

6. C. A. Cornell, H. Banon, and A. F. Shakal. "Seismic Motion and Response Prediction Alternatives". Earthquake Engineering and Structural Dynamics, 7:295-315, 1979.

7. R. C. Murray. Letter to Harold F. Perla. Lawrence Livermore National Laboratory, March 8, 1990.

8. J. B. Savy. Telefax to Robin K. McGuire. Lawrence Livermore National Laboratory, April 24, 1989.

9. J. B. Savy. Letter to George F. Flanagan. Lawrence Livermore National Laboratory, May 18, 1989. 


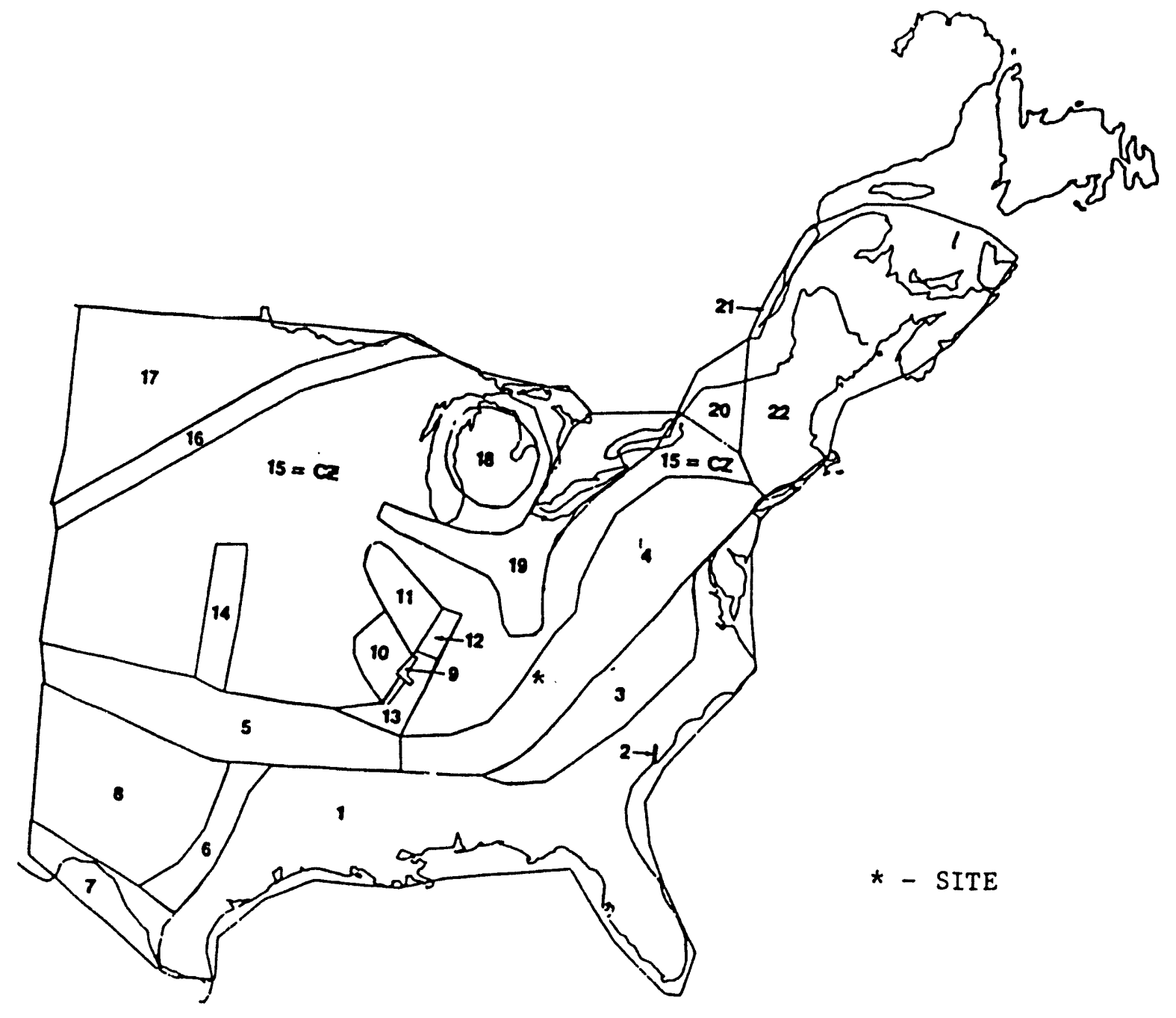

Figure 3-1. Main set of seismic sources provided by LLNL seismicity expert 1. Source: Volume 1 of $(\underline{1})$. 


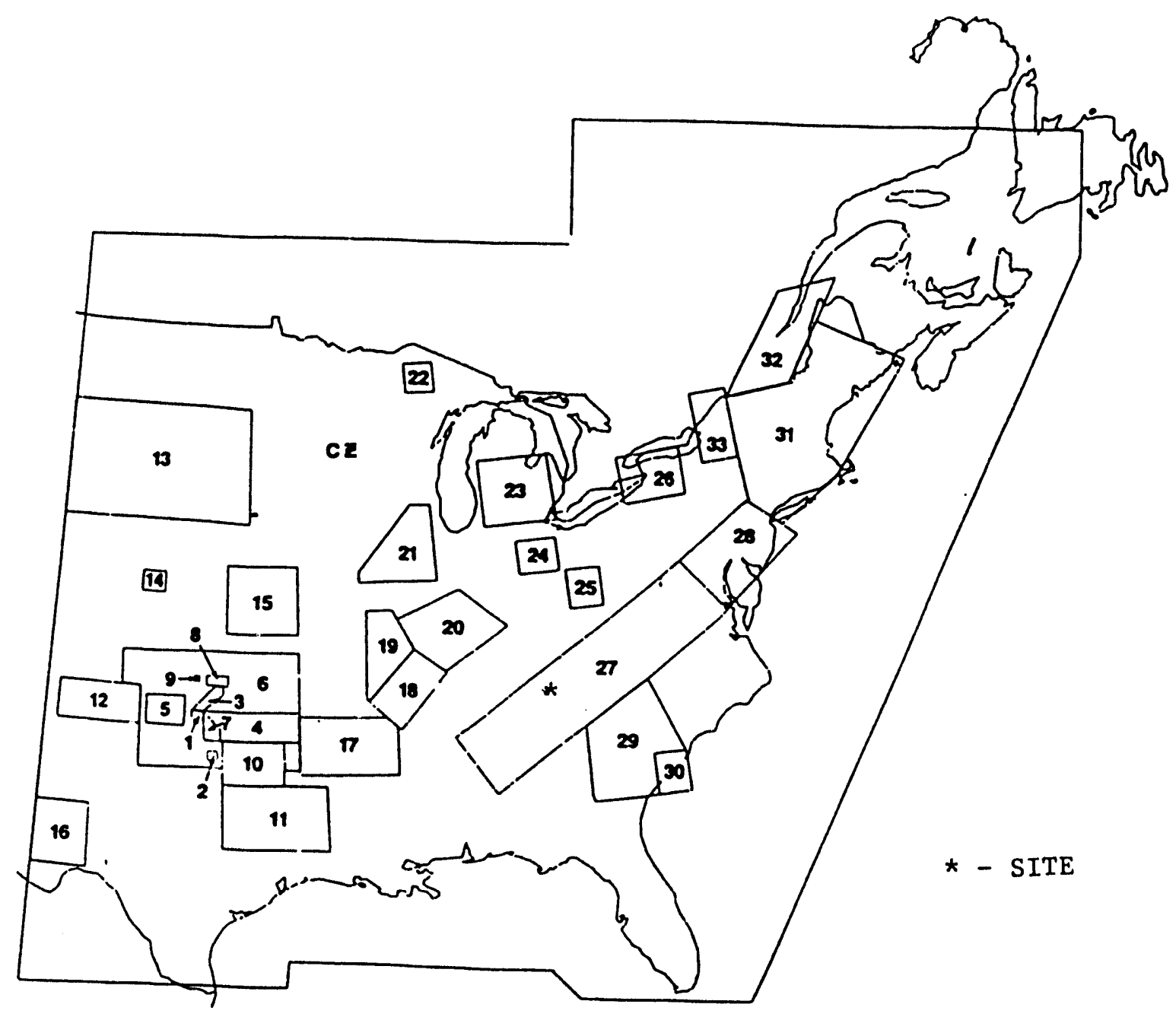

Figure 3-2. Main set of seismic sources provided by LLNL seismicity expert 2. Source: Volume 1 of (1). 


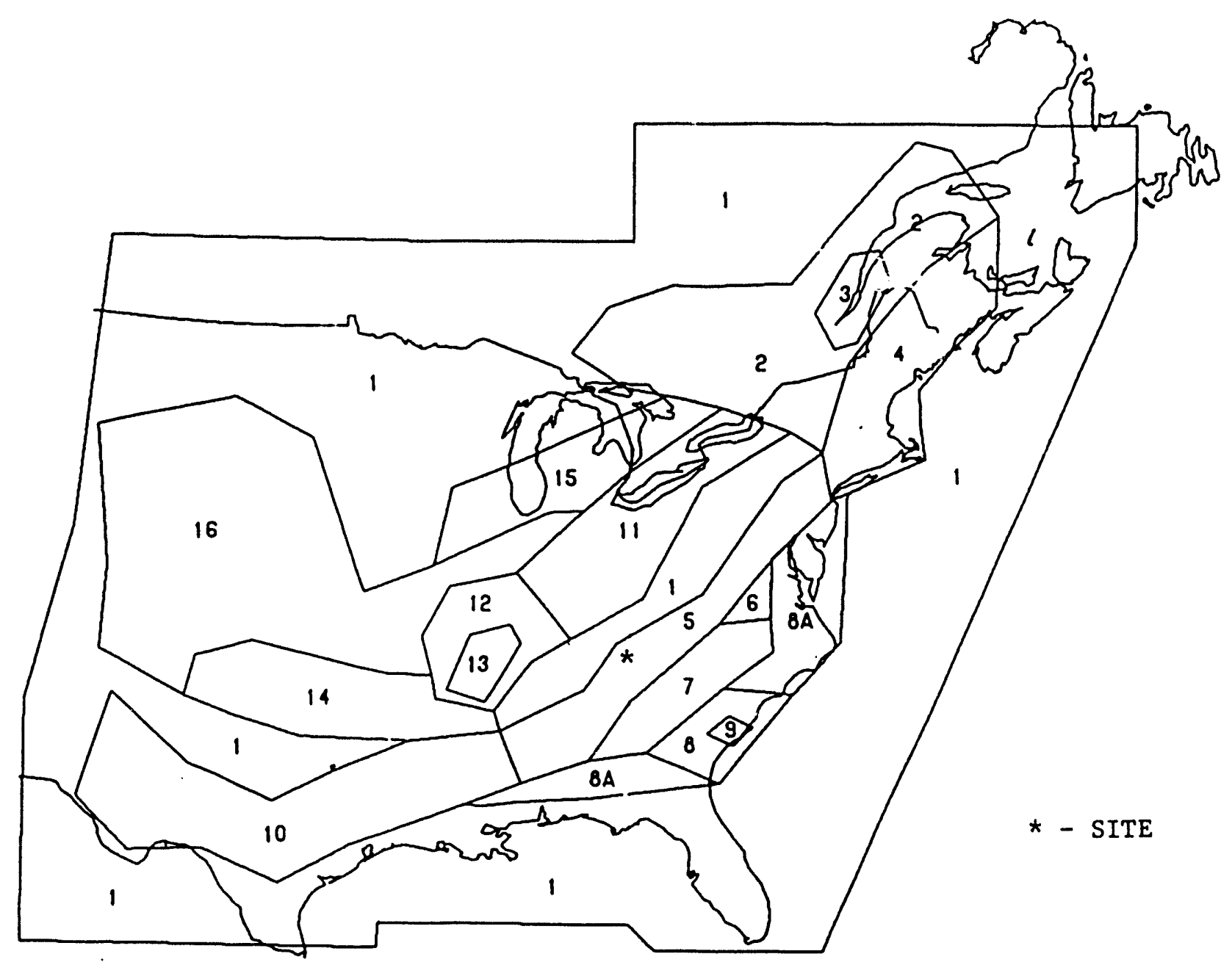

Figure 3-3. Main set of seismic sources provided by LLNL seismicity expert 3. Source: Volume 1 of $(\underline{1})$. 


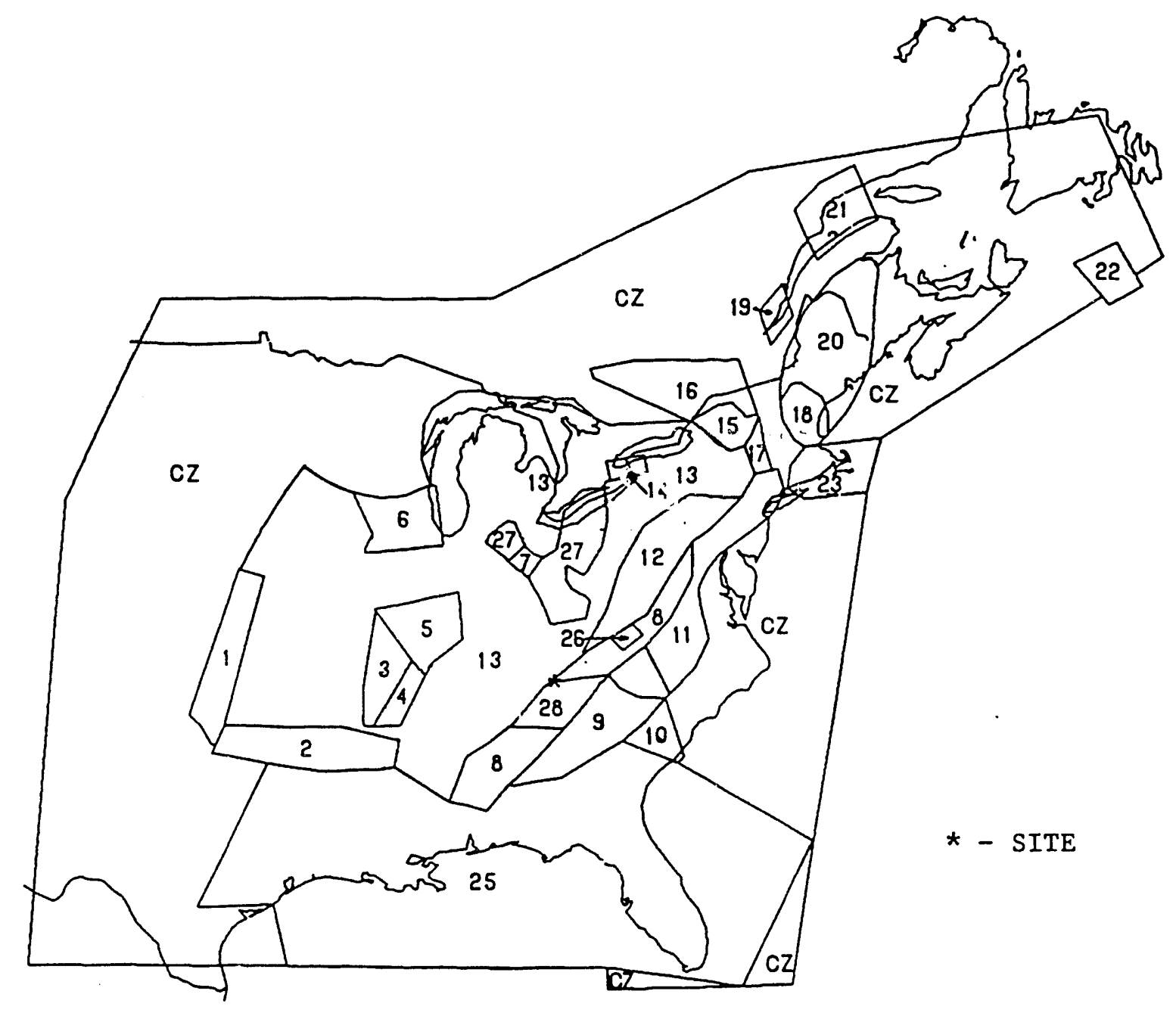

Figure 3-4. Main set of seismic sources provided by LLNL seismicity expert 4. Source: Volume 1 of (1). 


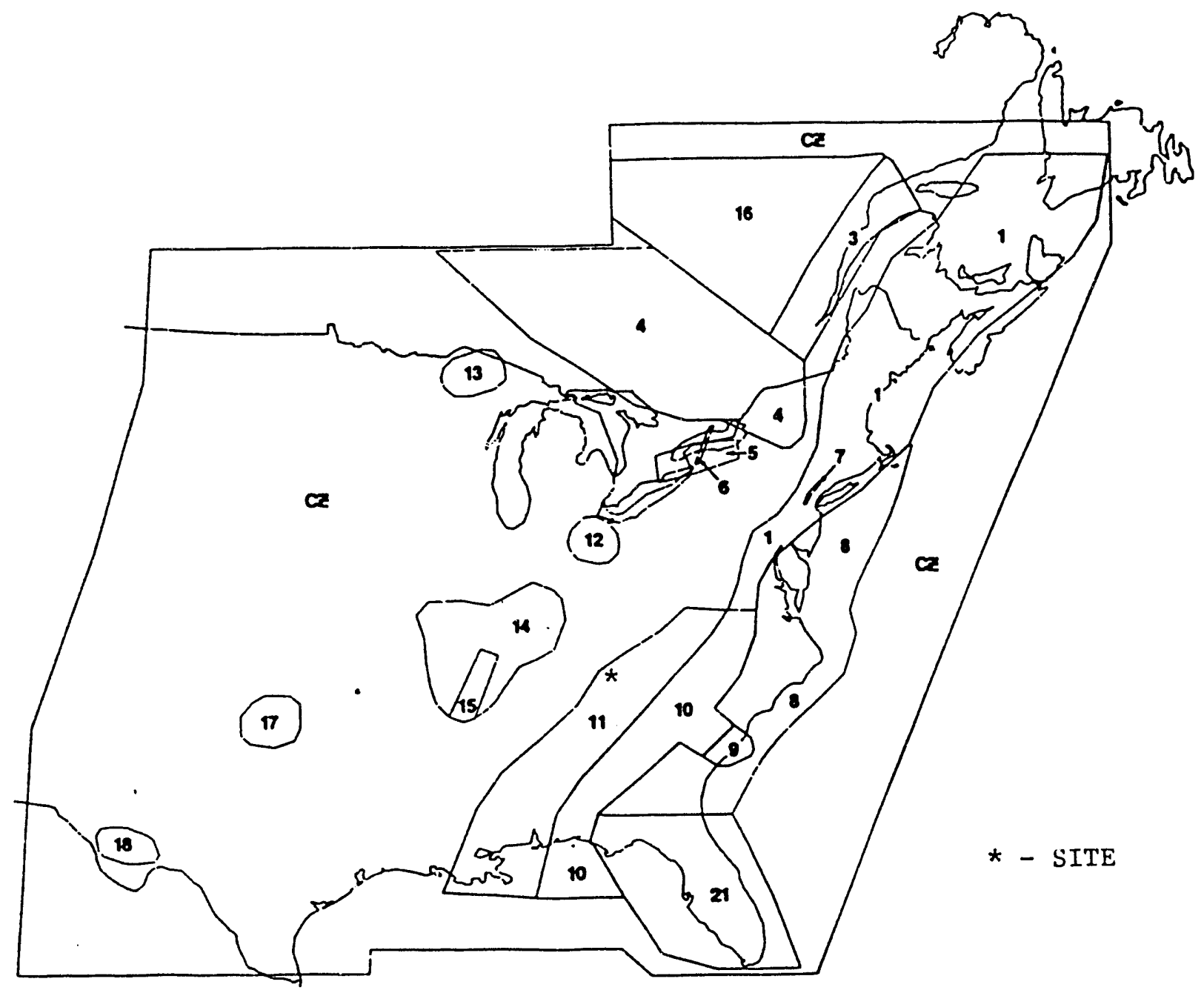

Figure 3-5. Main set of seismic sources provided by LLNL seismicity expert 5. Source: Volume 1 of $(\underline{1})$. 


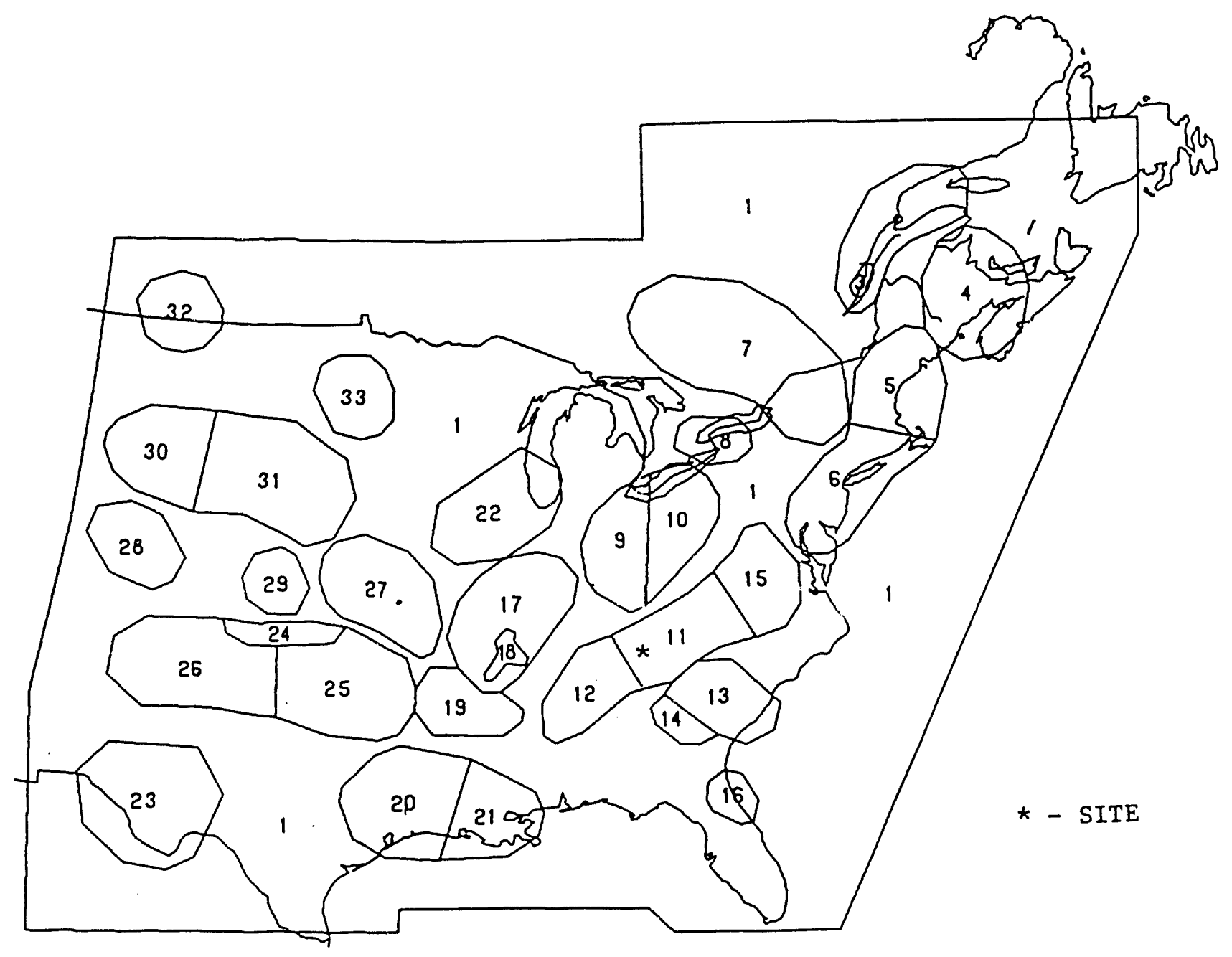

Figure 3-6. Main set of seismic sources provided by LLNL seismicity expert 6 . Source: Volume 1 of (1). 


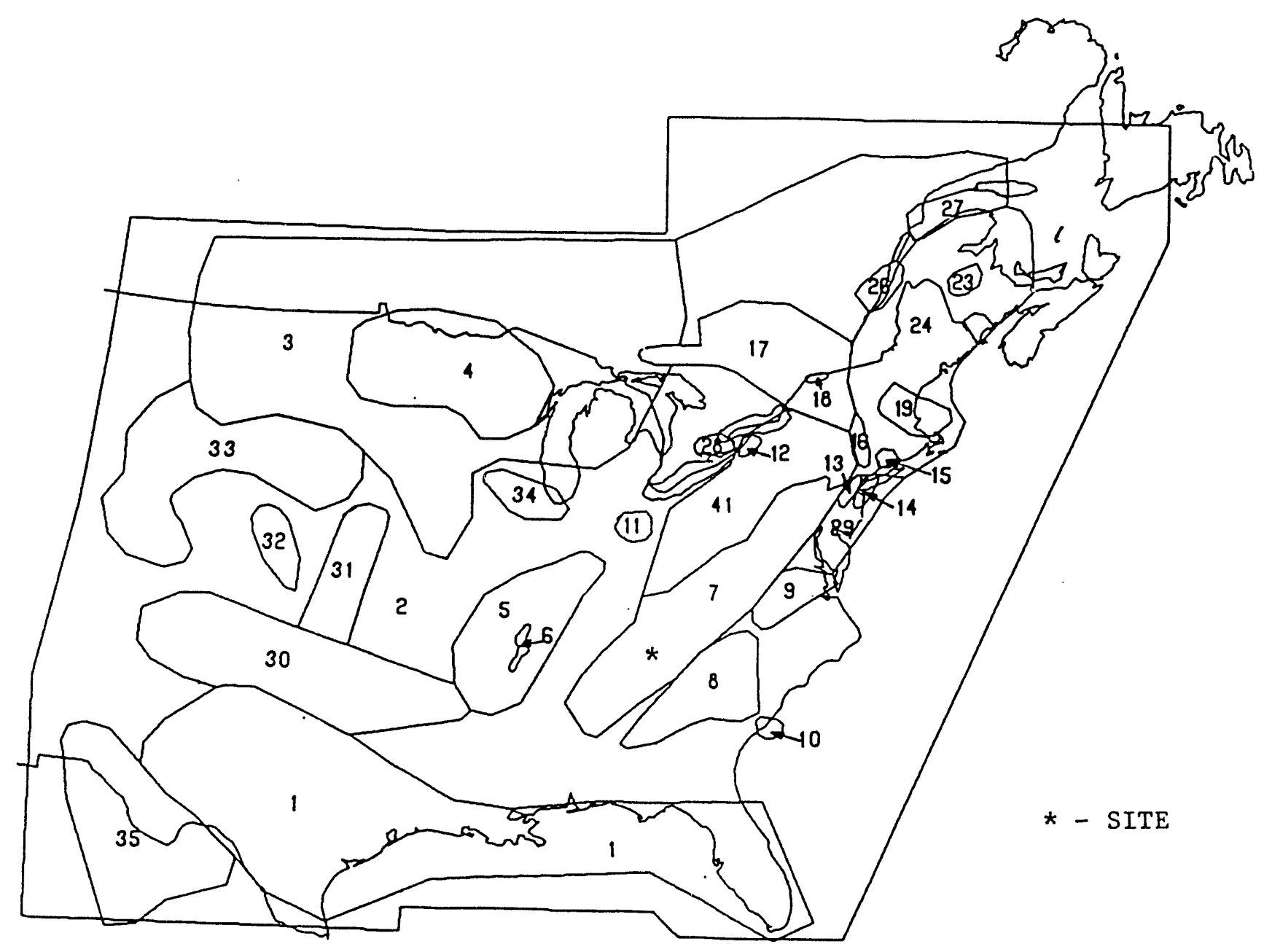

Figure 3-7. Main set of seismic sources provided by LLNL seismicity expert 7. Source: Volume 1 of (1). 


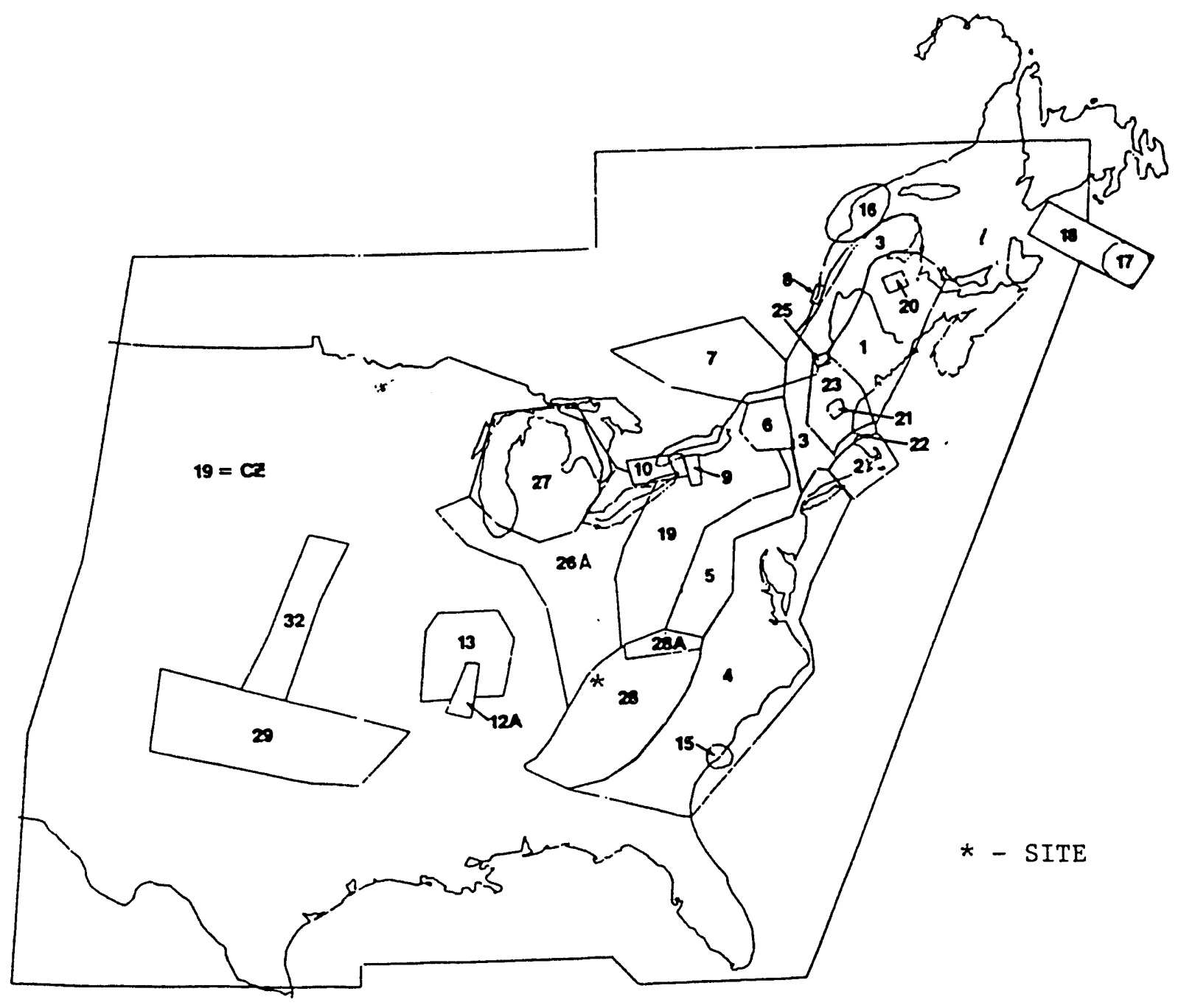

Figure 3-8. Main set of seismic sources provided iy LLNL seismicity expert 10. Source: Volume 1 of (1). 


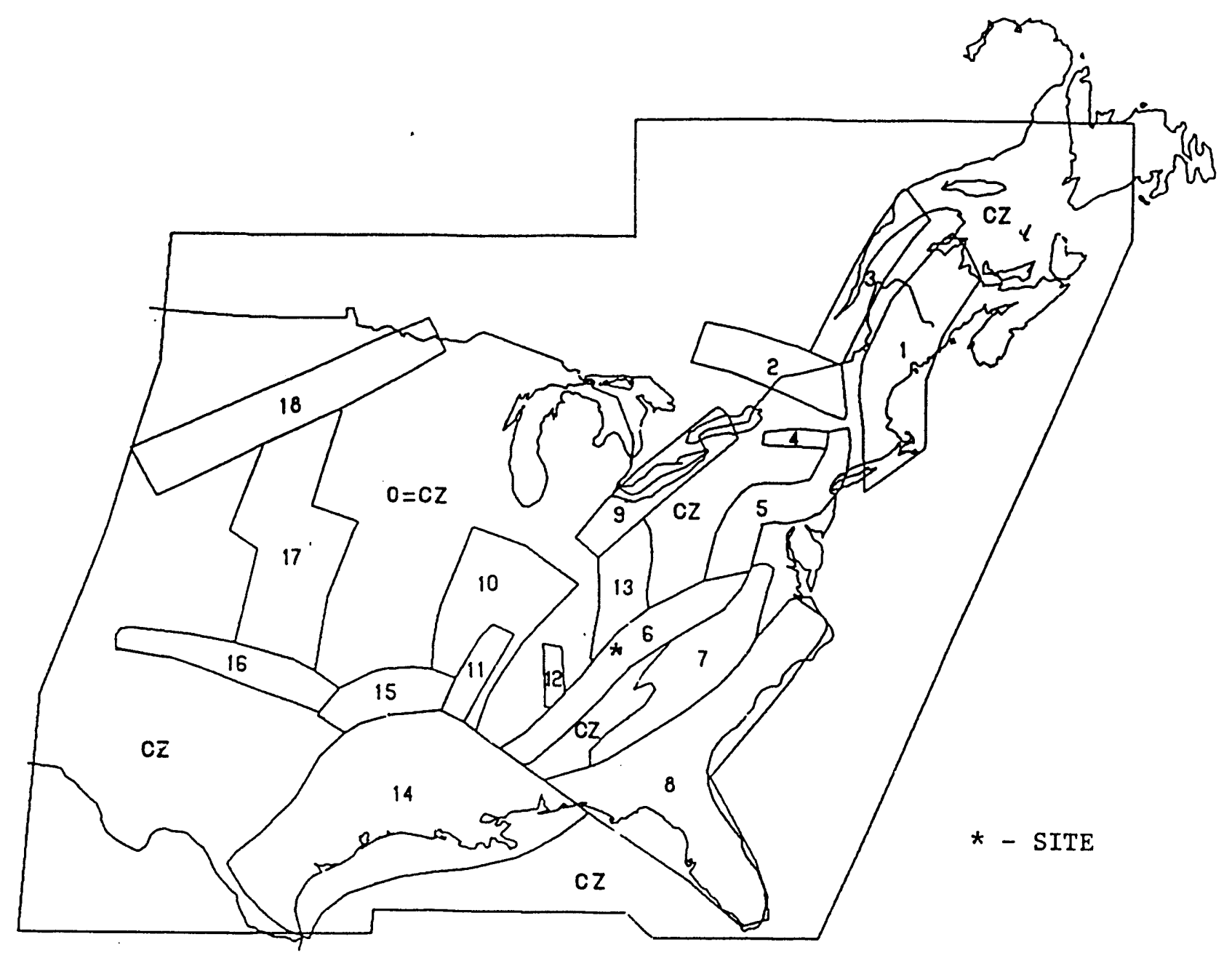

Figure 3-9. Main set of seismic sources provided by LLNL seismicity expert 11. Source: Volume 1 of (1). 


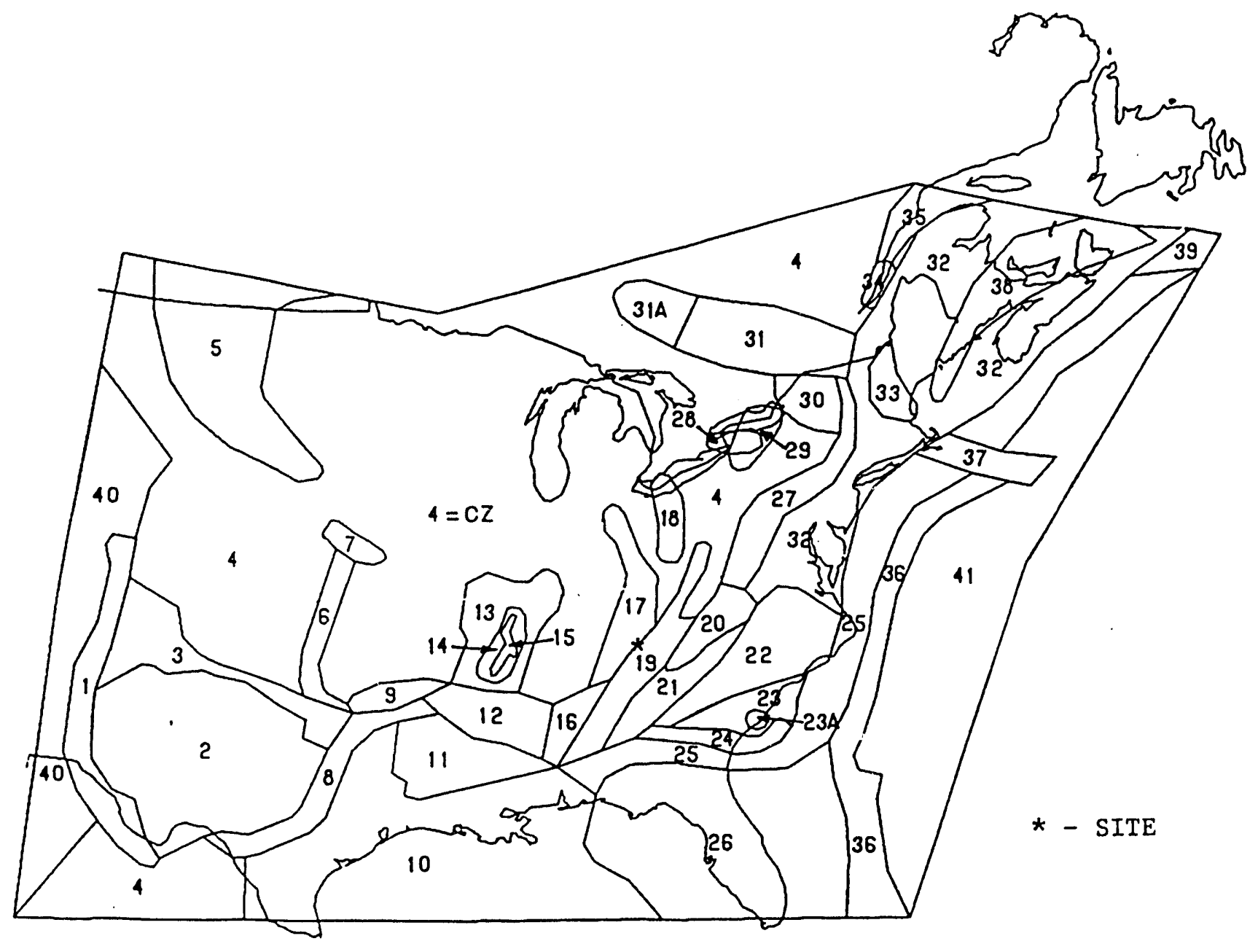

Figure 3-10. Main set of seismic sources provided by LLNL seismicity expert 12 . Source: Volume 1 of $(\underline{1})$. 


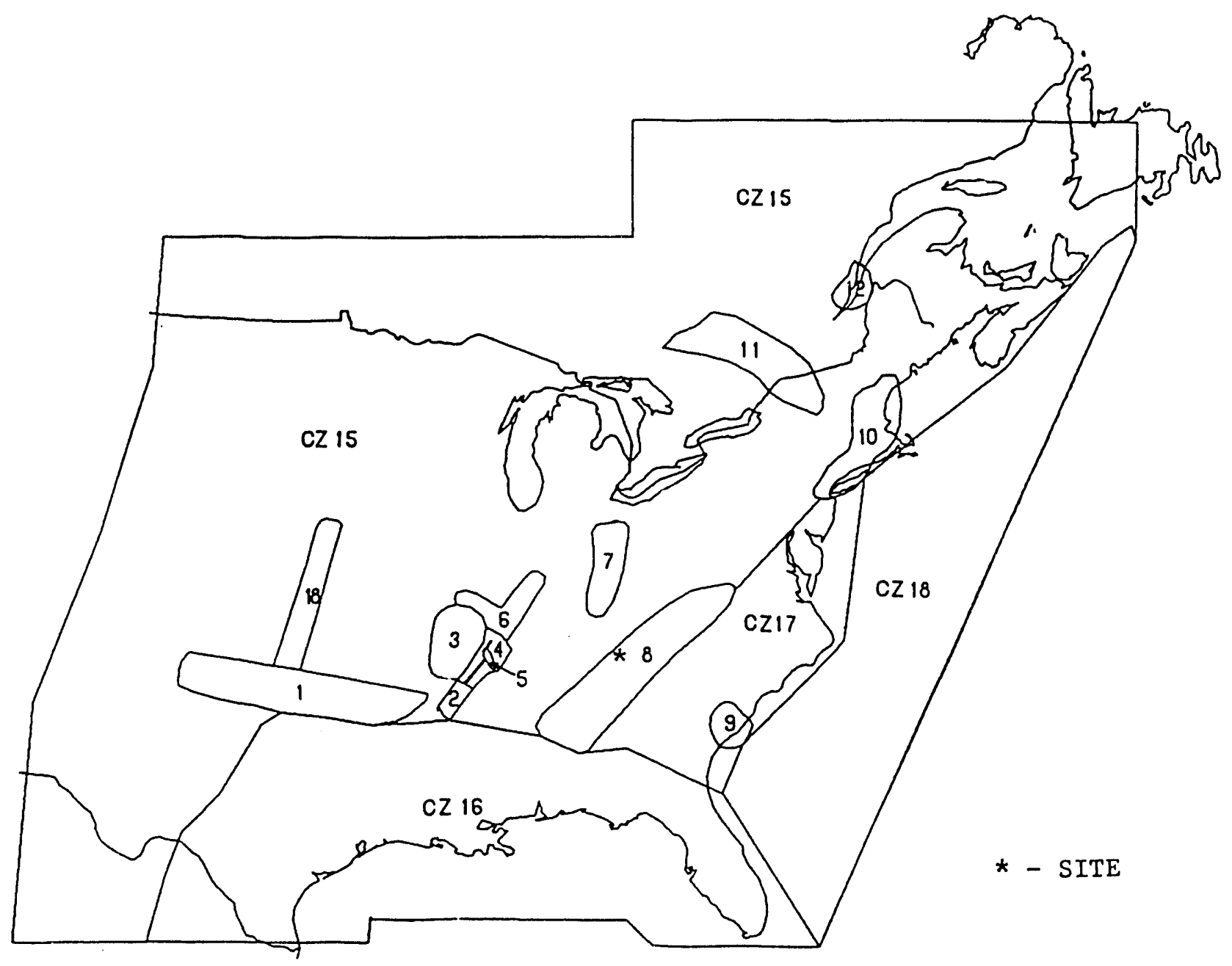

Figure 3-11. Main set of seismic sources provided by LLNL seismicity expert 13 . Source: Volume 1 of (1). 


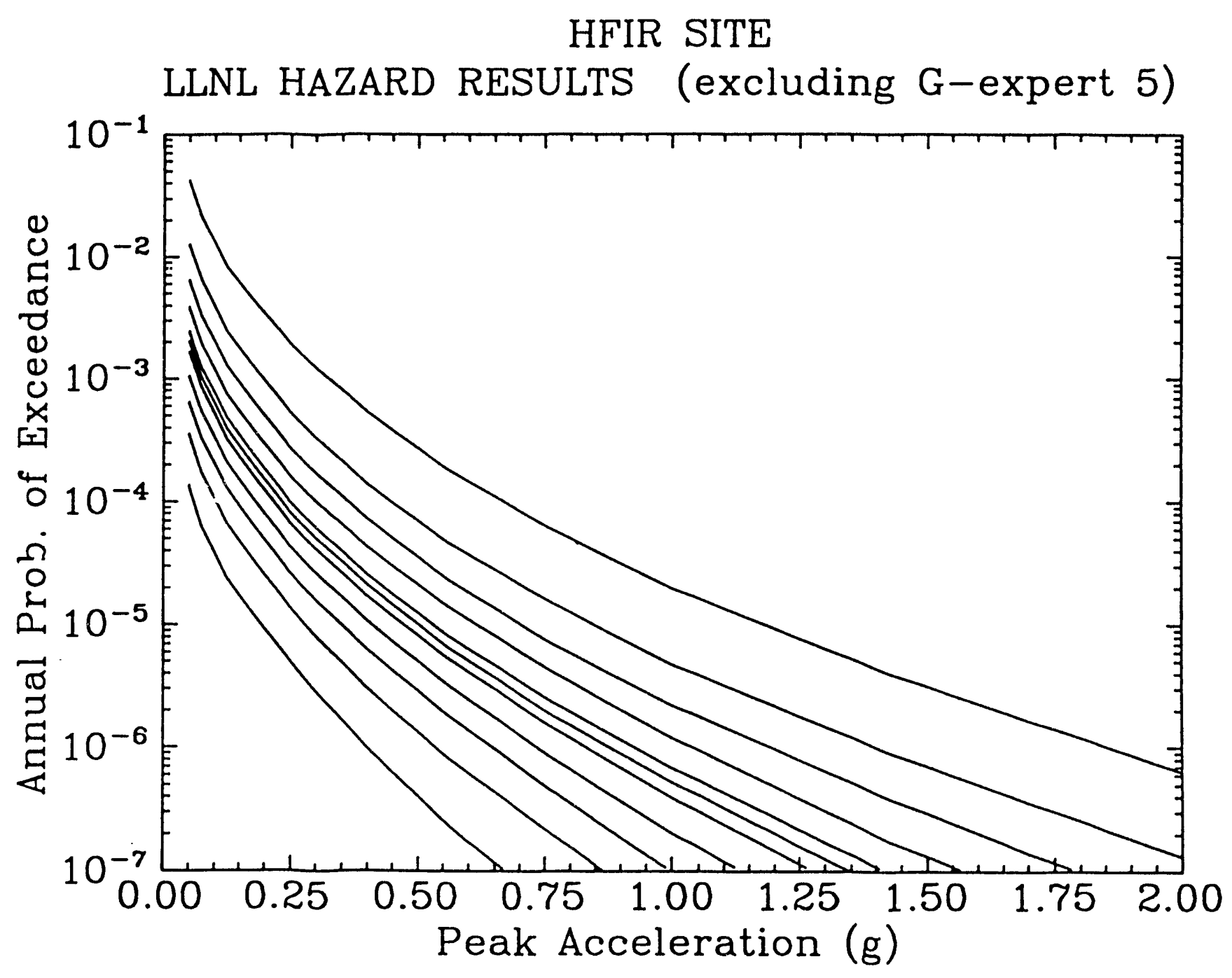

Figure 3-12. Seismic hazard at HFIR computed by LLNL using the LLNL methodology (excluding LLNL ground-motion expert 5). Results shown as fractile hazard curves for peak acceleration. The curves shown correspond to the following fractiles: 0.05 (bottom), 0.15 , $0.25,0.35,0.45,0.50,0.55,0.65,0.75,0.85,0.95$ (top). 


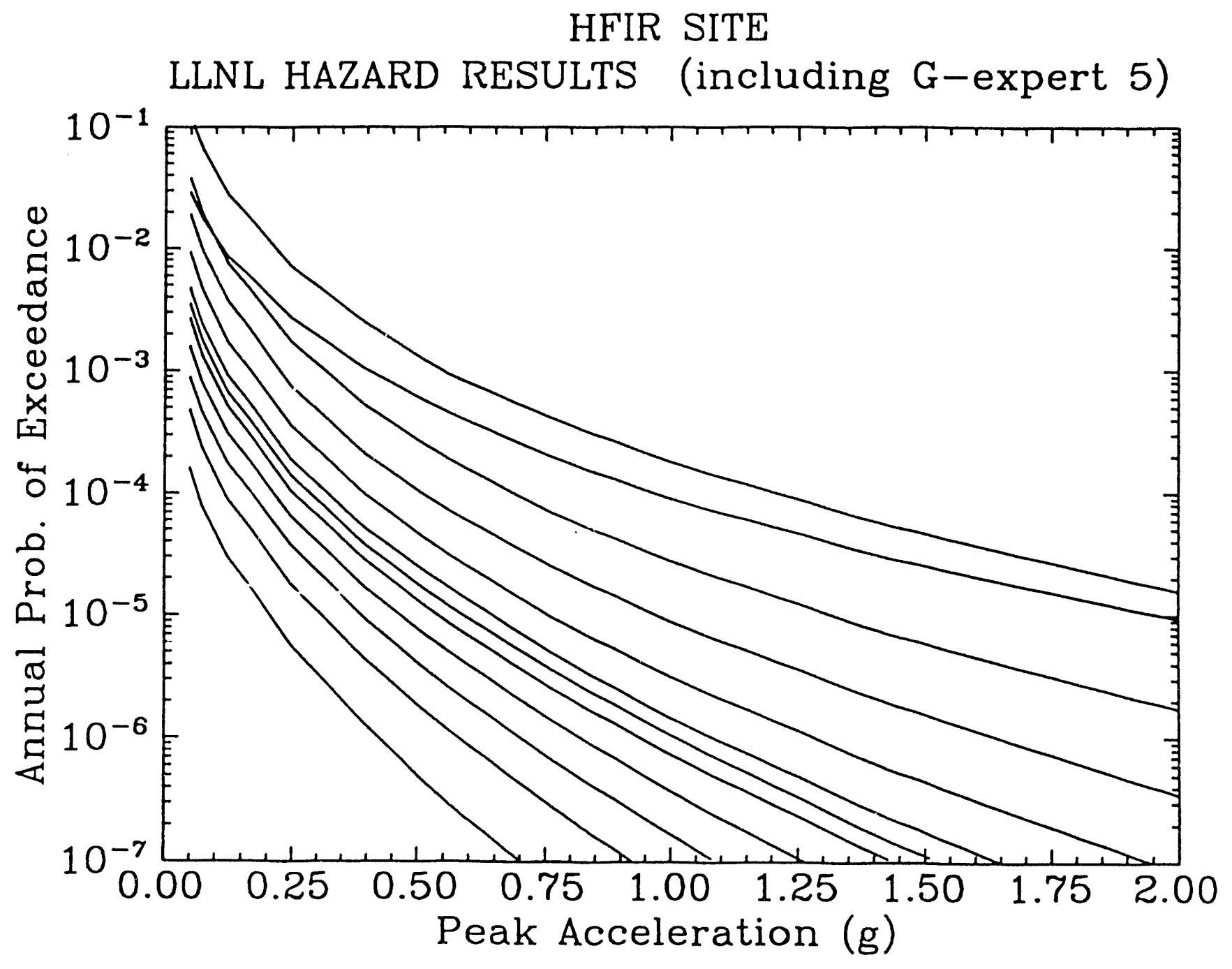

Figure 3-13. Seismic hazard at HFIR computed by LLNL using the LLNL methodology (including LLNL ground-motion expert 5). Results shown as fractile hazard curves for peak acceleration. The curves shown correspond to the following fractiles: 0.05 (bottom), 0.15 , $0.25,0.35,0.45,0.50,0.55,0.65,0.75,0.85,0.95$ (top). 


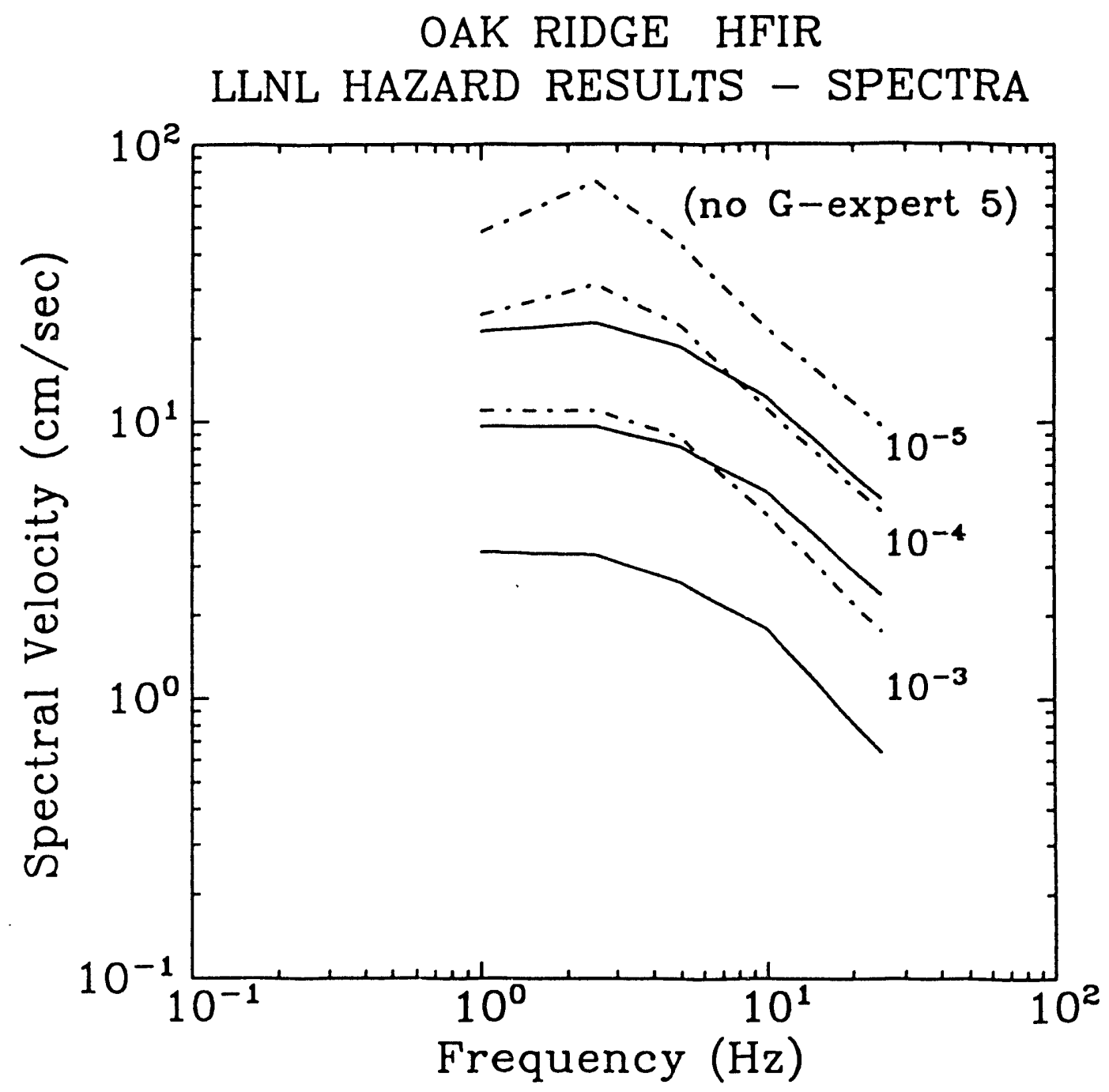

Figure 3-14. Seismic hazard at HFIR computed by LLNL using the LLNL methodology (excluding LLNL ground-motion expert 5). Results shown as median (solid) and 85-percentile (dot-dash) uniform hazard spectra for three values of the annual probability of exceedance. 


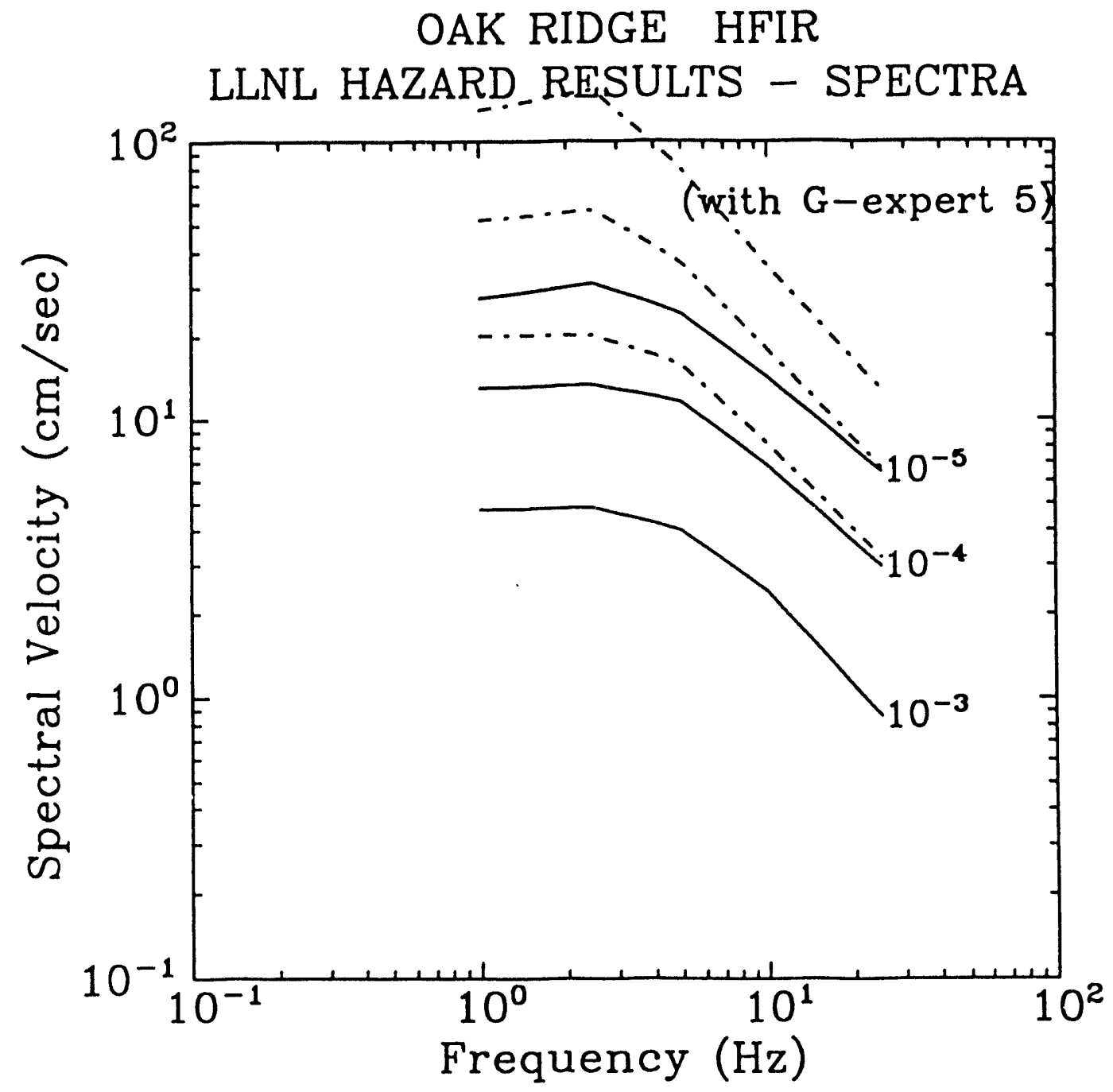

Figure 3-15. Seismic hazard at HFIR computed by LLNL using the LLNL methodology (including LLNL ground-motion expert 5). Results shown as median (solid) and 85-percentile (dot-dash) uniform hazard spectra for three values of the annual probability of exceedance. 


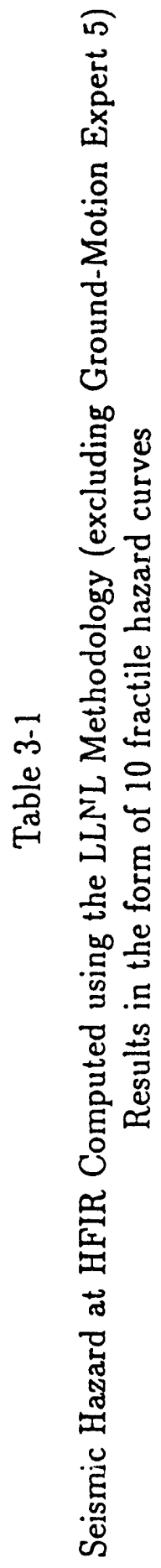

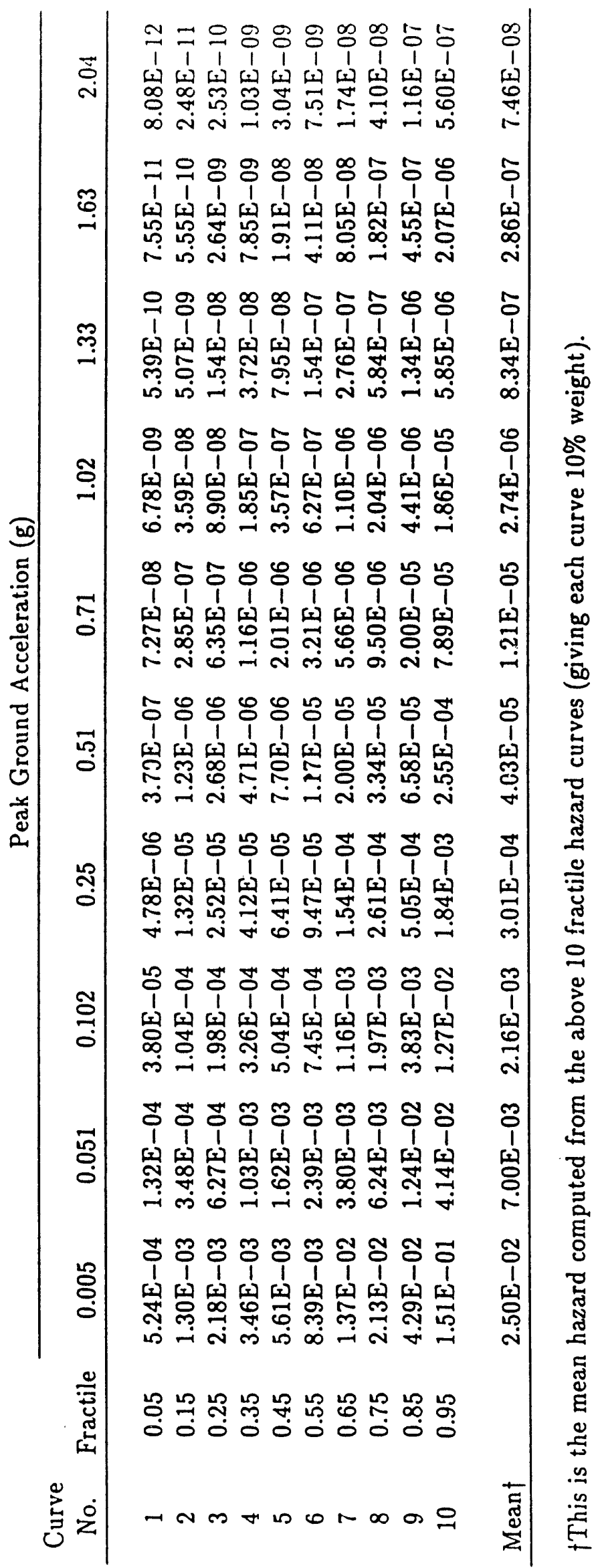




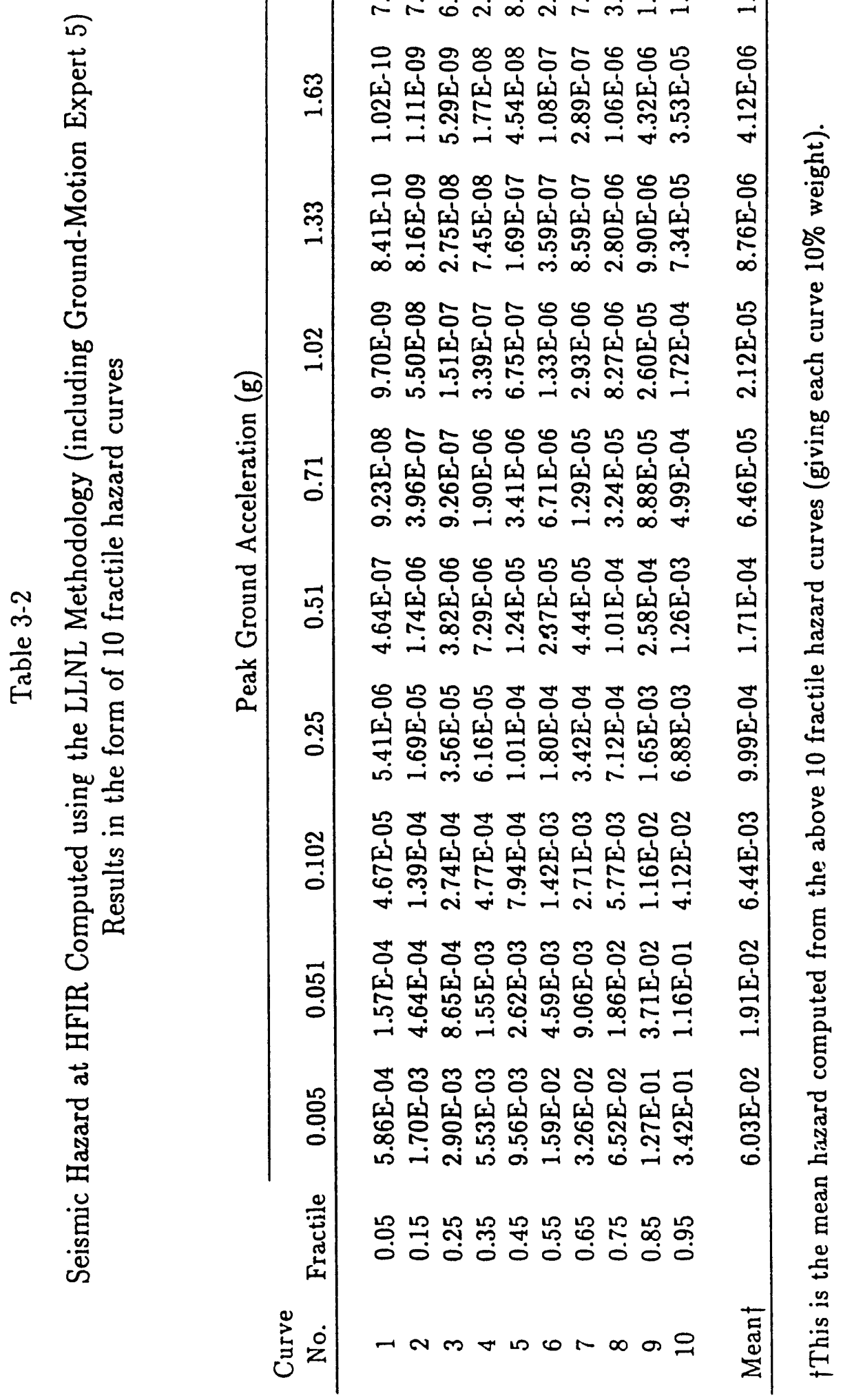


Section 4

RESULTS

\subsection{OVERVIEW}

This Section describes the procedure used to combine the EPRI/SOG and LLNL seismic hazard results presented in Sections 2 and 3, in order to obtain a synthesized representation of seismic hazard and its uncertainty at the Oak Ridge-HFIR site. Results are then presented as a family of hazard curves to be used as input for the PRA analysis. The hazard curves for spectral velocities are also combined and used to generate uniform-hazard spectra.

At the request of the client, we have developed two sets of results, which correspond to LLNL results with and without LLNL ground-motion expert 5 . In our opinion, only the results without LLNL expert 5 should be used.

\subsection{COMBINATION OF EPRI/SOG AND LLNL RESULTS}

The EPRI/SOG and LLNL results are given equal weights to obtain an overall representation of the seismic hazard and its uncertainty. The choice of equal weights is justified given the comparable caliber of the two studies. Both studies elicited interpretations by multiple experts - in order to capture all hypotheses with scientific validity-and both studies underwent extensive peer reviews. The EPRI/SOG and LLNL results for the HFIR site are compared in Figures 4-1 (without expert 5) and 4-2 (with expert 5).

For the development of combined hazard results, the EPRI/SOG results are represented by the 30 equally weighted hazard curves in Figure 2-14. The LLNL results are represented by 10 equally weighted hazard curves, which correspond to the $0.05,0.15, \ldots 0.95$ fractile curves, as shown in Figure 3-12 (without expert 5) and 3-13 (with: spert 5). The validity of the latter procedure is discussed in Section 4.3

These 40 hazard curves were transformed into 8 equivalent hazard curves by means of an aggregation algorithm that reduces the large number of hazard curves to a few, using a procedure that optimally determines how to combine sequentially, pairs of curves so that the character of the original curves will be maintained, and the set of aggregate curves will represent as much of the original uncertainty in hazard as possible, for each ground motion amplitude. The procedure uses the following steps: 
1. The hazard curves are characterized by the frequency of exceedance at three ground motion amplitudes, chosen as those most critical to the dectermination of plant response and system state. The total variance in frequency of exceedance at these three amplitudes is calculated.

2. A small number of possible aggregate curves is estimated by dividing the ranges of frequencies of exceedance into intervals and constructing a first set of aggregates at the centers of these intervals.

3. Each of the hazard curves is assigned to a tentative aggregate curve, based on its proximity in frequency-of-exceedance for the three amplitudes.

4. The tentative aggregate curves are re-computed as the conditional mean of the assigned curves.

5. Steps 3 and 4 are repeated, because step 4 may change the assignments based on proximity, until the tentative aggregate curves are stable (i.e. until there are no changes in assignments). A weight for each tentative aggregate curve is calculated as the sum of weights of the assigned curves.

6. All possible pairs of tentative aggregate curves are examined as candidates for combination; the pair that, when combined, will result in the minimum reduction in represented variance is selected and combined by computing the weighted average frequency of exceedance iur all three amplitudes. The combined curve is assigned a weight equal to the sum of the weights of the two curves used to calculate it.

7. Steps 3 through 6 are repeated to sequentially reduce the number of tentative aggregate curves. The process ends when the desired number of aggregate curves is reached.

8. The curve assignments are used to calculate aggregate hazard curves for all ground motion amplitudes; the weights given to each aggregate is the sum of the weights of the assigned curves.

There is no unique solution technique for aggregating a discrete, multi-dimensional distribution, but the above algorithm has been tested for a number of seismic hazard problems and works well. Typically, six to twelve aggregate curves can be constructed with this algorithm; these aggregate curves generally replicate greater than 90 percent of the total variance of the original data set, for all ground motion amplitudes. The algorithm also conserves differences in the siopes of the original hazard curves. 
The 8 hazard curves obtained with the aggregation algorithm are shown in Figure 4-3 and Table 4-1 (without expert 5) and in Figure 4-4 and Table 4-2 (with expert 5), in a format suitable for input to PRA analysis.

To generate uniform-hazard spectra corresponding to the combination of the EPRI/SOG and LLNL studies, we combined the hazard curves for spectral velocities at $1,2.5,5,10$, and $25 \mathrm{~Hz}$. For each frequency, 30 EPRI hazard curves were combined with 10 LLNL hazard curves, as was done for peak acceleration. We then used the resulting 40 hazard curves, and their weights, to compute fractile hazard curves and read the spectral velocities where the median and 0.84 fractile hazard curves reach exceedance probabilities of $10^{-3}, 10^{-4}$, and $10^{-5}$. The resulting spectra are shown in Figures 4-5 through 4-7 (without expert 5) and Figures 4-8 through 4-10 (with expert 5).

\subsection{TREATMENT OF LLNL MEAN HAZARD}

A reviewer for the U.S. Department of Energy has pointed out that the procedure of representing the LLNL hazard results by 10 equally weighted hazard curves (with these 10 curves defined as the $0.05,0.15, \ldots 0.95$ fractile hazard curves) does not preserve the "exact" mean hazard (which was calculated by LLNL considering thousands of original hazard curves emanating from their Monte Carlo simulation). The reviewer contends that the mean core-damage frequencies calculated from the synthesized EPRI/SOG-LLNL hazard curves are in error because the LLNL "exact" mean hazard has not been preserved.

The above argument ignores the fact that the LLNL "exact" mean-hazard curves are highly unreliable. This lack of reliability is due to two main reasons, as follows:

1. The LLNL seismicity experts were allowed to draw zone boundaries and assign seismicity parameters based entirely on their judgment, without requiring any formal statistical analysis or ensuring that the expert's assessments are consistent with the data. As a result, some seismicity experts made assumptions and assigned parameter ranges that are incompatible with existing data and with our knowledge of earthquakes in CEUS ${ }^{1}$. Unlikely combinations of erroneous parameter values often lead to

\footnotetext{
${ }^{1}$ Consider, for example, LLNL expert 13's source 8, which is this expert's host zone for HFIR. The upper-limit seismicity parameters for this source are $a=4.72$ and $b=-0.85$, which imply an annual rate of earthqua'ies with $m_{b}>5$ equal to 2.9 per year. The rate of $m_{b}>6$ is 0.4 per year (or 1 event every 2.5 years). These values are clearly incornpatible with our earthquake catalogs, but they are still used in the computations. Admittedly, the probability associated with this combination of $a$ and $b$ is very low, but the associated hazards are extremely high and may control the meañ hazàid.
} 
extremely high individual hazards curves, which dominate the mean hazard in spite of their very low weights. Other central measures of the hazard, particularly the median, are affected much less by these "outlier assumptions".

2. The Monte Carlo simulation procedure used by LLNL exacerbates the problem above. If the expert's parameters lead to very skewed distribution of the hazard, the simulation will produce unstable estimates of the mean, unless the number of samples is greatly increased.

As a result of these problems with the "exact"-LLNL mean hazard curve, it is not desirable to match this curve. The mean hazard that one computes from our 10-curve representation of the LLNL results, is a much more stable quantity, less sensitive to outlier assumptions and to instability introduced by the simulation. The mean hazard obtained from these 10 curves is not incorrect and is very much in the spirit of robust statistics (1).

We have discussed this issue with one member of the LLNL staff ( $\underline{2})$, and he is in general agreement with the argument stated above. Furthermore, he stated the following points:

- The processes of elicitation of expert opinion and calculations in the LLNL methodology were not designed to provide an accurate assessment of the mean hazard. As a result, he does not have a high level of confidence on the mean.

- In applications that require a mean estimate of the hazard, LLNL staff prefer to use a "pseudo-mean", instead of the "exact" mean. The pseudo-mean is less sensitive to outliers; it is computed in terms of the median and the 0.85 -fractile of the hazard, without any regard for the "exact" mean.

In conclusion, our representation of th $=$ LLNL hazard in terms of 10 equally weighted hazard curves is not in error. The mean hazard implicit in these curves is a much more stable estimate of the mean LLNL hazard (without the errors), because it is affected less by outlier assumptions.

\subsection{CAUSES OF DIFFERENCES BETWEEN EPRI/SOG AND LLNL RESULTS}

This section explores the differences between input parameters used in the EPRI/SOG and LLNL calculations, which may explain observed differences in calculated hazard. 
The first source of differences between the two studies is attenuation functions. LLNL results for HFIR using all 5 ground-motion experts are significantly higher than EPRI results (see Figure 4-2). If one removes ground-motion expert 5 , the median and 0.15 -fractile results are very similar, but the LLNL 0.85 -fractile is considerably higher than EPRI for accelerations below $1 \mathrm{~g}$. Similar results have been obtained in ( $\underline{3})$ for 6 test sites.

Figures 4-11 and 4-12 compare the predictions by the EPRI/SOG and LLNL sets of attenuation functions. Again, these comparison show that the EPRI/SOG and LLNL (excluding expert 5) sets of attenuation functions predict similar ground motions.

Next, we focus on differences in the seismic zonations and seismicity parameters used by the various EPRI/SOG teams and LLNL experts. We will focus on their best-estimate and median values of the parameters, but we recognize that large differences in their uncertainty bands may also exist.

Table 4-3 contains a summary of the EPRI sources that dominate the calculated hazard at HFIR and their median seismicity parameters. The identification of dominant sources and the source's contributions are based on the screening performed in Section 2 (tables 2-8 through 2-13; some adjustments are required when combination sources are important). Activity in the host source or neighboring sources is characterized by its rate per unit area; activity in distant sources is characterized by its rate. Table 4-3 shows that the hazard is usually dominated by the host source, although the New Madrid source makes a modest contribution for $1-\mathrm{Hz}$ spectral velocity. The median rate of the various team's dominant sources is approximately $2 \times 10^{-7}$ events/year $/ \mathrm{km}^{2}$; the median value of the maximum magnitude is 6.8 .

Table 4-4 shows a similar table for the LLNL experts. The identification of dominant sources and the source's contributions are obtained from ( $\underline{4}$, tables 1.1 through 1.11 ; these results include ground-motion expert 5). Table 4-4 indicates that the New Madrid source dominates the hazard for three seismicity experts. Also, the Charleston source is an important contributor for two experts. The large influence of New Madrid and Charleston on these results is likely due to ground-motion expert 5 , whose attenuation functions have large magnitude coefficients (emphasizing large earthquakes) and small distance coefficients (emphasizing distant sources).

Results obtained without ground-motion expert 5 would most likely show that the host sources dominate the hazard. Focusing on the host sources, we find that their rates per 
unit area are similar to those specified by the EPRI teams. The median value of maximum magnitude is 6.4 , which is somewhat lower than the EPRI teams' value of 6.8 .

We conclude, therefore, that attenuation functions is the largest source of differences between the EPRI/SOG and LLNL results for HFIR. If LLNL ground-motion expert 5 is excluded, differences became small. The two studies use comparable values of the seismicity parameters for the host sources, which dominate the hazard if expert 5 is excluded. Small differences remain, however in the 0.85 -fractile results and in the median uniform-hazard spectra at low frequencies.

\subsection{REFERENCES}

1. P. J. Huber. Robust Statistics. Wiley, New York, 1981.

2. J. B. Savy. Personal communication, July 7, 1990.

3. R. K. McGuire, G. R. Toro, and W. J. Silva. Probabilistic Seismic Hazard Evaluations in the Central and Eastern United States - Appendix A: Model of Earthquake Ground Motion for the Central and Eastern United States. Technical Report, Electric Power Research Institute, 1989. EPRI Project RP101-53, prepared by Risk Engineering, Inc.

4. R. C. Murray. Letter to Harold F. Perla. Lawrence Livermore National Laboratory, March 8, 1990.

5. R. K. McGuire, G. R. Toro, J. P. Jacobson, T. F. O'Hara, and W. J. Silva. Probabilistic Seismic Hazard Evaluations in the Central and Eastern United States: Resolution of the Charleston Earthquake Issue. Special Report NP-6395-D, Electric Power Research Institute, April 1989. 


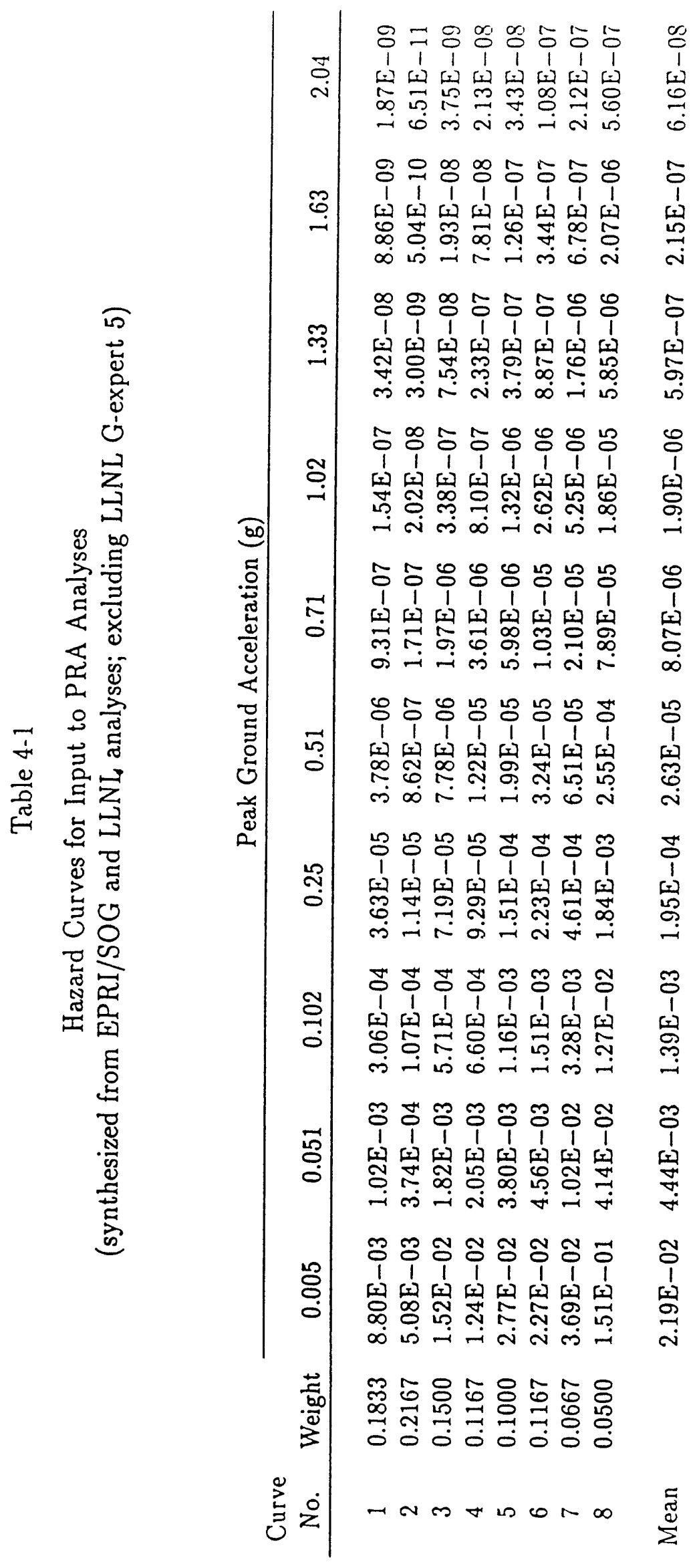




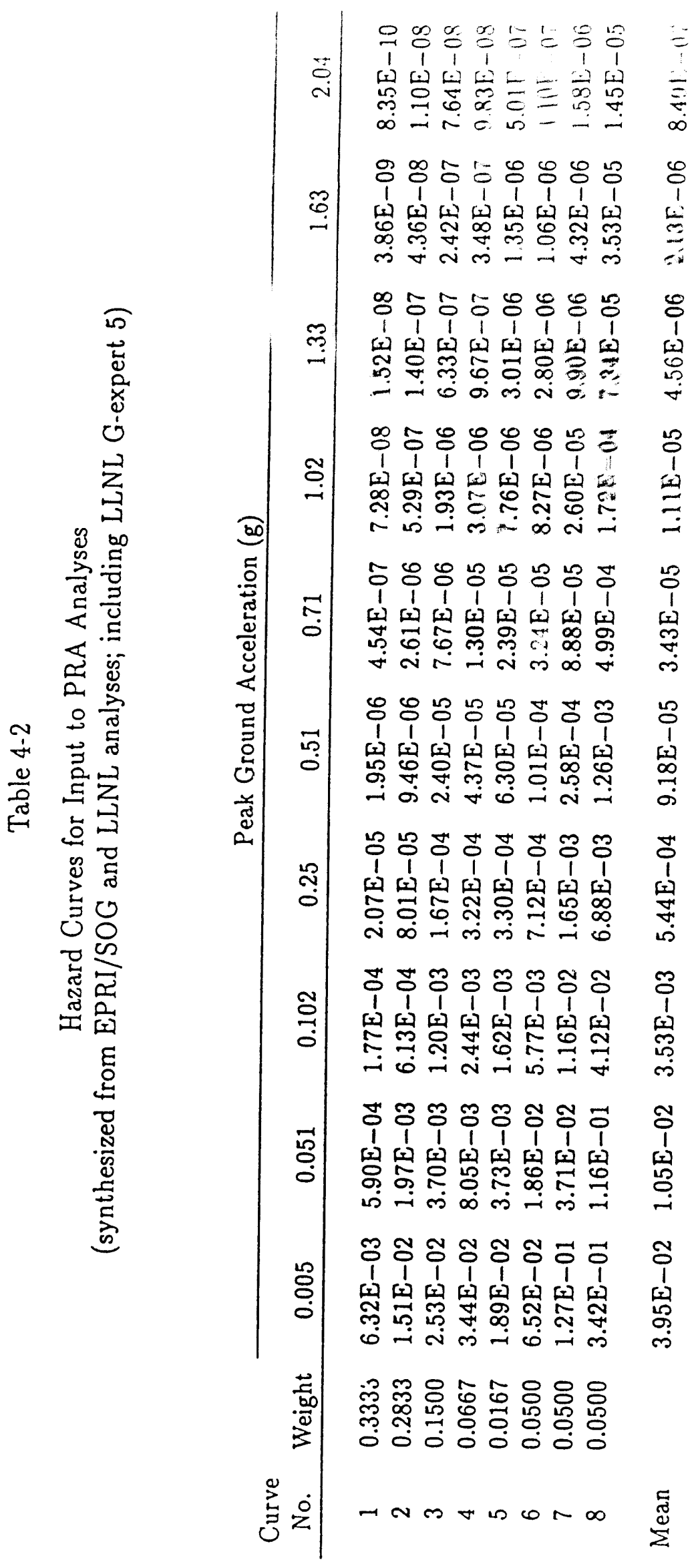




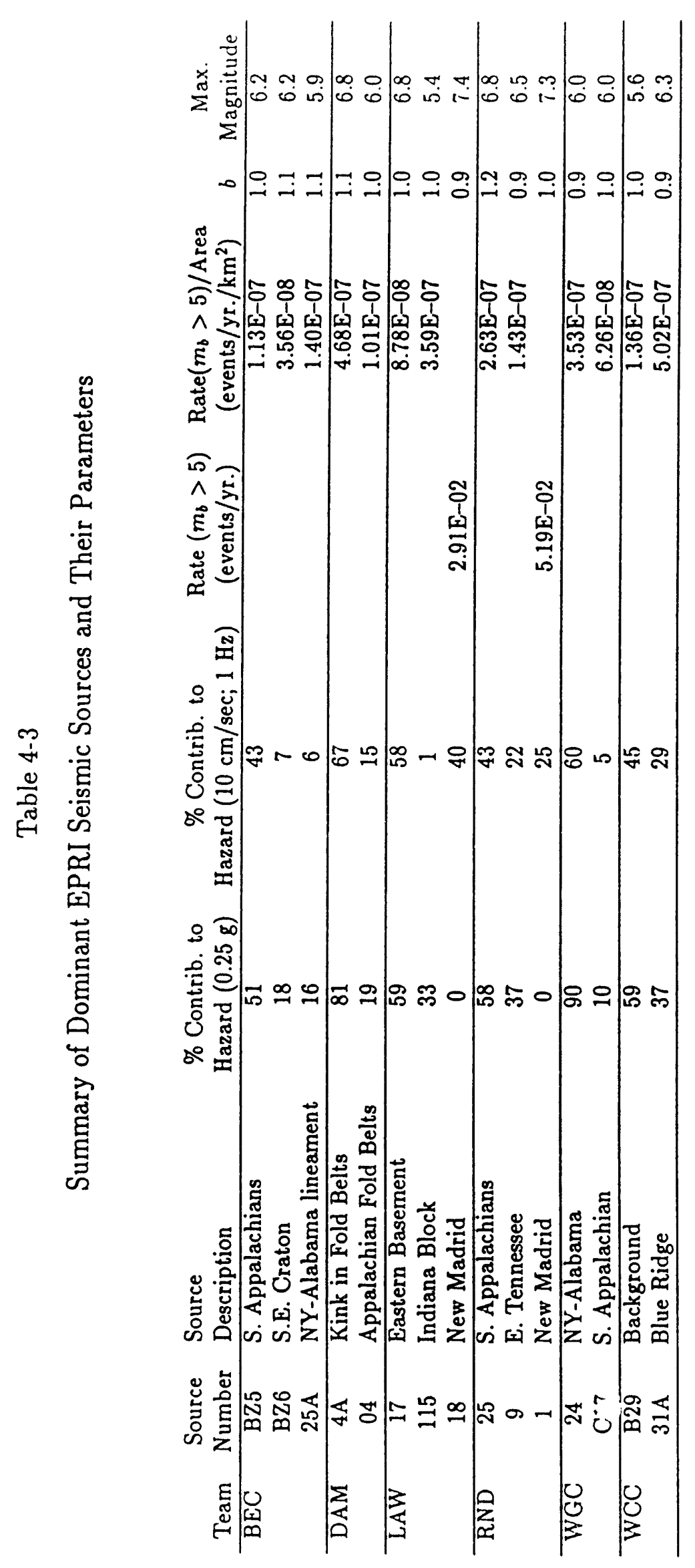




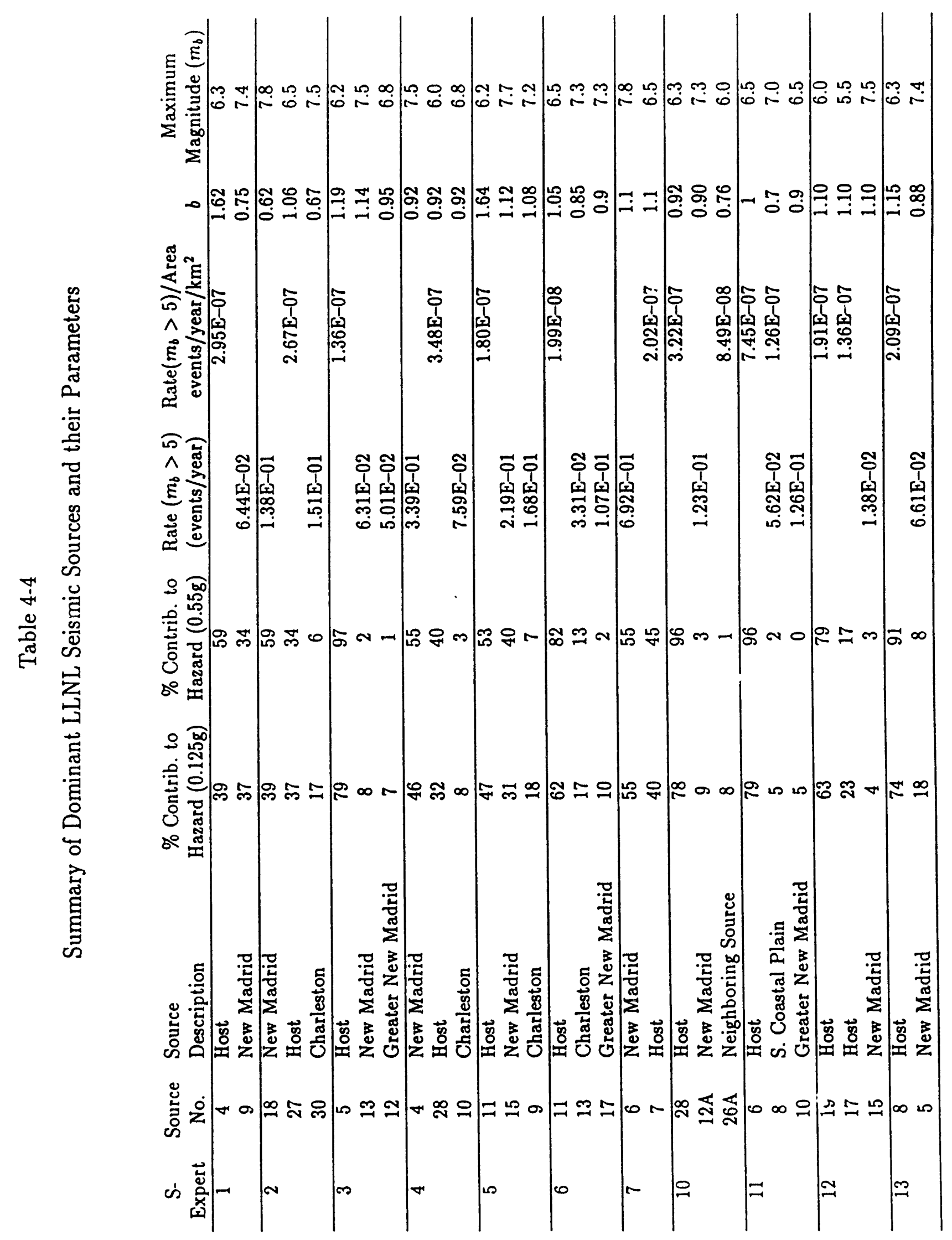




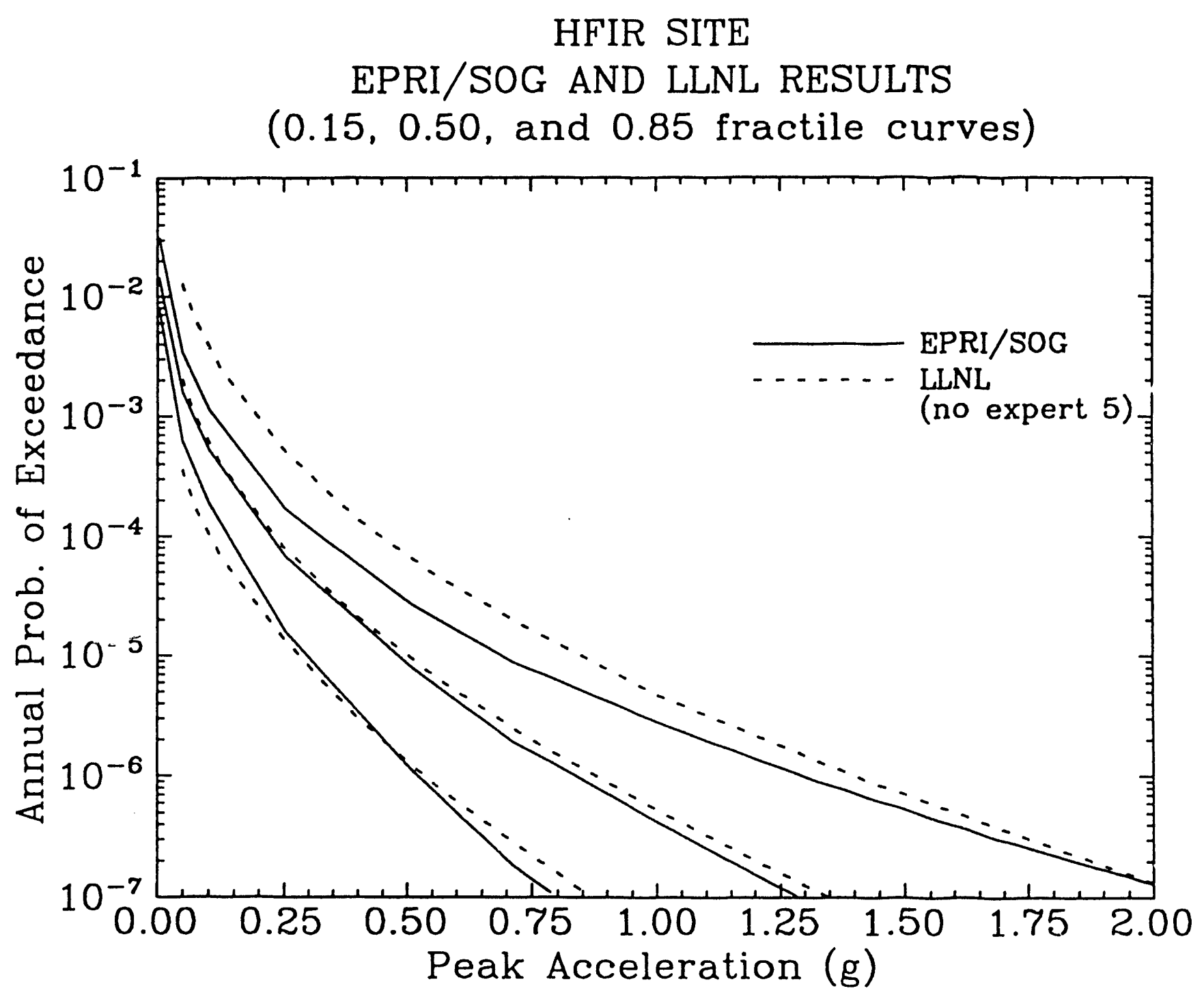

Figure 4-1. Comparison of EPRI/SOG and LLNL hazard results (excluding LLNL groundmotion expert 5). 


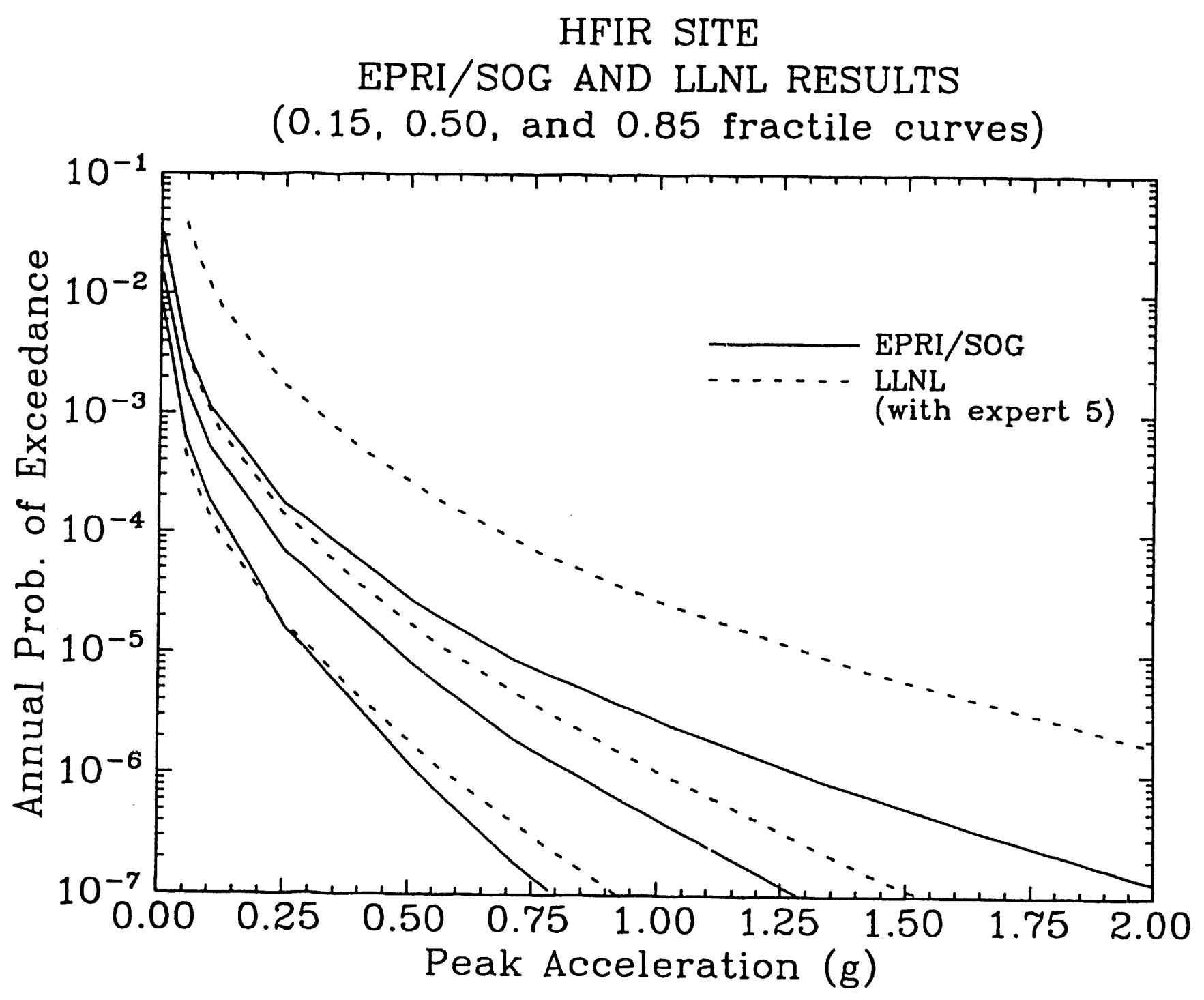

Figure 4-2. Comparison of EPRI/SOG and LLNL hazard results (including LLNL groundmotion expert 5). 


\section{HFIR SITE \\ COMBINED RESULTS - 8 AGGREGATE CURVES \\ (excluding LLNL G-expert 5)}

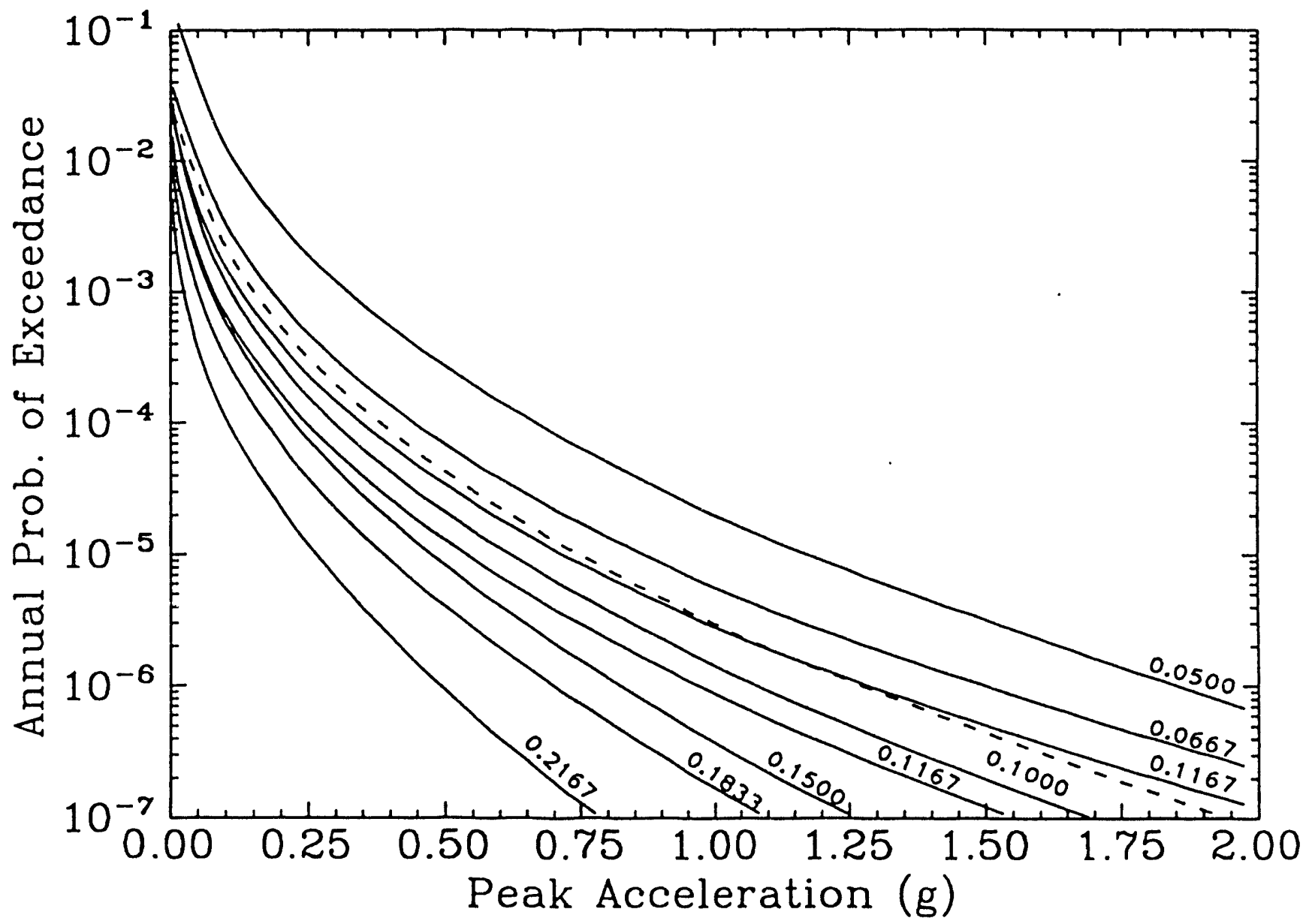

Figure 4-3. Hazard curves for input for PRA analyses. Synthesized from EPRI/SOG and LLNL analyses (excluding LLNL ground-motion expert 5). The dashed line represents the mean hazard curve. 
HFIR SITE

COMBINED RESULTS - 8 AGGREGATE CURVES

(including LLNL G-expert 5)

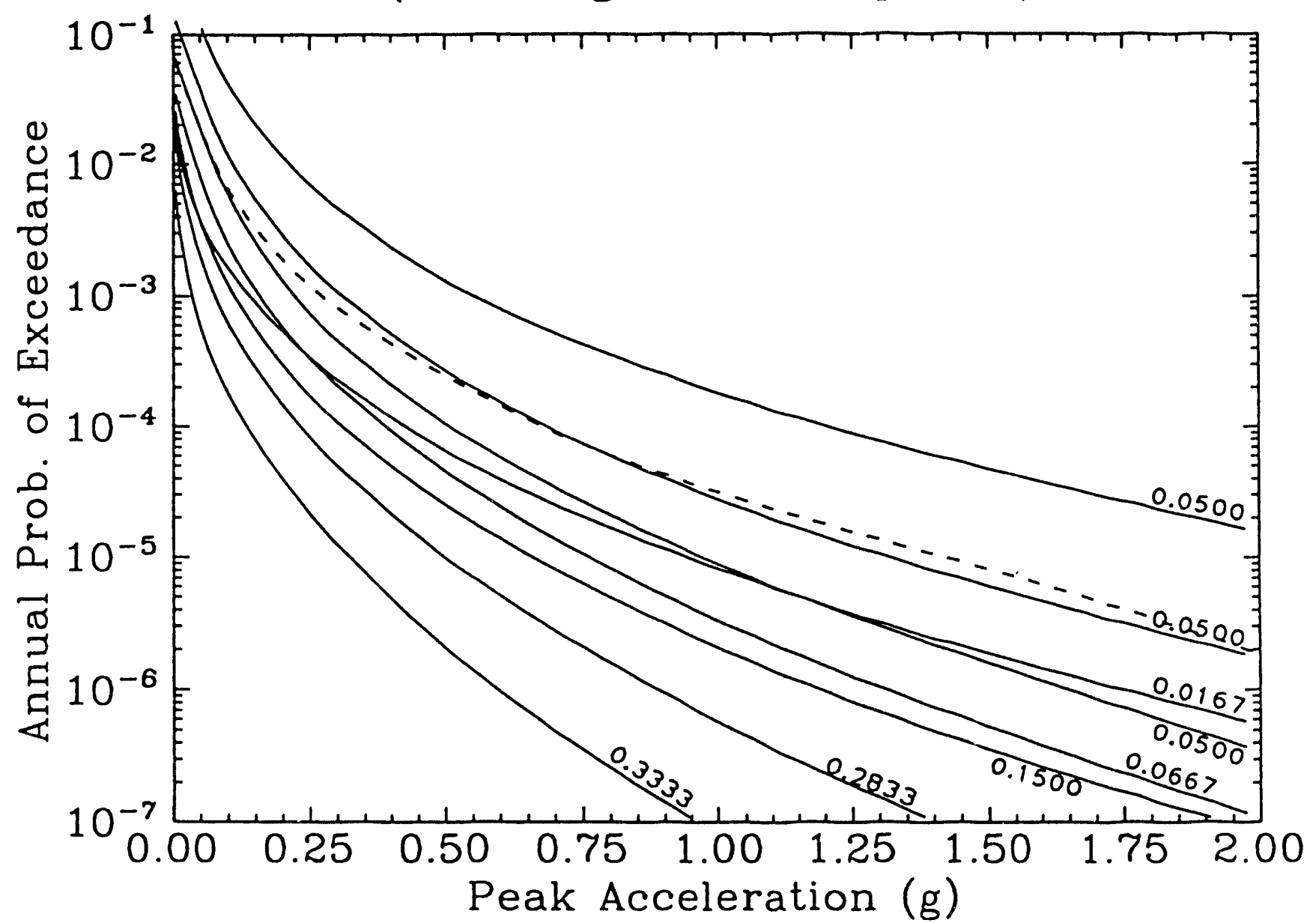

Figure 4-4. Hazard curves for input for PRA analyses. Synthesized from EPRI/SOG and LLNL analyses (including LLNL ground-motion expert 5). The dashed line represents the mean hazard curve. 


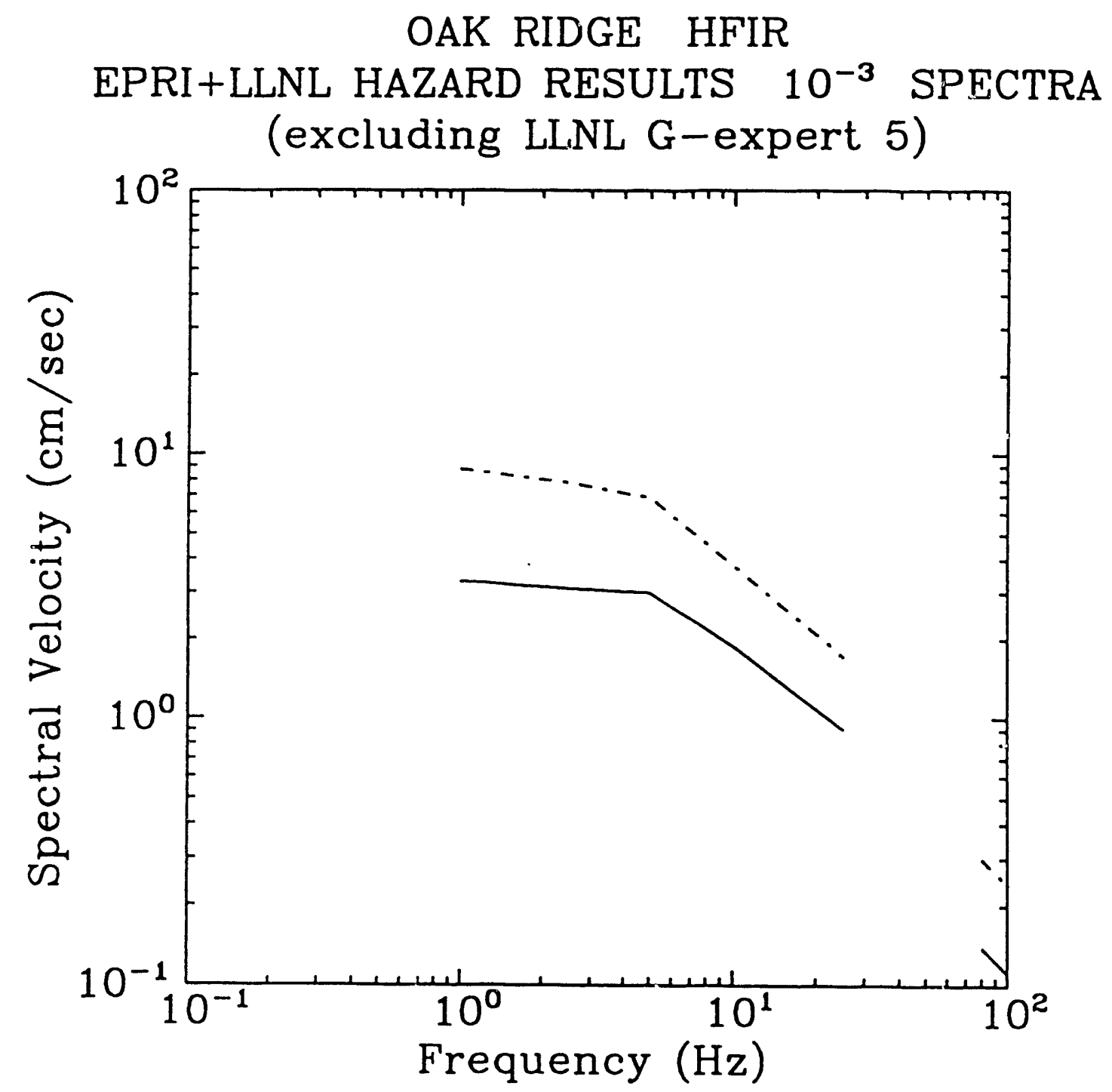

Figure 4-5. Uniform-hazard spectra synthesized from EPRI/SOG and LLNL analyses (excluding LLNL ground-motion expert 5 ).; $10^{-3}$ exceedance probability. Solid line: median spectrum; dot-dash line: 85-percentile spectrum. 


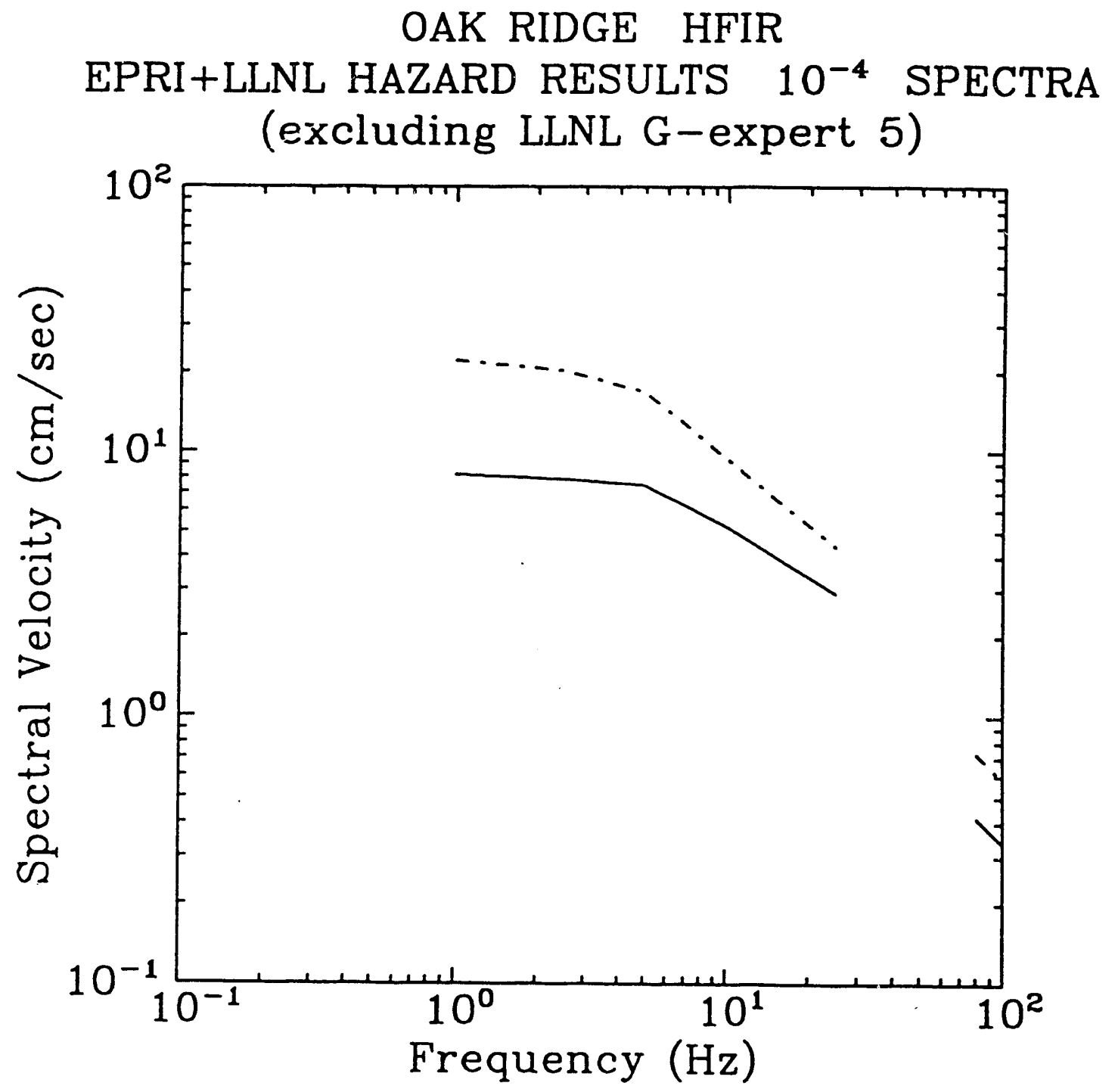

Figure 4-6. Uniform-hazard spectra synthesized from EPRI/SOG and LLNL analyses (excluding LLNL ground-motion expert 5).; $10^{-4}$ exceedance probability. Solid line: median spectrum; dot-dash line: 85 -percentile spectrum. 


\section{OAK RIDGE HFIR}

EPRI+LLNL HAZARD RESULTS $10^{-5}$ SPECTRA (excluding LLNL G-expert 5)

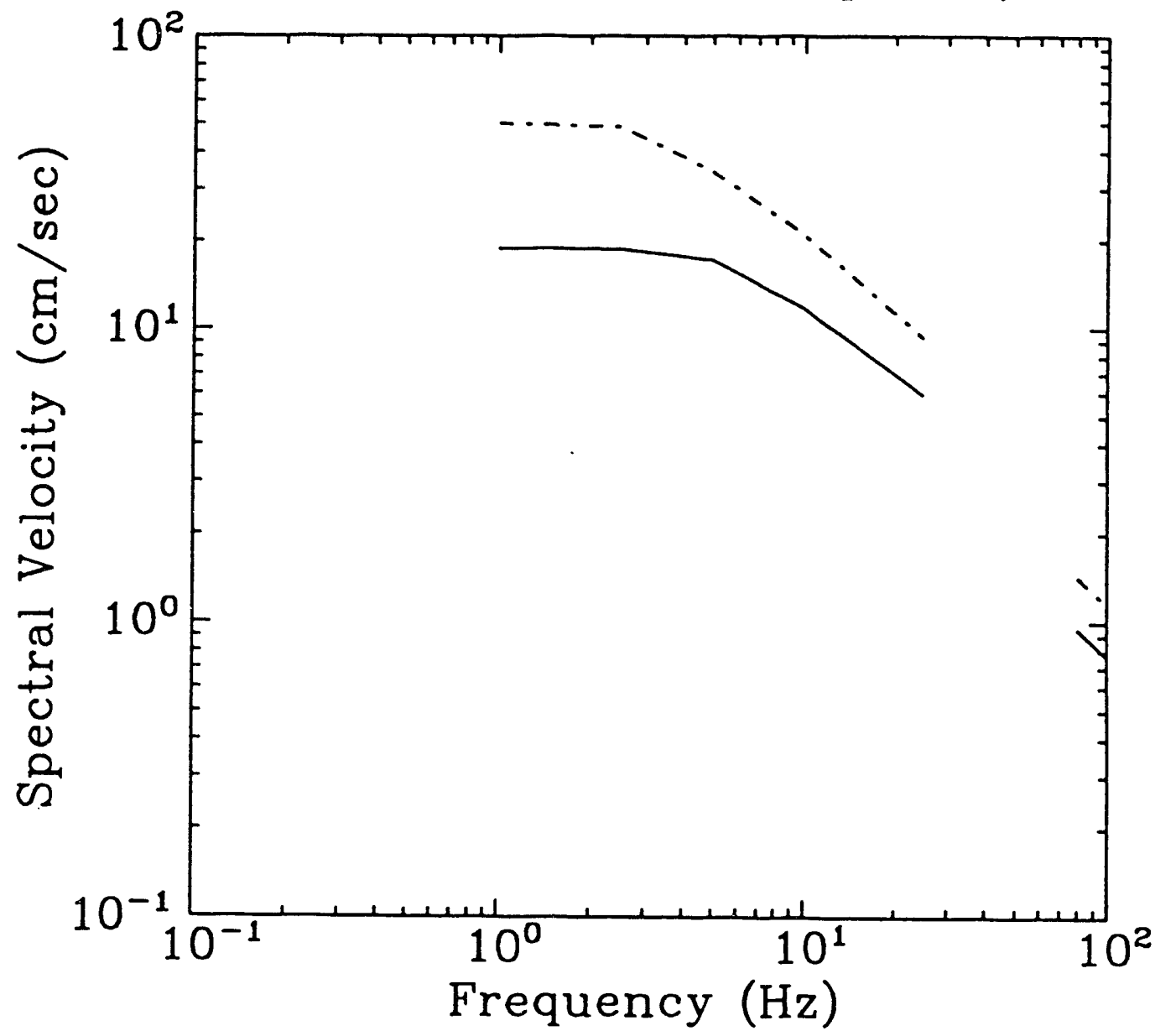

Figure 4-7. Uniform-hazard spectra synthesized from EPRI/SOG and LLNL analyses (excluding LLNL ground-motion expert 5 ).; $10^{-5}$ exceedance probability. Solid line: median spectrum; dot-dash line: 85-percentile spectrum. 


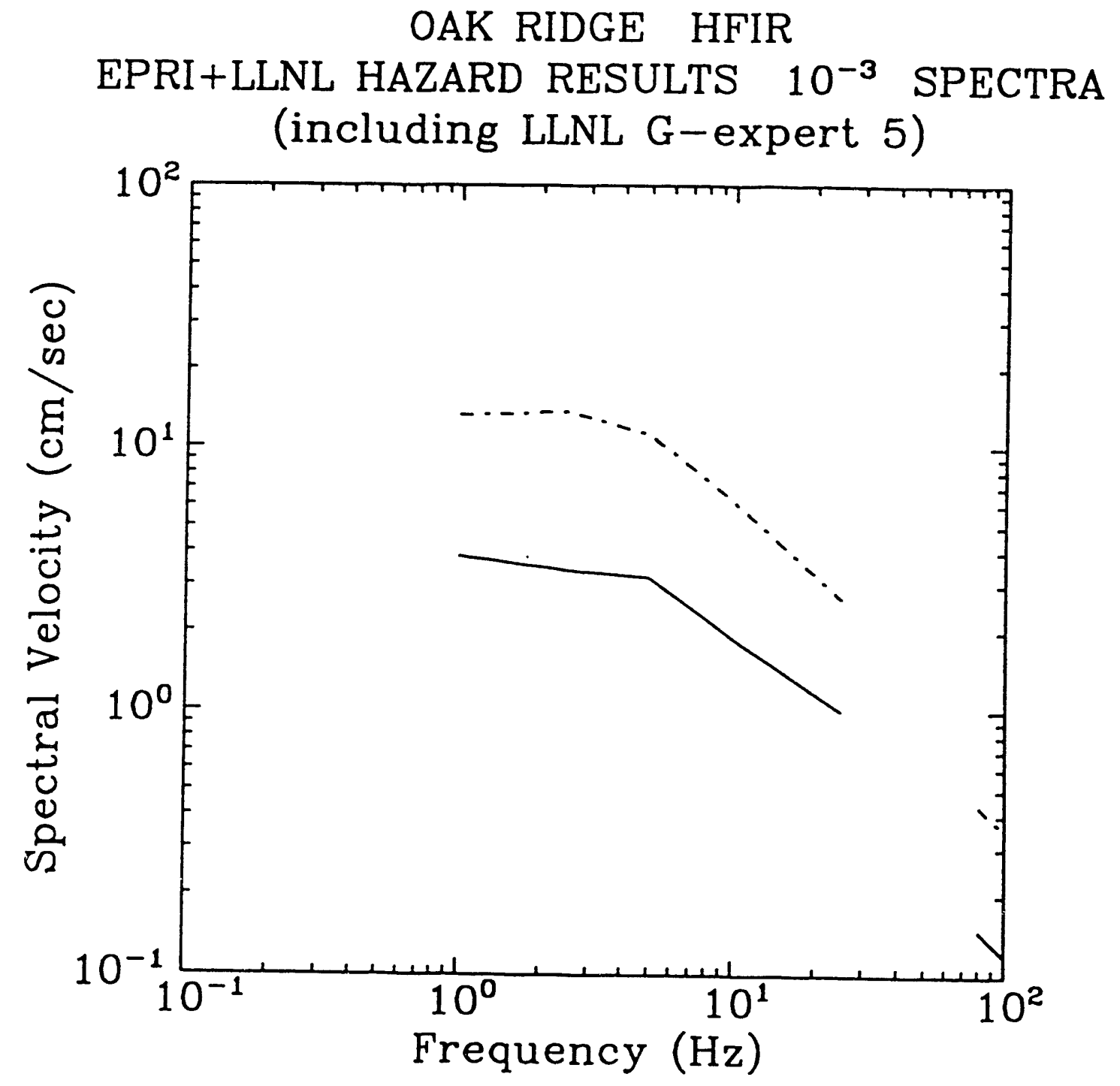

Figure 4-8. Uniform-hazard spectra synthesized from EPRI/SOG and LLNL analyses (including LLNL ground-motion expert 5).; $10^{-3}$ exceedance probability. Solid line: median spectrum; dot-dash line: 85 - percentile spectrum. 
OAK RIDGE HFIR

EPRI+LLNL HAZARD RESULTS $10^{-4}$ SPECTRA (including LLNL G-expert 5)

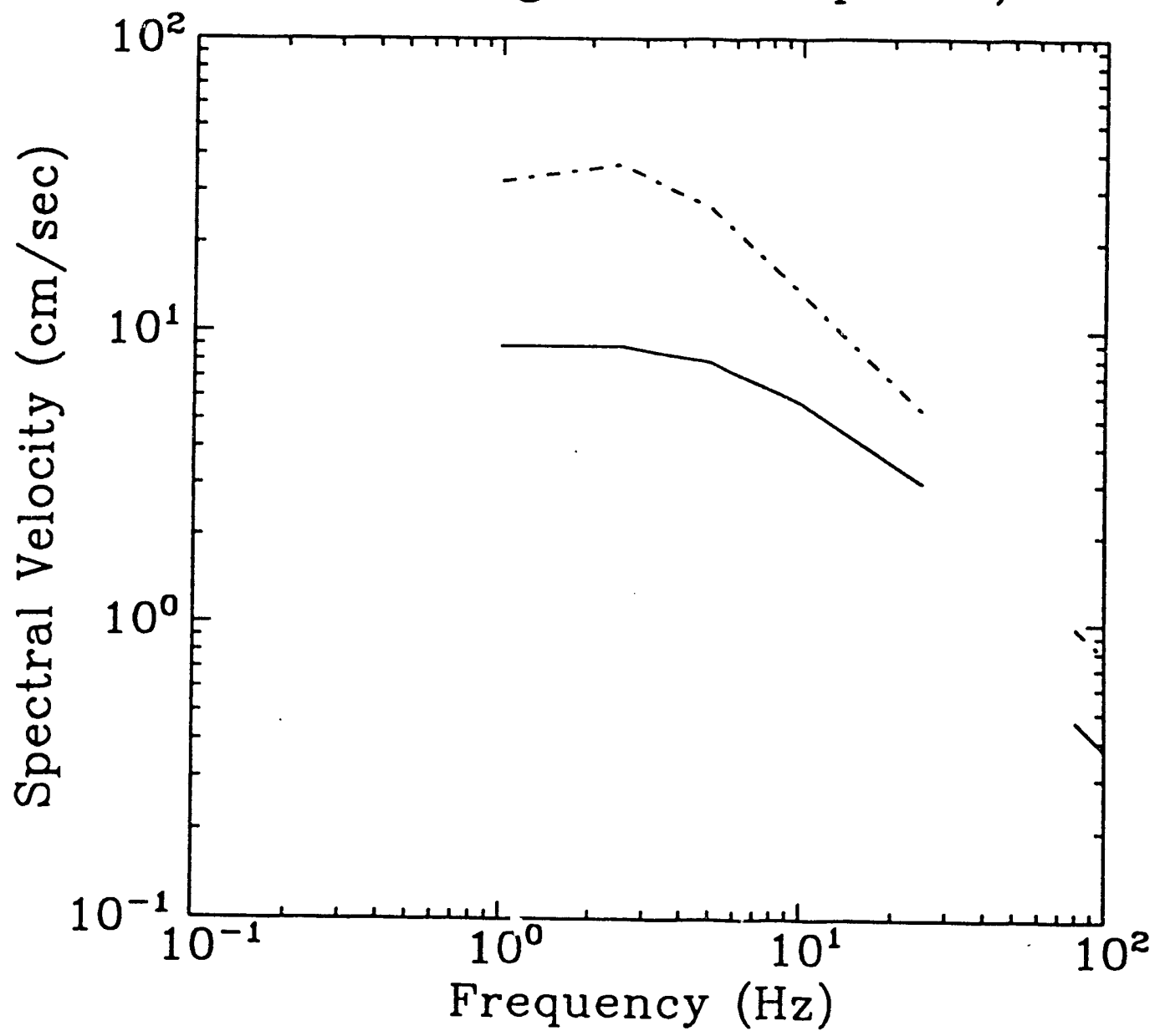

Figure 4-9. Uniform-hazard spectra synthesized from EPRI/SOG and LLNL analyses (including LLNL ground-motion expert 5).; $10^{-4}$ exceedance probability. Solid line: median spectrum; dot-dash line: 85-percentile spectrum. 


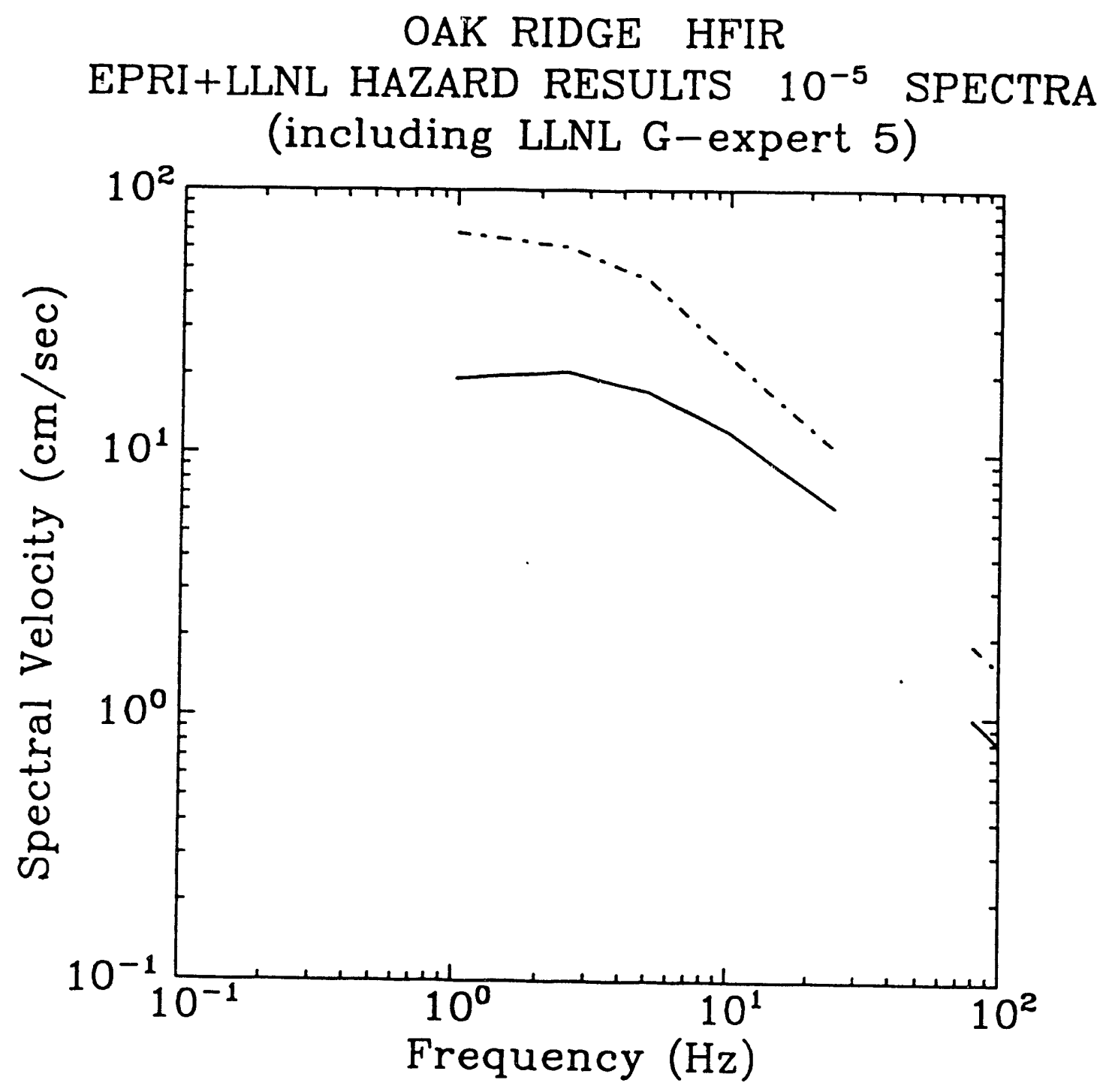

Figure 4-10. Uniform-hazard spectra synthesized from EPRI/SOG and LLNL analyses (including LLNL ground-motion expert 5).; $10^{-5}$ exceedance probability. Solid line: median spectrum; dot-dash line: 85-percentile spectrum. 


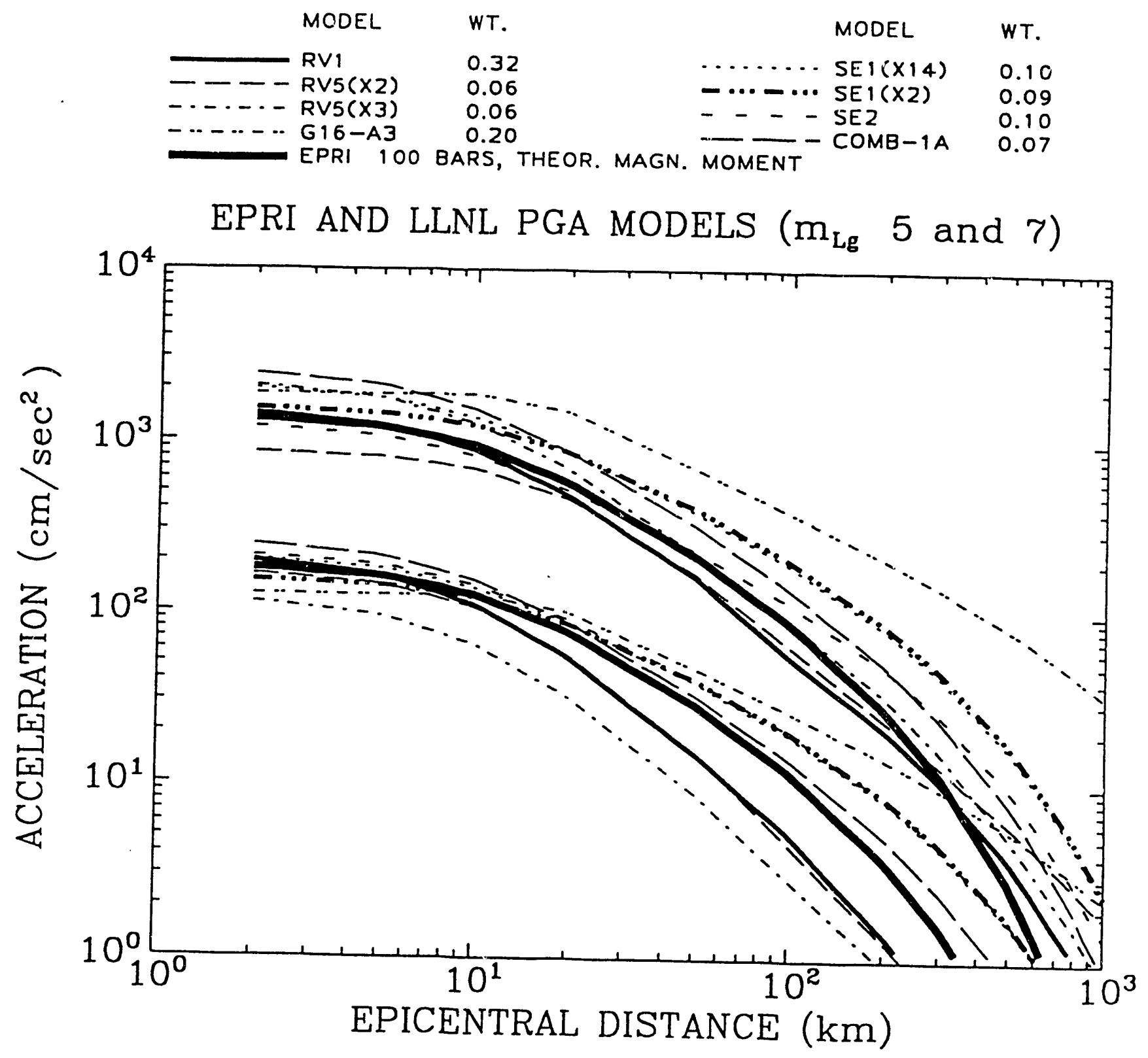

Figure 4-11. Comparison of predicted peak acceleration by the EPRI/SOG and LLNL attenuation equations. Predictions are shown for $m_{b} 5$ and 7. Models used by EPRI/SOG only are shown as heavy lines; models used by both EPRI and LLNL are used as medium-weight lines; models used by LLNL only are shown as thin lines. Source: ( $\underline{5})$ 


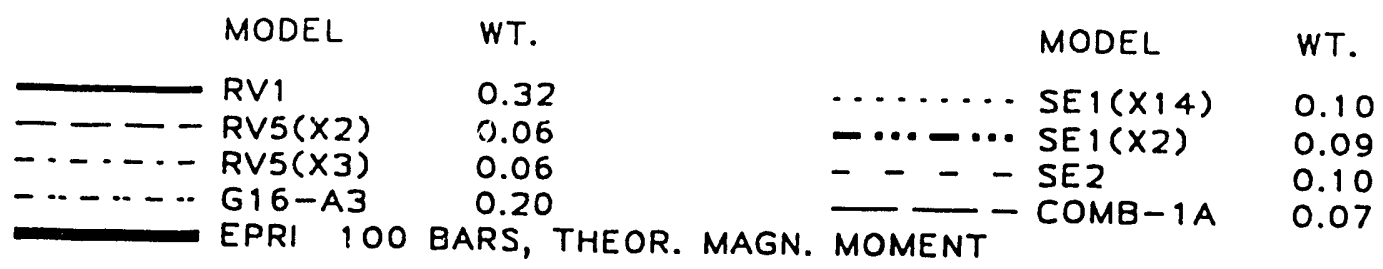

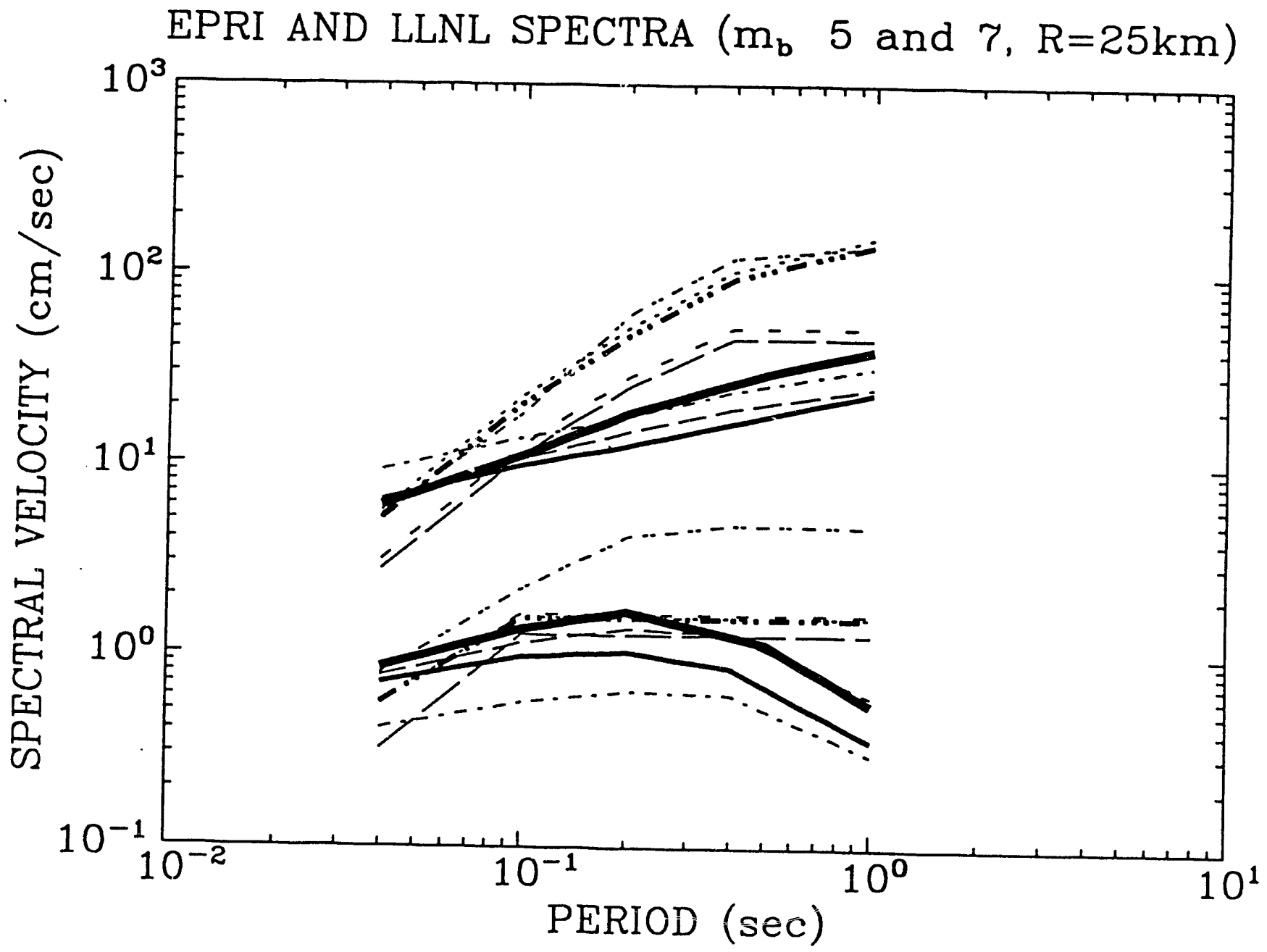

Figure 4-12. Comparison of response spectra predicted by the EPRI/SOG and LLNL attenuation equations. Predictions are shown for an epicentral distance of $25 \mathrm{~km}$ and for $m_{b} 5$ and 7. Models used by EPRI/SOG only are shown as heavy lines; models used by both EPRI and LLNL are used as medium-weight lines; models used by LLNL only are shown as thin lines. Source: (5) 


\section{Section 5}

\section{CONCLUSIONS}

In this study we have derived a set of seismic hazard curves that represent the frequency of exceedance of various PGA levels at the HFIR facility, and the uncertainty in that frequency of exceedance. For input to a PRA, these curves are represented as a family of discrete hazard curves, each with a finite weight. We have also developed a uniform-hazard spectrum to represent the types of ground motion associated with the various exceedance probabilities.

The EPRI and LLNL methods of seismic hazard evaluation for the CEUS have been used as input for this study. For the EPRI work, an analysis has been conducted using the seismological inputs and ground motion equations described in the EPRI study. For the LLNL method, calculations were performed by LLNL for the HFIR site and transmitted to us for use in this study. We have elected to weight the two studies equally.

We present two sets of results, corresponding to LLNL calculations with and without LLNL ground-motion expert 5 . The attenuation functions by LLNL ground-motion expert 5 lack credibility because they are inconsistent with all instrumental ground-motion data from eastern North America [including the 1988 Saguenay earthquake (1)], they are based on incorrect assumptions about intensity data, and they use an invalid substitution procedure. Therefore, we recommend that the results without LLNL ground-motion expert 5 should be used as input to the HFIR PRA.

It should be noted that both the EPRI study and the LLNL study were undertaken with low and moderate levels of ground motion in mind (PGA levels up to $0.5 \mathrm{~g}$ or so). At those levels, certain effects such as truncation of the ground motion distribution and decrease of the scatter in ground motion with increasing earthquake magnitude can and were ignored, because they have a minor effect. (The LLNL study allowed the ground motion experts to specify a truncation on the ground motion distribution, but only two experts chose to do so, and the limits they specified have virtually no effect even at $2 \mathrm{~g}$.) In the current study the two methodologies have been pushed to calculate results for a PGA of $2 \mathrm{~g}$, where the effects of limits on ground motion may be quite important. We believe that the result has been to somewhat over-estimate the frequencies of exceedance for ground motions above $1 \mathrm{~g}$. If 
these ground motion levels contribute significantly to the frequency of plant damage states, and if the seismic initiators are important relative to other initiators, some work should be undertaken to refine the EPRI and LLNL hazard curves at these high amplitudes to account for truncations and other causes that would reduce the frequencies compared to current results.

\subsection{REFERENCES}

1. Risk Engineering, Inc. Assessment of the 1988 Saguenay Earthquake - Implications on Attenuation Functions for Seismic Hazard Analysis. Report to Pickard, Lowe and Garrick, Inc, February 1991. 


\section{INTERNAL DISTRIBUTION}

1. J. E. Beavers

2. W. K. Brown

3. S. E. Burnette

4. D. H. Cook

5. G. F. Flanagan

6. H. A. Glovier

7. R. J. Hunt

8. S. S. Hurt

9. L. King

10-14. M. A. Linn
15. L. D. Proctor

16. D. G. Renfro

17. J. B. Richard

18. R. L. Stover

19-20. Central Research Library

21-22. Laboratory Records

23. Laboratory Records - RC

24. ORNL Patent Office

25-34. RRD-DCC

35. Y-12 Technical Library

\section{EXTERNAL DISTRIBUTION}

36. Office of Assistant Manager for Energy Research and Development, Department of Energy, Oak Ridge Operations Office, P.O. Box E, Oak Ridge, TN 37831

37-48. OSTI, P. O. Box 62, Oak Ridge, TN 37830 

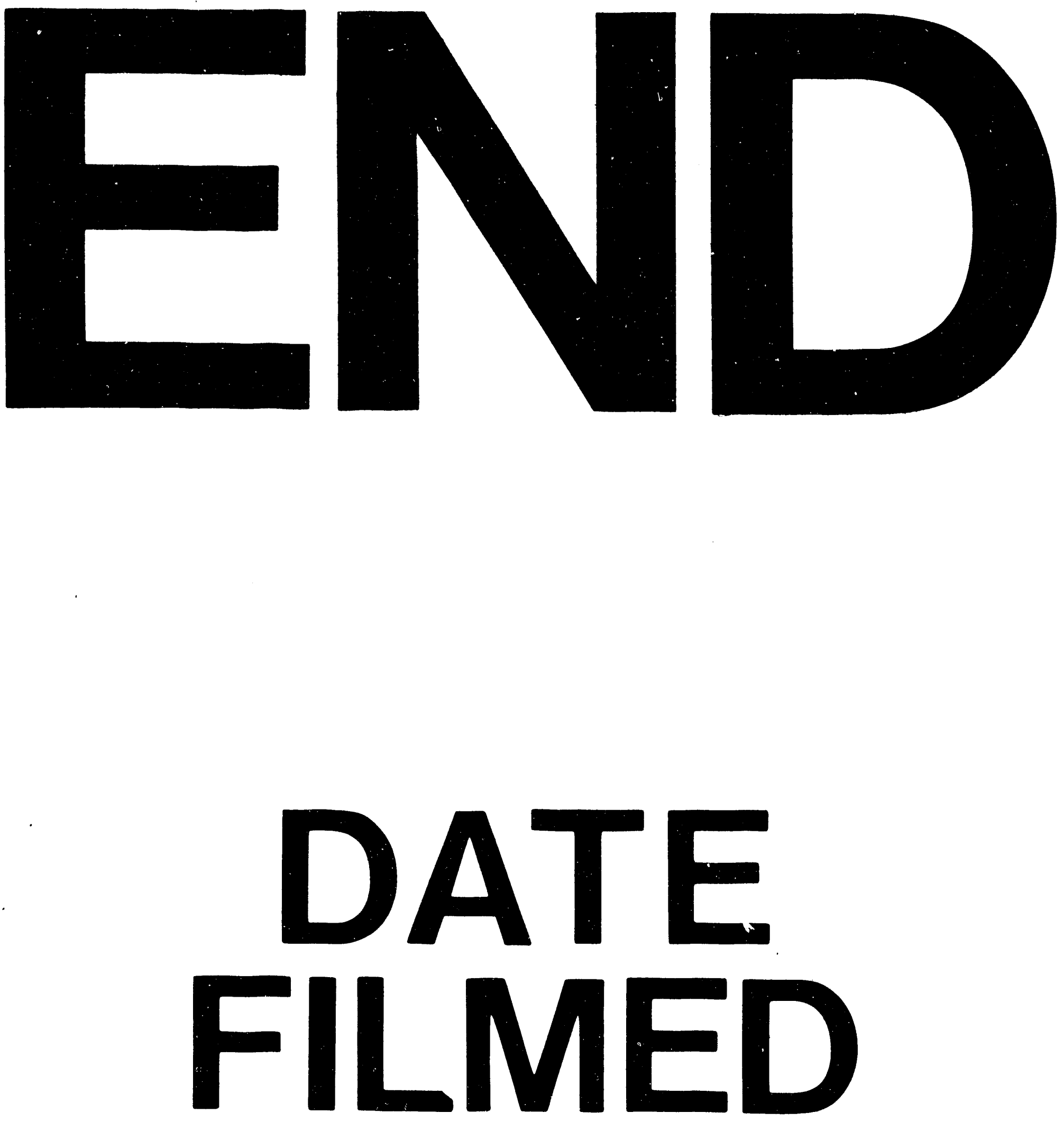

$\$$

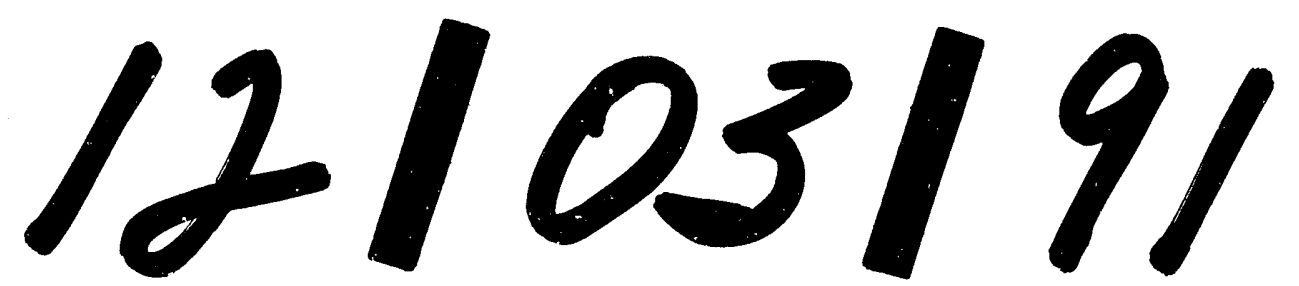

